Jorge Johanny Sáenz Noval

\title{
Metodologia para a Otimização do Rendimento e Desempenho dos Circuitos Analógicos usando Programação Geométrica
}

Dissertação apresentada à Escola Politécnica da Universidade de São Paulo para obtenção do Título de Mestre em Ciências. 
Jorge Johanny Sáenz Noval

\title{
Metodologia para a Otimização do Rendimento e Desempenho dos Circuitos Analógicos usando Programação Geométrica
}

\author{
Dissertação apresentada à Escola \\ Politécnica da Universidade de São \\ Paulo para obtenção do Título de Mestre \\ em Ciências. \\ Área de concentração: \\ Microeletrônica \\ Orientador: \\ Prof. Dr. Wilhelmus A. M. Van \\ Noije
}


Este exemplar foi revisado e alterado em relação à versão original, sob responsabilidade única do autor e com a anuência de seu orientador.

São Paulo, 4 de Julho de 2012

Assinatura do autor

Assinatura do orientador

Ficha Catalográfica

Noval, Jorge Johanny Sáenz

Metodologia para a Otimização do Rendimento e Desempenho dos Circuitos Analógicos usando Programação Geométrica / J.J. Sáenz Noval - ed. rev. - São Paulo, 2012.

$89 \mathrm{p}$.

Dissertação (Mestrado) - Escola Politécnica da Universidade de São Paulo. Departamento de Engenharia de Sistemas Eletrônicos.

1. DFM 2. Otimização Restrita (Rendimento;Desempeho) 3. Circuitos analógicos 4. Processos aleatórios I. Universidade de São Paulo. Escola Politécnica. Departamento de Engenharia de Sistemas Eletrônicos II. t. 
A mi primero sobrino: Santiago Andrés Gonzalez Sáenz, que lleno de brillo nuestras vidas. 


\section{AGRADECIMENTOS}

Agradeço à minha família pelo apoio prestado durante o curso da minha vida. A minhas irmãs pelos momentos juntos nos quais aprendi a levar os tempos fácies e difíceis de minha vida. E a meus pais, nos quais sobre sua experiência construí uma grande parte de minha formação.

Aos meus amigos e amigas os quais surgiram nos diferentes cenários de minha vida. Aqueles com os quais compartilhe desde minha infância e adolescência na Colômbia, até aqueles com os quais foram parte importante na minha estadia no Brasil. Os meus amigos fazem parte da minha experiência e o conhecimento do diário viver obtido ao longo da maestria.

Ao professor Dr. Wilhelmus A.M. Van Noije pela sua contribuição no desenvolvimento do meu trabalho de mestrado em conjunto com as discussões de pesquisa desenvolvidas ao longo da realização de meu mestrado. Adicionalmente, agradeço ao professor Elkím Roa pela oportunidade de ter sido iniciado na área da Microeletrônica. Suas motivantes e valiosas suggestões fizeram de mim um bom pesquisador.

A todos meus amigos e colegas do Grupo de Investigación en Diseño de Circuitos Integrados (CIDIC) na Colômbia, e do Laboratório de Sistemas Integráveis (LSI) no Brasil, pois sua colaboração, motivação e suporte constante foram importantes. Este trabalho faz parte de minha dedicação e esforço embora o aprendizado e as experiencias de pesquisa entorno a este foram conjuntas com esta galera.

Ao Conselho Nacional de Desenvolvimento Científico e Tecnológico (CNPq) pela bolsa oferecia, a qual foi útil no suporte econômico de meus estudos de Mestrado no Brasil. Também agradeço à Fundação de Amparo à Pesquisa do Estado de São Paulo (FAPESP) pelo financiamento das duas fabricações associadas ao desenvolvimento deste mestrado. 


\section{Resumo}

Este trabalho propõe uma metodologia de projeto para fabricação ou Design Methodology for Manufacturing (DFM) utilizando a Programação Geométrica (PG) e os métodos tipo Newton para resolver problemas de otimização não-linear, os quais definem e assistem o projeto de circuitos analógicos. Depois, essa metodologia é aplicada e validada através do projeto de uma fonte de referência.

Nos últimos anos, a tendência do aumento na densidade de transistores previsto pela lei de Moore tornou o problema do projeto dos circuitos dimensionalmente mais complexo. Além disso, uma maior densidade de transistores implica diminuição das dimensões características do processo tornando-o mais sensível às variações de processo e às condições ambientais. As diferenças apresentadas entre o circuito projetado e aquele testado dão evidências de perdas de rendimento, as quais são atribuídas numa grande proporção ao processo de projeto. Devido à grande responsabilidade que o projetista tem neste problema, o projeto analógico deve ser focado para novas abordagens que levem em conta o desempenho e o rendimento conjuntamente.

Em primeiro lugar, a metodologia proposta obtém um ponto inicial com um conjunto de especificações de desempenho adequadas, o qual vai ser usado na análise do impacto que têm o mismatch e as variações de processo sobre as especificações. Uma vez que o comportamento estatístico e determinístico do circuito foi caracterizado, um nova estratégia de melhoria de rendimento foi implementada usando PG. A intenção de obter um projeto com um conjunto de especificações de bom desempenho envolve diretamente o rendimento do circuito, pois um conjunto de especificações ótimo obtido através da estrutura típica da PG não garante a obtenção de um projeto comercial e competitivo. Assim, este trabalho estabelece um método de projeto que combina a facilidade na obtenção do ótimo global da Programação Geométrica com uma nova análise de mismatch e de pior caso a qual permitiu uma redução nos tempos de computação mantendo semelhantes os valores de desempenho nominais. Usando a metodologia de projeto para fabricação proposta neste trabalho foi obtido um projeto de uma fonte de referência com um rendimento maior que $37 \%$ comparado com uma estratégia de projeto tipica, sem nenhuma penalização significativa nas especificações de desempenho.

Palavras chaves: DFM, Tensão de referência, Otimização, Metodologias de projeto, Programação Geométrica, $C A D$. 


\section{Abstract}

This work proposed a Design Methodology for Manufacturing (DFM) using Geometric Programming (GP) and Newton-like methods to solve non-linear optimization problems, which define and aid the design of analog circuits. Afterwards, this methodology is applied and validated through the design of a voltage reference circuit.

Over the last years, the tendency of the increasing on the transistor density predicted by the Moore Law has turned the circuit design problem dimensionally more complex. Additionally, a higher transistor density implies shrinkage on the feature dimensions of the process making it more sensitive to the process variations and environmental conditions. The differences between the designed circuit and the tested one give an evidence of yield losses, which are attributed in a great proportion to the design process. Due to the high responsibility of the designer on this problem, the analog design must be focused on new approaches that jointly manage performance and yield.

In first place, the proposed methodology obtain a initial point with a suitable set of performance specifications, which will be used to analyze the impact of the mismatch and process variation over the design specifications. Once the statistical and deterministic behavior of the circuit was characterized, a new yield improvement strategy is implemented using Geometric Programming. Attempting to obtain a design with a set of high performance specifications directly involves the circuit yield, because an optimal performance set obtained by the traditional framework of GP does not assure the obtaining of a marketable and competitive design. So, this works establish a design method that combine the advantage of obtaining global optimum in Geometric Programming with a new mismatch and worst-case analysis that enabled a reduction in their computation time and maintain the initial nominal performance values. Using the design methodology for manufacturing proposed in this work, a voltage reference design with $37 \%$ better yield than one obtained with a typical design strategy without any significant penalty on their performance specs was achieved.

Key Words: DFM, Voltage Reference, Optimization, Design Methodologies, Geometric Programming, $C A D$. 


\title{
Lista de abreviaturas e siglas
}

\author{
CAD Computer Aided Design \\ CI Circuito Integrado \\ CMOS Complementary Metal-Oxide-Semiconductor \\ DFM Design For Manufacturing \\ DFT Design For Test \\ GPU Graphics Processing Unit \\ ITRS International Technology Roadmap for Semiconductors \\ LR Line Regulation \\ MATLAB MATrix LABoratory \\ MOP Multiple Objetive Optimization \\ OPAMP Operational Amplifier \\ PF Pareto Front \\ PG Programação Geométrica \\ PSRR Power Supply Rejection Ratio \\ PTAT Proportional To Absolute Temperature \\ RET Resolution Enhancement Techniques \\ RSM Response Surface Methodology \\ SQP Sequential Quadratic Programming \\ SRAM Static Random-Access Memory \\ TC Temperature Coefficient \\ WCD Worst Case Distance
}




\section{Lista de símbolos}

$\mathscr{A}$ Região de aceitabilidade das funções de desempenho.

$A_{F} \quad$ Exponente do ruído flicker para o modelo BSIM3v3.

$A_{R} \quad$ Constante do modelo Pelgrom para o mismach no valor nominal do resistor R.

$A_{V_{t}} \quad$ Constante do modelo Pelgrom para o mismach na tensão limiar do transistor MOS.

$\mathscr{B} \quad$ Contorno da fronteira de Pareto.

$\mathscr{C} \quad$ Conjunto de restrições estruturais e de projeto.

$\mathscr{D}_{N, P} \quad$ Espaço de projeto para as polarizações do transistor $\mathrm{N}$ e $\mathrm{P}$.

$\delta p_{i} \quad$ Desvio do $i$-ésimo parâmetro de processo.

$\mathscr{E} \quad$ Conjunto de elementos do circuito.

f Vetor de funções de desempenho.

$f_{c} \quad$ Frequência de corte da resposta no domínio da frequência do PSRR.

$k_{b} \quad$ Constante de Boltzmann.

$K_{F} \quad$ Coeficiente do ruído flicker para o modelo BSIM3v3.

LR Regulação de linha (Line Regulation).

$n \quad$ Número de variavéis de projeto envolvido no esquema de otimização.

$N_{c h} \quad$ Concentração de dopantes no substrato.

P Conjunto de especificações para otimizar o circuito.

$P(z) \quad$ Probabilidade de ocorrência do evento $\mathrm{z}$.

$p \quad$ Número de especificações para otimizar.

$P F \quad$ Fronteira de Pareto (Pareto Frontier).

PSRR Taxa de rejeição às variações da fonte de alimentação (Power Supply Rejection Ratio).

$\phi_{\mathbf{f}} \quad$ Função de densidade de probabilidade conjunta.

$\mathbf{p}_{w c} \quad$ Vetor de parâmetros de processo no pior caso.

$R_{S H} \quad$ Resistência de folha do poli-silicio.

$\operatorname{Sim}_{p_{i}}^{f_{j}}$ Simetria da variação $\delta f_{j}(\boldsymbol{\delta} \mathbf{p})$ em relação ao parâmetro $p_{i}$.

$T \quad$ Temperatura em graus Kelvin.

$t_{o x} \quad$ Espessura do óxido de porta.

$V_{D D} \quad$ Tensão da fonte de alimentação.

$V_{D S} \quad$ Tensão entre o dreno (D) e a fonte (S) do transistor.

$V_{f b} \quad$ Tensão em faixa plana. 


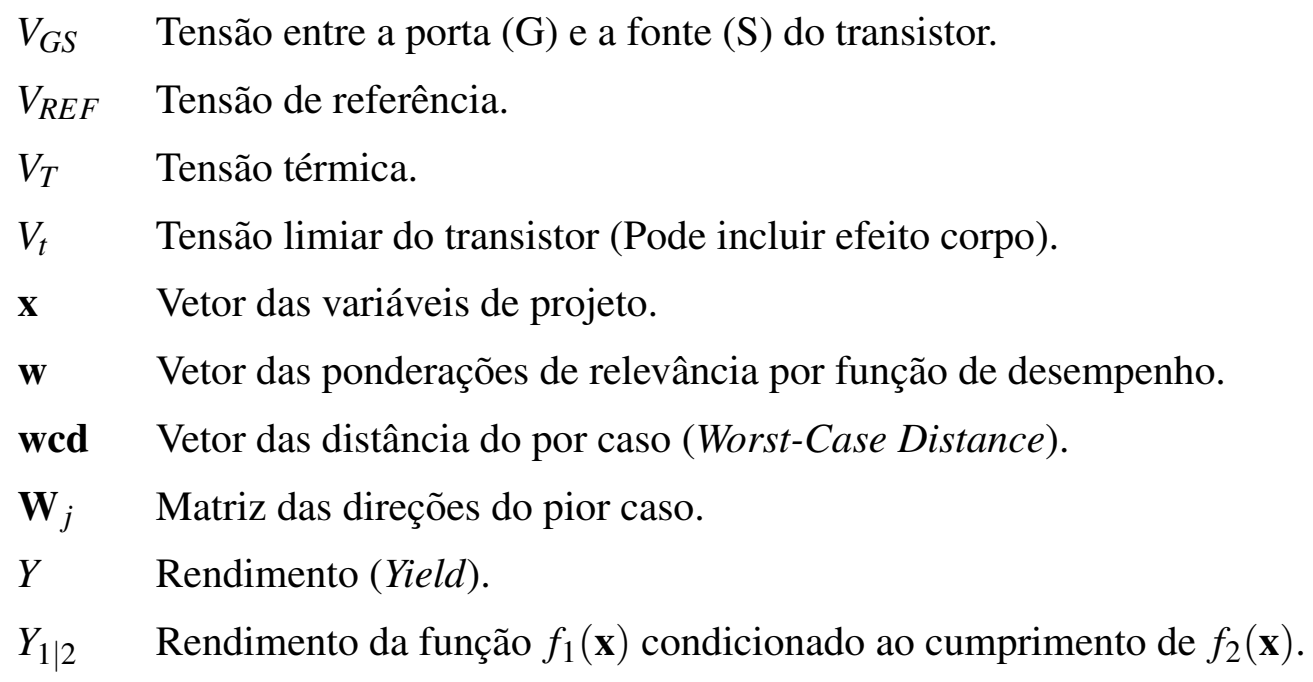




\section{Sumário}

1 Introdução 1

1.1 Levantamento do problema . . . . . . . . . . . . . . . . 1

1.2 Motivação . . . . . . . . . . . . . . . . . . . 3

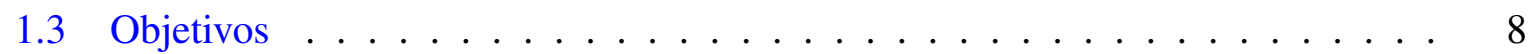

1.4 Estado da arte . . . . . . . . . . . . . . . . . . . . 9

1.5 Organização do documento . . . . . . . . . . . . . . . . . . . . . . 13

2 Proposta da Metodologia de projeto para Fabricação (DFM) 15

2.1 Fundamentação . . . . . . . . . . . . . . . . . . . . 15

2.2 Gerador de sementes e exploração do projeto inicial . . . . . . . . . . . . . . . 17

2.3 Explorador da polarização f . . . . . . . . . . . . . . . . 21

2.4 Otimização multi objetivo e fronteira de Pareto . . . . . . . . . . . . . . . . 22

2.5 Análise de mismatch e ruído flicker . . . . . . . . . . . . . . . . . . . . . 24

2.6 Otimização nominal (Programação Geométrica) . . . . . . . . . . . . . . . 27

2.6.1 Leis de Kirchhoff em PG . . . . . . . . . . . . . . . . . . 28

2.6.2 Programação Geométrica aplicada para minimizar mismatch . . . . . . 29

2.7 Análise do pior caso . . . . . . . . . . . . . . . . . . 30

2.8 Otimização da distância do pior caso $(W C D) \ldots \ldots$. . . . . . . . . . . . . 34

3 Aplicação da Metodología DFM na Otimização de uma fonte de referência 37

3.1 Topologia, especificações e restrições de partida . . . . . . . . . . . . . . 37

3.2 Projeto semente e migração processo . . . . . . . . . . . . . . . . 43 
3.3 Otimização Nominal via Programação Geométrica . . . . . . . . . . . . . 45

3.4 Otimização multi-objetivo e curvas de Pareto . . . . . . . . . . . . . . . . 49

3.5 Otimização do Mismatch e ruído flicker . . . . . . . . . . . . . . 51

3.5.1 Análise da influência do processo no mismatch . . . . . . . . . . . 51

3.5.2 Modificando as restrições de área . . . . . . . . . . . . . . . . . . 54

3.5.3 Modificando a topologia . . . . . . . . . . . . . . . . . 57

3.5.4 Layout e considerações de mismatch . . . . . . . . . . . . . . . . . 61

3.6 Análise do pior caso da fonte de referência . . . . . . . . . . . . . . . . . . . 64

3.7 Otimização do pior caso f . . . . . . . . . . . . . . . 67

3.8 Validação final . . . . . . . . . . . . . . . . . . . . . . . 69

4 Conclusões e recomendações $\quad 77$

4.1 Conclusões . . . . . . . . . . . . . . . . . . . . . . . 77

4.2 Recomendações . . . . . . . . . . . . . . . . . . . . . . 79

Apêndice A - Análise da regulação de linha do bloco PTAT 83

Apêndice B - Estimativa de rendimento com base na distância do pior caso 85 


\section{Introdução}

\subsection{Levantamento do problema}

A indústria eletrônica atual conduz ao crescimento e massificação tecnológica, fins que normalmente se opõem com o tempo de projeto, a confiabilidade e a eficiência no desenvolvimento dos dispositivos. A rápida mudança do processo de fabricação de semicondutores implica uma reavaliação das topologias e arquiteturas desenvolvidas em processos anteriores, para escalar ou pelo menos manter o desempenho funcional nos novos processos tecnológicos. Além disso, a redução no comprimento efetivo de canal dos novos processos leva a um incremento na variabilidade dos parâmetros elétricos do transistor, em relação a processos anteriores, produzindo assim uma deterioração no rendimento dos dispositivos.

Enquanto os circuitos digitais podem ser frequentemente redirecionados para uma nova tecnologia por meio de um escalamento geométrico do layout, este procedimento não garante automaticamente o sucesso nos circuitos analógicos. Um fluxo típico de migração de projeto

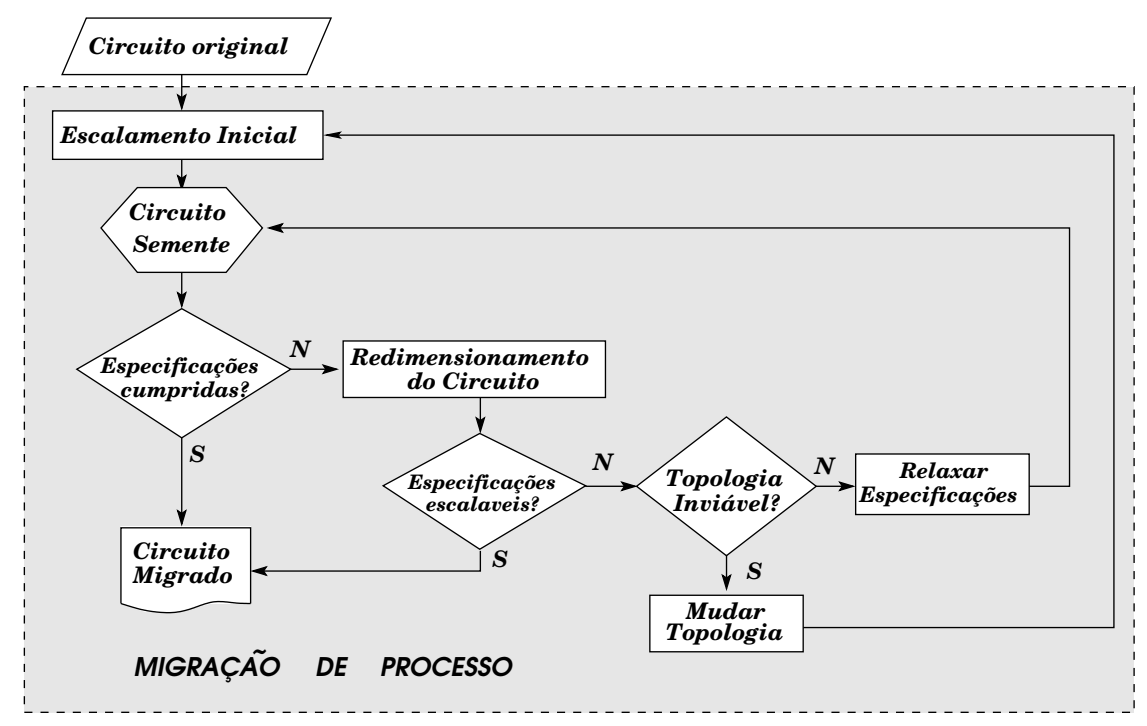

Figura 1.1: Fluxo típico de migração de processo mais avançado para circuitos analógicos. 
analógico pode ser visto na Figura 1.1. Mantendo a mesma topologia, o primeiro passo é realizar um escalamento inicial das dimensões, o qual nos dá um ponto de partida relativamente perto da solução final no processo de tecnologia alvo. Após esta etapa, o circuito é redimensionado usando algum tipo de otimização quando as especificações iniciais não fossem garantidas, ou quando não fosse possível reduzir a potência e/ou área, mantendo o mesmo desempenho. Após os resultados são verificados mais uma vez e, se forem satisfatórios, o circuito vai ser migrado com sucesso. No entanto, quando as especificações não são adequadamente transferidas ao novo processo, uma avaliação da topologia tem que ser feita e o projetista escolherá uma de duas opções: mudar a topologia ou relaxar as suas especificações.

Embora a experiência do projeto inicial possa ser aproveitada, o fato de ter uma topologia inviável, um relaxamento de especificações ou um desconhecimento dos limites das mesmas pode implicar um aumento no tempo de projeto e até uma mudança na arquitetura geral do sistema. O relatório do ano 2009 da $\operatorname{ITRS}^{1}$ [1] estabelece, entre outras áreas, o escalamento não ideal das parasitas dos dispositivos, das tensões de alimentação e da tensão limiar do transistor em conjunto com a variabilidade do processo como os fatores que dificultam a migração tecnológica. Para superar o aumento da complexidade no novo processo e reduzir os custos $N R E^{2}$ associados ao projeto, a etapa de redimensionamento do circuito mostrada na Figura 1.1 deve consistir em um algoritmo de otimização muito mais robusto e intuitivo. Ao lado disso, para tentar resolver o problema do aumento na variabilidade, o fluxo de projeto deve reavaliar a topologia e o dimensionamento nas etapas iniciais, ainda na mesma migração tecnológica. No entanto, a falta de informação sobre a variabilidade e o mismatch durante o dimensionamento do circuito representa um fator limitante para esta finalidade.

Em um esforço para maximizar a confiabilidade dos circuitos, uma expressão de rendimento deve ser derivada ou pelo menos aproximada em função das variáveis do projeto. A razão entre o número de chips que atendem o desempenho esperado do total de chips fabricados é definida como rendimento paramétrico. A menos que a caracterização da função de rendimento seja computacionalmente viável ou facilmente derivada como no caso de [2], a aplicação direta de uma rotina de otimização é quase inviável. Frequentemente, em células digitais e alguns similares analógicos, a confiabilidade é abordada em termos de variáveis de projeto conhecidas como a área. No caso do projeto analógico ou de $R F$, propostas como [3,4] estão preocupadas com a aproximação do espaço de projeto e a região de viabilidade para ajustar o projeto em um ponto menos sensível às variações de processo.

\footnotetext{
${ }^{1}$ International Technology Roadmap for Semiconductors (ITRS) é um conjunto de documentos produzidos por um grupo de especialistas na indústria semicondutora.

${ }^{2}$ Non-Recurring Engineering (NRE): refere-se ao custo único de pesquisa, desenvolvimento, concepção, máscaras e ensaio de um novo produto.
} 
O desafio atual é criar novos algoritmos e suas metodologias correspondentes que otimizem o desempenho dos circuitos levando em conta as variações do processo nas etapas iniciais de exploração do projeto e dimensionamento do circuito. Considerando este cenário surgem algumas necessidades na área da automatização de projeto analógico, tais como:

- Aumentar a produtividade de projeto através de três aspectos importantes: a reutilização do projeto de células analógicas e digitais, o qual significa uma rápida curva de aprendizagem na etapa de migração tecnológica, explorar os limites das diferentes topologias e processos, e otimizar o rendimento e as especificações desde o nível de sistema até o nível de dispositivo.

- Ser suficientemente geral para ser aplicado em qualquer circuito analógico, em qualquer tecnologia e em qualquer outra distribuição de parâmetros de processo.

- Consumir menos esforço computacional em comparação com outros métodos usuais.

- Modelar cada um dos blocos nos diferentes níveis de abstração, levando em conta os fatores importantes em cada um dos estágios de projeto.

- Avaliar os compromissos como rendimento versus desempenho, ou potência versus velocidade comum para os circuitos analógicos, fazendo uso dos modelos mencionados no item anterior.

Neste trabalho será proposta uma metodologia de projeto para fabricação, ou Design For Manufacturing (DFM) de circuitos analógicos com ênfase nas necessidades anteriores. Parte desta metodologia já foi publicada [5] e será suportada por uma plataforma de Software atualmente em desenvolvimento conhecida pelo nome de Anubis ${ }^{3}$.

\subsection{Motivação}

Nos últimos anos tem-se evidenciado uma clara tendência no avanço tecnológico dos dispositivos que contêm Circuitos Integrados (CI); enquanto o desempenho médio se incrementou e se teve um decremento no custo geral do dispositivo, a complexidade do projeto aumentou nos novos processos de fabricação. O custo de desenvolvimento dos dispositivos continuará aumentando junto com a sua massificação, em contraste com a relação custo/beneficio para o usuário, a qual naturalmente diminuirá. O problema acima leva a uma

\footnotetext{
${ }^{3}$ Anubis é o nome dado pelos antigos gregos ao deus associado com a mumificação e a vida após a morte da mitologia grega. O nome foi escolhido com a intenção de ressaltar o fato do retorno a uma nova vida após a morte dos circuitos considerados inviáveis.
} 
determinação: análise dos fatores preponderantes na queda de desempenho do dispositivo e sua dependência nos métodos e meios de projeto. A Figura 1.2 mostra uma curva de rendimento em função do tempo de projeto um circuito integrado característico. A área sob a curva representa o grau de adaptação do projetista ao novo processo de fabricação. A linha não pontilhada simboliza a rampa de rendimento ou aprendizagem do rendimento para um processo de fabricação específico e a linha pontilhada a rampa de rendimento inerente ao processo de projeto de um determinado circuito. Do ponto de vista do projetista, ele ou ela deveria tender a cobrir a curva de rendimento do processo de fabricação para obter o melhor beneficio deste. No entanto, esse fato não é tão verdadeiro, porque o projeto é um processo de realimentação, no qual a experiência sob um processo específico é independente dos outros e é obtida através do tempo. Um dos objetivos das metodologias de projeto para fabricação é a generalização e a autoaprendizagem do processo de projeto ajudado com o uso das ferramentas de projeto assistido ou Computer Aided Design (CAD). Isso implica que o impacto das variações de processo e da migração tecnológica será preliminarmente quantificado e controlado para assim evitar perdas de rendimento durante as seguintes etapas de projeto. Inicialmente, quando o primeiro tapeout acontece, o rendimento do circuito é muito ruim, essencialmente porque o projeto ainda é bastante imaturo sob este novo processo de fabricação. Baseado nas deficiências do primeiro protótipo, o rendimento é melhorado para obter o primeiro silício comercializável. Logo após o dispositivo é lançado no mercado, ele produz uma baixa rentabilidade e seu rendimento deve ser melhorado para o novo nó tecnológico. Na etapa seguinte, denominada rampa de produção, a indústria procura satisfazer conjuntamente o mercado e os lucros do ingresso do produto,

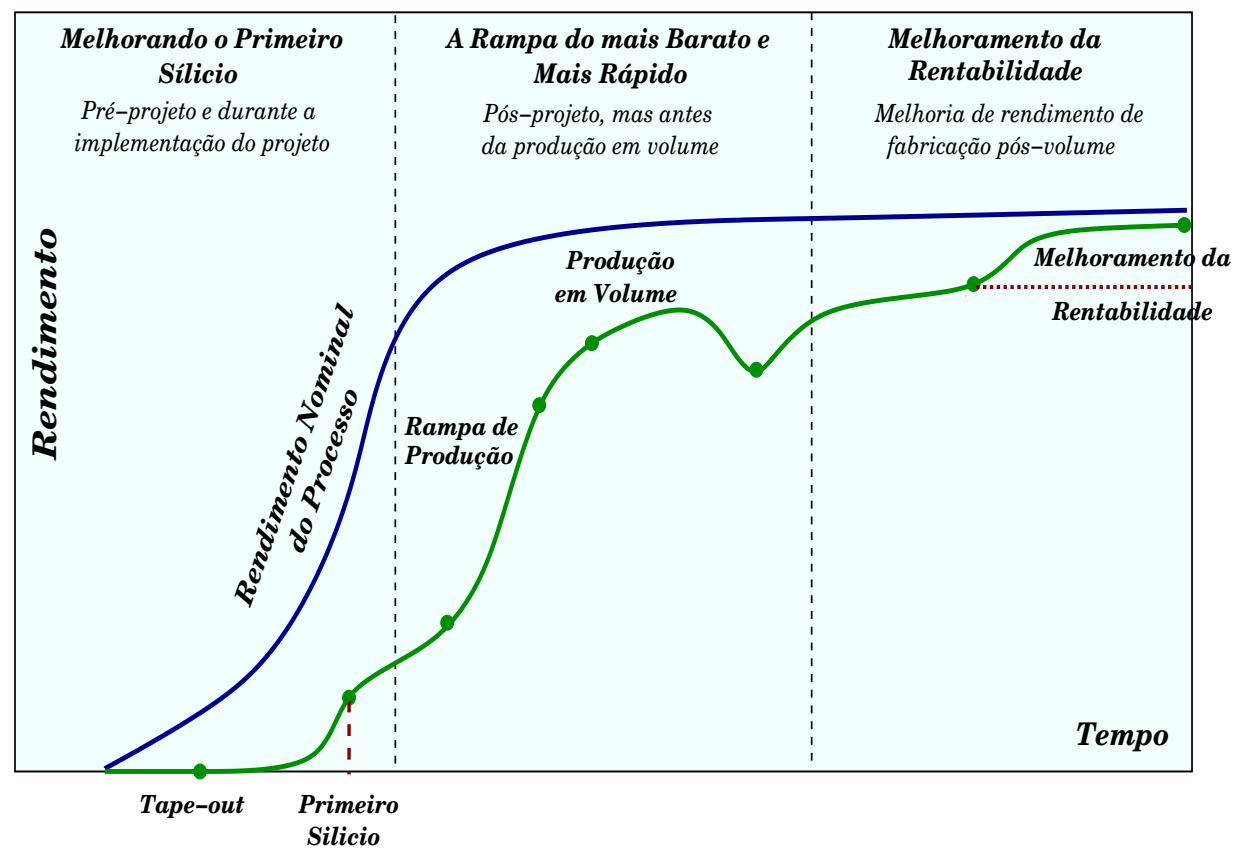

Figura 1.2: Curva de aprendizado do processo de fabricação e do projeto, tomada de [6]. 
tornando-se na premissa essencial até que um volume de produção máxima é atingido. As perdas de rendimento durante a final da rampa do mais barato e mais rápido correspondem aos dispositivos com falhas iniciais e aqueles que incluem as datas de garantia do produto. Finalmente, no último estágio, a melhora de rendimento está focada para obter a melhor rentabilidade do dispositivo, quando o conhecimento do projeto é muito maduro e o dispositivo está perto de ser substituído por um mais recente. Sobre essas fases o lucro máximo é atingido e a indústria está-se preparando para implementar um novo produto. Por causa da redução nas dimensões do transistor, a área sob a rampa de rendimento do processo de fabricação tem-se diminuído e o mesmo processo de projeto tornou-se crítico para garantir níveis de rentabilidade ótima ao rápido mercado atual. Isto, entre outros fatores, tem acrescentado a indústria de ferramentas de projeto assistido numa quantidade incrível durante os últimos 20 anos.

No caso da Figura 1.3 onde as quedas de rendimento são traçadas em função da dimensão característica do processo de fabricação, os resultados apontam ao incremento na necessidade das ferramentas de projeto assistido $(C A D)$. Como foi esperado, o rendimento diminuiu com a dimensão característica do processo. No entanto, o mais interessante é ver como uma quantidade maior que $25 \%$ da queda no rendimento nominal está relacionada com o projeto e apenas $10 \%$ ao processo. A quantidade restante está relacionada com a impressão visual das camadas usando $R E T^{4}$. Estes resultados atribuem uma responsabilidade incrível no problema para os projetistas de circuitos, compartilhada em menor medida pelos responsáveis do controle de processo.

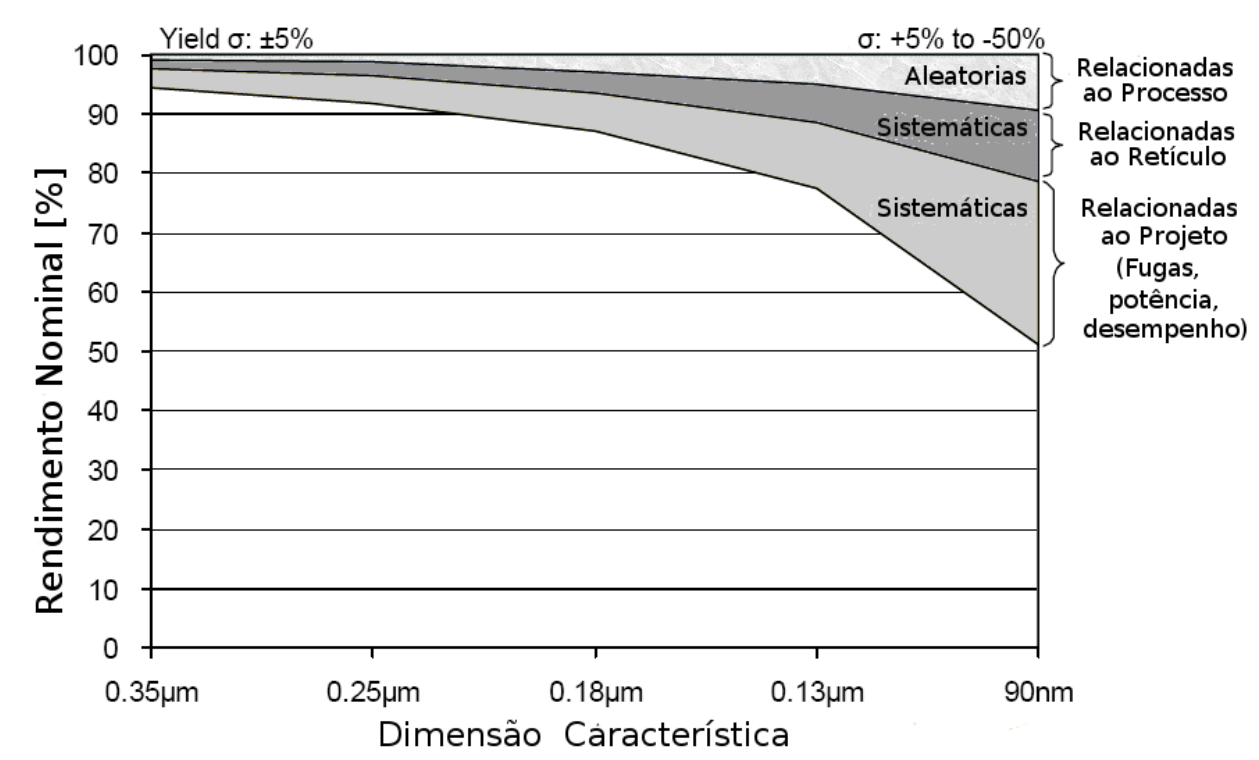

Figura 1.3: O rendimento em função da Lei de Moore, tomada de [7].

\footnotetext{
${ }^{4}$ RET (Resolution Enhancement Techniques): São técnicas para reduzir o tamanho e melhorar a resolução do processo litográfico de impressão de máscaras.
} 
Dada a grande diferença entre a complexidade inerente aos dispositivos atuais e as capacidades de projetar, as ferramentas que o projetista tem à sua disposição não são suficientes para enfrentar o problema. A melhoria na produtividade das ferramentas de projeto assistido tem crescido cerca de $20 \%$ ao ano, em comparação com uma taxa de crescimento exponencial aproximadamente de $60 \%$ ao ano na complexidade dos dispositivos semicondutores [8]. Este deficit de $40 \%$ leva a uma crise iminente no projeto e fabricação de semicondutores. Também marca uma tendência em ferramentas $C A D$, que juntamente com a modelagem bem sucedida de dispositivos e células, deve permitir que o projetista estime com intervalos de confiança estreitos o rendimento e desempenho antes da fabricação do CI.

A metodologia $D F M$, no campo dos dispositivos semicondutores, pode ser definida como uma correta interação entre todas as fases de projeto, fabricação e comercialização, de modo que o desempenho e o rendimento esperado nos estágios iniciais seja refletido no CI desenvolvido. Algumas interações que ocorrem durante o processo de desenvolvimento de um chip são mostradas na Figura 1.4. A parte central deste trabalho será focada na otimização nominal e de rendimento, a partir do qual emergem aspectos importantes como a produtividade de projeto, a abstração de alto nível, o tempo de comercialização e marketing do dispositivo. Cada uma das derivações estão relacionadas com este trabalho de maneira diferente, por exemplo, a otimização nominal e de rendimento facilita a comercialização do dispositivo através da melhoria da sua confiabilidade. Adicionalmente, as tarefas emergentes estão conjuntamente ligadas, por exemplo, a abstração de alto nível com o tempo de mercado, através da antecipada definição das especificações de desempenho e variabilidade do sistema e dos blocos. A filosofia de projeto para fabricação e suas práticas são muito utilizadas nas indústrias, pois reconhece-se

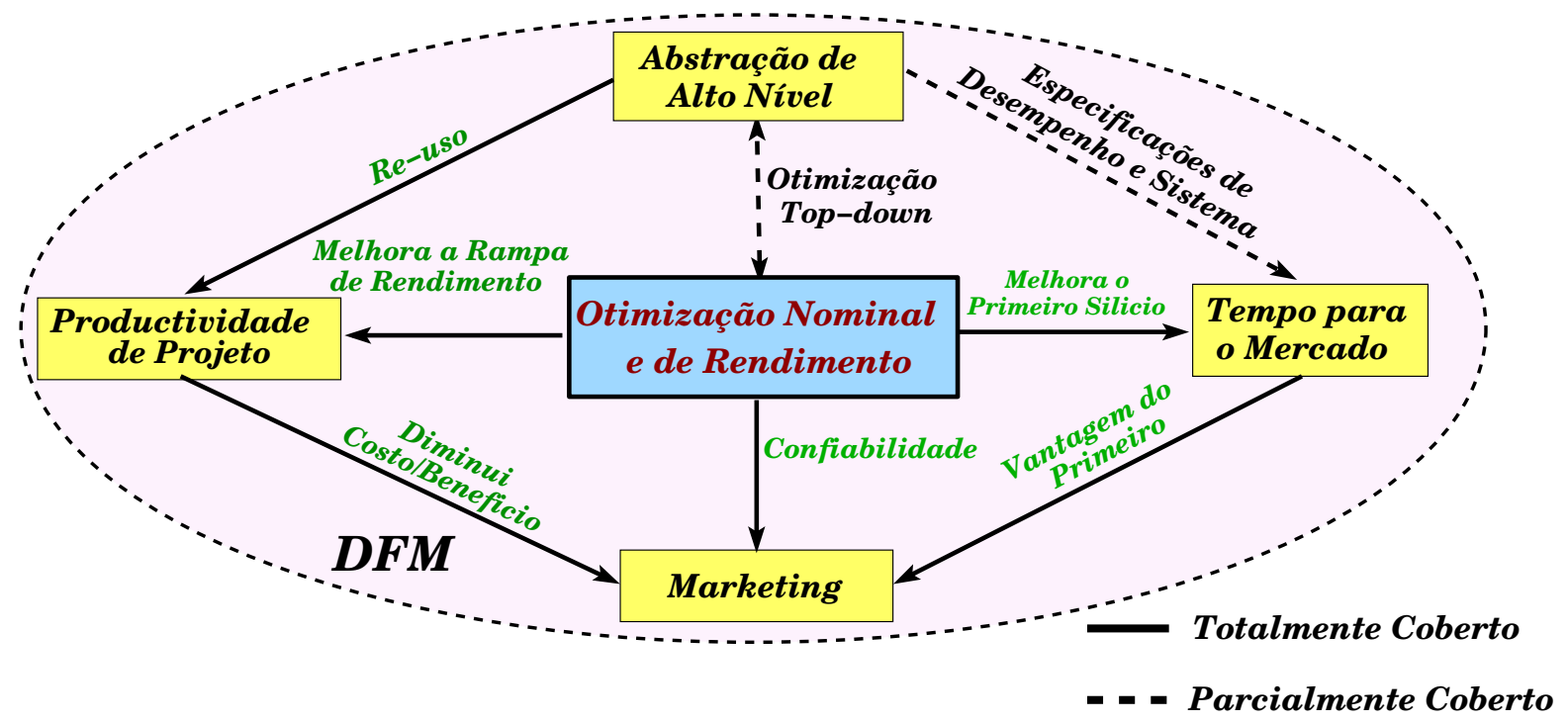

Figura 1.4: Fluxo de tarefas envolvidas na metodologia $D F M$ 
que entre o $70 \%$ e $90 \%$ do custo do dispositivo semicondutor é determinado, e portanto pode ser otimizado antes de passar pela linha de produção.

Para avaliar a eficiência da metodologia usada uma compilação de aspectos relevantes no projeto de fabricação deve ser realizada, destacando-se os seguintes:

Desempenho: O aumento nas funcionalidades dos dispositivos eletrônicos e especialmente em aqueles que fazem parte dos sistemas portáteis, implica para o projetista de CIs a obtenção de um conjunto de especificações de desempenho cada vez mais rigoroso. Conforme o comprimento de canal é reduzido, a velocidade dos dispositivos é incrementada sem uma penalidade considerável na potência, no entanto, um processo de projeto mais rigoroso é necessário para garantir níveis de confiabilidade adequados. Em qualquer circuito eletrônico, o projetista deve levar em conta um conjunto $\mathbf{f}$ de $p$ especificações de desempenho em função de $n$ variáveis de projeto definidas como:

$$
\mathbf{f}(\mathbf{x})=\left[f_{1}(\mathbf{x}), \cdots, f_{j}(\mathbf{x}), \cdots, f_{p}(\mathbf{x})\right] \quad \in \mathfrak{R}^{p}
$$

sendo $f_{j}$ a $j$-ésima função de desempenho e $\mathbf{x}$ o vetor $n$-dimensional das variáveis de projeto

Rendimento: Representa a probabilidade de obter após a fabricação do dispositivo eletrônico, o conjunto de especificações dentro da região de aceitabilidade definida pelo projetista. Matematicamente o rendimento paramétrico de um circuito é uma função de natureza probabilística dada por:

$$
Y=\int_{\mathscr{A}_{x}} \Phi_{\mathbf{f}}(\mathbf{x}) d \mathbf{x}
$$

onde f é o vetor de funções de desempenho do dispositivo, $\mathbf{x}$ é o vetor dos valores nominais das variáveis de projeto, $\Phi_{\mathbf{f}}(\mathbf{x})$ é a função de densidade de probabilidade conjunta e $\mathscr{A}_{x}$ é a região de aceitação no espaço de variáveis de projeto $\mathbf{x}$ definida pelas restrições de aceitabilidade. A região de aceitação é um conjunto $\mathscr{A}_{x}$ geralmente definido como: $\mathscr{A}_{x}=\left\{\mathbf{x} \mid \mathbf{f}^{L} \leq \mathbf{f}(\mathbf{x}) \leq \mathbf{f}^{U}\right\}$. Os limites superior $\mathbf{f}^{U}$ e inferior $\mathbf{f}^{L}$ correspondem aos valores que demarcam as características do pior caso do dispositivo. Devido a variações de processo e o mismatch nos CIs não podem ser estabelecidos deterministicamente, é necessário recorrer a uma definição probabilística da região de aceitabilidade $\mathscr{A}_{x}$, que pode ser expressa matematicamente por:

$$
\mathscr{A}_{x}=\left\{\mathbf{x} \in \mathfrak{R}^{p} \mid P(\mathbf{f}(\mathbf{x})) \leq \mathscr{F}\left(\mathbf{f}^{U}\right)-\mathscr{F}\left(\mathbf{f}^{L}\right), \forall j \in \mathscr{P}\right\}
$$

onde $P(z)$ é a probabilidade de ocorrer o evento $z$ sob uma função de distribuição cumulativa $\mathscr{F}$ determinada. Assumindo que a natureza aleatória do vetor de funções de desempenho f possa ser caracterizado como um conjunto e variáveis normais $\mathscr{N}\left(\overline{\mathbf{f}}(\mathbf{x}), \sigma_{\mathbf{f}}^{2}\right)$, os valores na região 
de aceitabilidade vão a flutuar no intervalo $\left[-n_{s} \sigma_{\mathbf{f}},+n_{s} \sigma_{\mathbf{f}}\right]$ e em torno do valor nominal $\overline{\mathbf{f}}(\mathbf{x})$. A metodologia $D F M$ pode definir intervalos até de $6 \sigma_{\mathbf{f}}$, ou seja, pelo menos $99,9997 \%$ dos dispositivos fabricados no nível funcional são considerados adequados para a comercialização.

Funcionalidade: Corresponde a transferir os resultados do comportamento geral do circuito ao silício. Diz-se que um circuito é funcional quando atende às restrições estruturais e de projeto que determinam a região de polarização dos dispositivos e cumpre os requerimentos de aceitação $\mathscr{A}_{x}$ das variáveis de projeto $\mathbf{x}$.

Projeto para teste ou $\boldsymbol{D F T}^{5}$ : Está relacionada com a inclusão e arranjo de certos elementos físicos no projeto ou seja de Hardware, com o fim de facilitar a medição automatizada do primeiro silício e o adequado controle de qualidade na linha de produção.

Tempo de entrada no mercado (Time-to market): Define o intervalo de tempo que demora o circuito desde sua concepção como necessidade até o tempo em que é liberado para o mercado. Este tempo está amplamente relacionado com o conhecimento do processo e do circuito e o método que é adotado. Quando o mercado não foi ainda conquistado, o tempo de mercado define a liderança tecnológica na área, fato que dá ao fabricante uma vantagem muito forte sobre seus competidores.

Custo: O preço de um CI é determinado pelo rendimento funcional e paramétrico, a área ocupada, o tempo e complexidade dos testes de verificação e a prototipagem. A metodologia DFM para esta finalidade opta pela redução de custos através de um aumento de rendimento, a obtenção de uma ótima área para mismatch, em conjunto com o lançamento de uma linha única de produção de protótipos.

\subsection{Objetivos}

- Abordagem e desenvolvimento de uma metodologia de síntese de circuitos analógicos, que vai possibilitar a melhoria conjunta de desempenho e rendimento.

- Minimização da degradação das funções de desempenho após uma análise da influência e natureza das variações inerentes ao processo de fabricação e aquelas devidas a mismatch, causantes desta degradação.

- Validação do correto funcionamento da metodologia de projeto para fabricação desenvolvida através de simulações de Monte Carlo do circuito projetado por meio desta.

\footnotetext{
${ }^{5}$ Iniciais em inglês para Design For Testability (DFT)
} 


\subsection{Estado da arte}

$\mathrm{Na}$ área das ferramentas de projeto assistido de circuitos integrados podem ser definidas varias categorias, que vão desde a otimização unicamente do desempenho até esquemas de otimização multiobjetivo levando em conta as variações de processo. A Tabela 1.1 apresenta os trabalhos mais relevantes relacionados com os métodos de projeto assistidos por computador, que procuram otimizar o desempenho e/ou rendimento dos circuitos. O pioneiro e um dos mais representativos otimizadores nos anos oitenta foi o DELIGHT.SPICE [9], com foco na otimização de desempenho com base em formulações clássicas como o método de direções fatíveis. Com ele podia ser definido o nível de cumprimento das restrições e, num processo de três fases, garantir a obtenção de um bom conjunto de especificações. Ao mesmo tempo, métodos metaheurísticos de otimização como Simulated Annealing foram introduzidos na síntese de circuitos analógicos. Trabalhos abordando este tópico como o proposto em [10] faz uma modelagem analítica das funções de desempenho, obtendo até avaliações da topologia. No entanto resultam bastante inadequados para escalas nanométricas, devido ao fato do aumento na complexidade da modelagem dos dispositivos CMOS.

Depois das propostas de otimizações iterativas, vieram abordagens que estão focadas na otimização não linear sujeita a restrições. Primeiramente, Maulik em [11] tenta resolver o problema crescente da migração tecnológica através da definição de dois tipos de equações: algumas que descrevem o comportamento do circuito e outras o comportamento dos dispositivos. Assim tenta construir uma fundamentação para a rápida mudança tecnológica fazendo uso da programação não linear restrita, mantendo as equações que caracterizam a topologia e mudando aquelas dos dispositivos. No entanto, a principal desvantagem é a definição das restrições relacionadas com as leis de Kirchhoff em circuitos analógicos muito grandes. Juntamente com estas propostas, a área do projeto analógico automatizado trabalha em abordagens para a optimização do rendimento em circuitos analógicos para reduzir os problemas de variabilidade nos novos processos. Um trabalho interessante que associa muitas das preocupações da época foi proposto por Dharchoudhury em [12]. Inicialmente o desempenho é modelado com uma superfície de resposta ou $R S M^{6}$, em função de variáveis de projeto e parâmetros variáveis. A otimização do pior caso indiretamente implica uma melhora no rendimento do circuito ao lado de um menor tempo de computo, embora o grande problema seja manter o desempenho depois da melhora no rendimento do circuito.

Uma das propostas que conduz nesse sentido foi apresentada por Debyser em [13],

\footnotetext{
${ }^{6}$ Response Surface Methodology (RSM): explora as relações entre várias variáveis dependentes e uma ou mais variáveis de resposta.
} 
otimizando ao mesmo tempo rendimento e desempenho. Para poupar tempo no cálculo do rendimento via Monte Carlo, uma nova técnica de estimativa é proposta fazendo uso só dos parâmetros independentes do transistor. Seu maior problema é que sua técnica de cálculo simbólico das sensibilidades pode resultar inadequada para as escalas nanométricas e o conjunto de parâmetros independentes nos modelos de simulação atuais está diminuindo. Outra ferramenta proposta por B. Wu em [14] aborda a síntese de circuito e o re-uso do projeto em diferentes tecnológicas fazendo uso dos otimizadores disponíveis em MATLAB. O mais importante desta proposta é a consecução de 7 diferentes estratégias sequenciais para a otimização dos circuitos analógicos e a filosofia de mudar os propósitos de otimização em função do número de iterações. Nesse mesmo ano foi proposta Wicked, uma ferramenta atualmente comercial e que tenta resolver com Programação Sequencial Quadrática os problemas das variações locais e do mismatch no circuitos. O maior problema desta abordagem é a alta dependência do resultado final com respeito ao projeto inicial.

Durante os últimos dez anos, estratégias baseadas em programação convexa restrita foram estudadas. Uma das mais relevantes corresponde ao trabalho feito pela Maria del Mar em [15], onde a Programação Geométrica (PG) é usada para a síntese de circuitos analógicos. Sua vantagem é a obtenção de ótimos globais eficientemente e a possibilidade de avaliar com baixo custo computacional os compromissos através do esboço das curvas de Pareto ${ }^{7}$. No entanto, ainda é muito restritiva nas equações suportadas, sendo assim dependente da topologia, razão pela qual não garante uma diminuição no tempo de projeto nos casos quando a topologia tem que ser mudada na migração do processo. Além disso, o ótimo global as vezes pode ficar na fronteira da região de aceitabilidade ou simplesmente pode ser dimensionalmente inviável de fabricar. O trabalho proposto em [16] leva em conta as variações do processo na Programação Geométrica por meio da inclusão de um elipsóide de confiança como uma função convexa suportada. O maior inconveniente desta abordagem está relacionado com a caracterização do elipsóide de confiança em função das variações dos parâmetros físicos independentes. Finalmente a proposta feita por G. Yu em [17] faz uma extração dos compromissos em rendimento e especificações usando otimização em nível de sistema. A modelagem das variações de processo é feita usando a expressão do modelo de Pelgrom [18] para o mismatch e as variações locais, a qual é incluída dentro do modelo de sistema. Assim, Yu faz um esboço dos compromissos de rendimento e de uma especificação no PLL: lock time. A otimização do sistema é feita hierarquicamente, através da partição do sistema em $N$ sub-blocos. A principal vantagem desta abordagem é a inclusão da variabilidade em etapas iniciais do projeto, como

\footnotetext{
${ }^{7}$ Esboça o espaço de projeto dos circuitos em termos das especificações, normalmente uma por eixo. A fronteira inferior do espaço de projeto representa o conjunto de ótimos de Pareto, cada um representando um valor ótimo sob uma condição específica
} 
são as simulações em nível de sistema, embora seja uma aproximação pouco adequada para determinar o rendimento final do sistema.

Como é possível ver, nenhuma das propostas anteriores leva em conta uma aproximação de métodos numéricos e o uso de otimização convexa sob a variações de processo. A aposta forte das indústrias atuais é transferir o maior conhecimento e trabalho de um processo para outro, mantendo os níveis de confiabilidade anteriores. A proposta feita neste trabalho junta o baixo tempo de implementação de otimizações numéricas iterativas com a obtenção de ótimos globais do esquema de otimização convexo, para assim propôr uma ferramenta de otimização do rendimento focada para a migração tecnológica. 


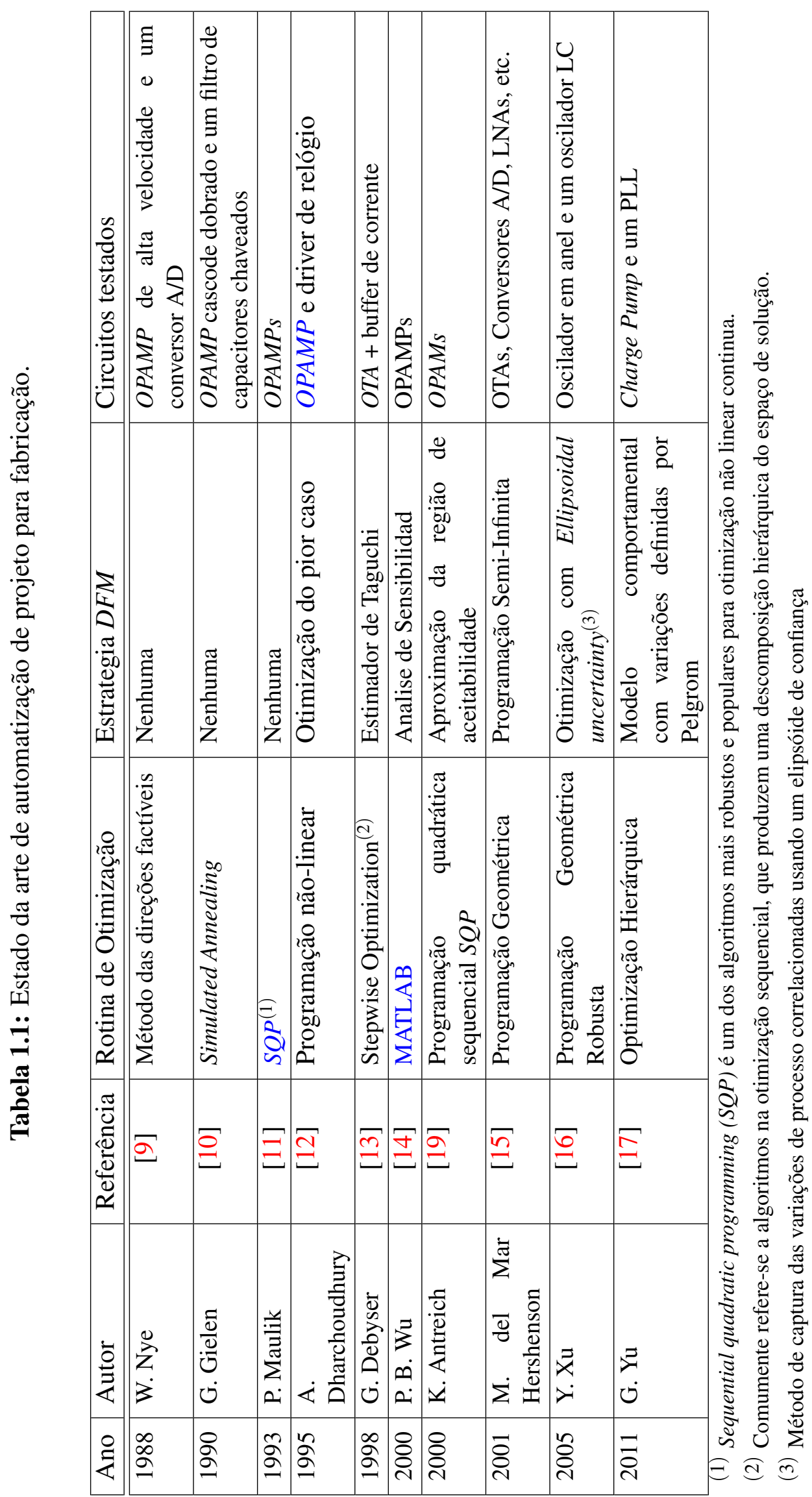




\subsection{Organização do documento}

Neste presente documento a metodologia de projeto para fabricação (DFM) será abordada na seguinte ordem:

No Capitulo 2 é desenvolvida a proposta deste trabalho, tanto no âmbito teórico como no matemático, e mantendo como eixo a otimização nominal e de rendimento dos circuitos analógicos. Inicialmente a base da metodologia é dada, sendo descritas as etapas do início ao fim, ou seja, desde a geração da semente ou ponto inicial até a análise e otimização do pior caso. O processo de geração de sementes envolve uma otimização iterativa utilizando algoritmos de ponto interior inclusos numa rotina de $M A T L A B$, como é exposto na Seção 2.2. A análise de polarização, descrita na Seção 2.3, aproxima o espaço de projeto com base nas restrições estruturais de polarização de cada um dos elementos do circuito. Entretanto, a otimização do circuito é executada em três etapas: otimização multi-objetivo nominal apresentada na Seção 2.4, otimização da área mínima ocupada estabelecido uns valores de desvio devido ao mismatch das funções de desempenho como é mostrado nas Seções 2.5 e 2.6.2. E finalmente, como culminação do Capítulo 2, nas Seções 2.7 e 2.8, uma derivação analítica de um método de análise e otimização do pior caso nos circuitos analógicos é desenvolvida em termos de uma expressão denominada distância do pior caso ou Worst-Case Distance (WCD). Além disso, são introduzidas novas definições para caracterizar o comportamento das especificações ante as diferentes variações e obter assim um melhor discernimento da estratégia futura para adotar.

A fundamentação matemática e teórica dada no Capítulo 2 é validada através do projeto de um circuito analógico, neste caso corresponde a uma fonte geradora de uma tensão de referência polarizada em sub-limiar. A análise e descrição da estratégia completa de projeto da fonte levando em conta as variações de processo e nos fatores de ambiente é descrita no Capítulo 3. Inicialmente na Seção 3.1, a topologia, as especificações e seus valores esperados são definidos com base num projeto anterior publicado em [20]. Esta seção também estabelece as relações entre as variáveis de projeto e as especificações, as quais são de fundamental importância para garantir um apropriado comportamento do circuito. A Seção 3.2 aborda a influência do atraso no tempo de ingresso ao mercado da fonte de referência quando esta deve ser implementada num processo de fabricação diferente ou mais avançado, no qual não foi desenvolvida ainda. Adicionalmente, esta avalia os benefícios obtidos utilizando o gerador de semente na fase inicial do projeto. As duas seções seguintes são dedicadas à otimização nominal multi-objetivo usando a Programação Geométrica (PG). A intenção dessas seções é estabelecer os compromissos entre as diferentes especificações, de modo que o projetista tenha a possibilidade de alterar ou manter a topologia e/ou processo. A Seção 3.5 analisa o impacto do mismatch sobre cada 
um das funções de desempenho, seis no caso da fonte de referência tratada, estabelecendo requerimentos mínimos de área por elemento. As seções 3.6 e 3.7 são dedicados à análise e otimização das distâncias do pior caso para o conjunto de parâmetros de processo e ambiente mais relevantes da fonte de referência. Os resultados finais são apresentados na Seção 3.8 aonde uma melhoria de aproximadamente $38 \%$ foi obtida, sem uma penalidade considerável na área ou nos valores das especificações, demostrando-se os benefícios na implementação da metodologia de projeto para fabricação proposta. 


\section{Proposta da Metodologia de projeto para Fabricação (DFM)}

\subsection{Fundamentação}

Provavelmente uma das vantagens e características mais importantes dos circuitos analógicos é sua flexibilidade para o projeto, tornando-o versátil e amplamente aplicável a muitos propósitos. Nesse sentido, a uma topologia vai estar vinculada uma ampla gama de possibilidades de desempenho e várias outras de operação, as quais no âmbito do projetista são percebidas como um conjunto de restrições $n$-dimensionais envolvidas um com outras. No entanto, apesar de ter um vasto conjunto de opções de dimensionamento, é comum ver como cada topologia tem em comum um próprio método de projeto, que pode ser representado sequencialmente como um algoritmo de projeto automatizado. O desafio atual é estender as metodologias de projeto e torná-las transparentes ao tipo de circuito e topologia adotada. Além disso, as ferramentas $C A D$ devem centrar-se na redução do tempo de aprendizagem tanto do rendimento e desempenho nos futuros processos nanométricos.

A flexibilidade de uma metodologia de projeto de circuitos analógicos começa com uma modelagem bem sucedida dos blocos mínimos funcionais, tais como transistores, de forma que seu comportamento global possa ser adequadamente estimado, controlado e, portanto, otimizado. É precisamente a modelagem do processo tecnológico o ponto de partida da metodologia proposta neste trabalho e a qual é visível na Figura 2.1. O modelador de processos tem entre outras funções simplificar os modelos de simulação para cálculos específicos, os quais incluem a análise de mismatch e a caracterização das funções de desempenho. A parte central da metodologia é o dimensionamento do circuito, esta começa com a preparação adequada do circuito e suas medidas nos denominados test-benchs. Após esta etapa, o projetista define o valor inicial do conjunto de variáveis de projeto, que apenas define um ponto de partida possível, mas altamente independente do resultado da metodologia. O próximo estágio, chamado Seeder ou gerador de sementes vai trabalhar para encontrar um conjunto adequado de variáveis de 


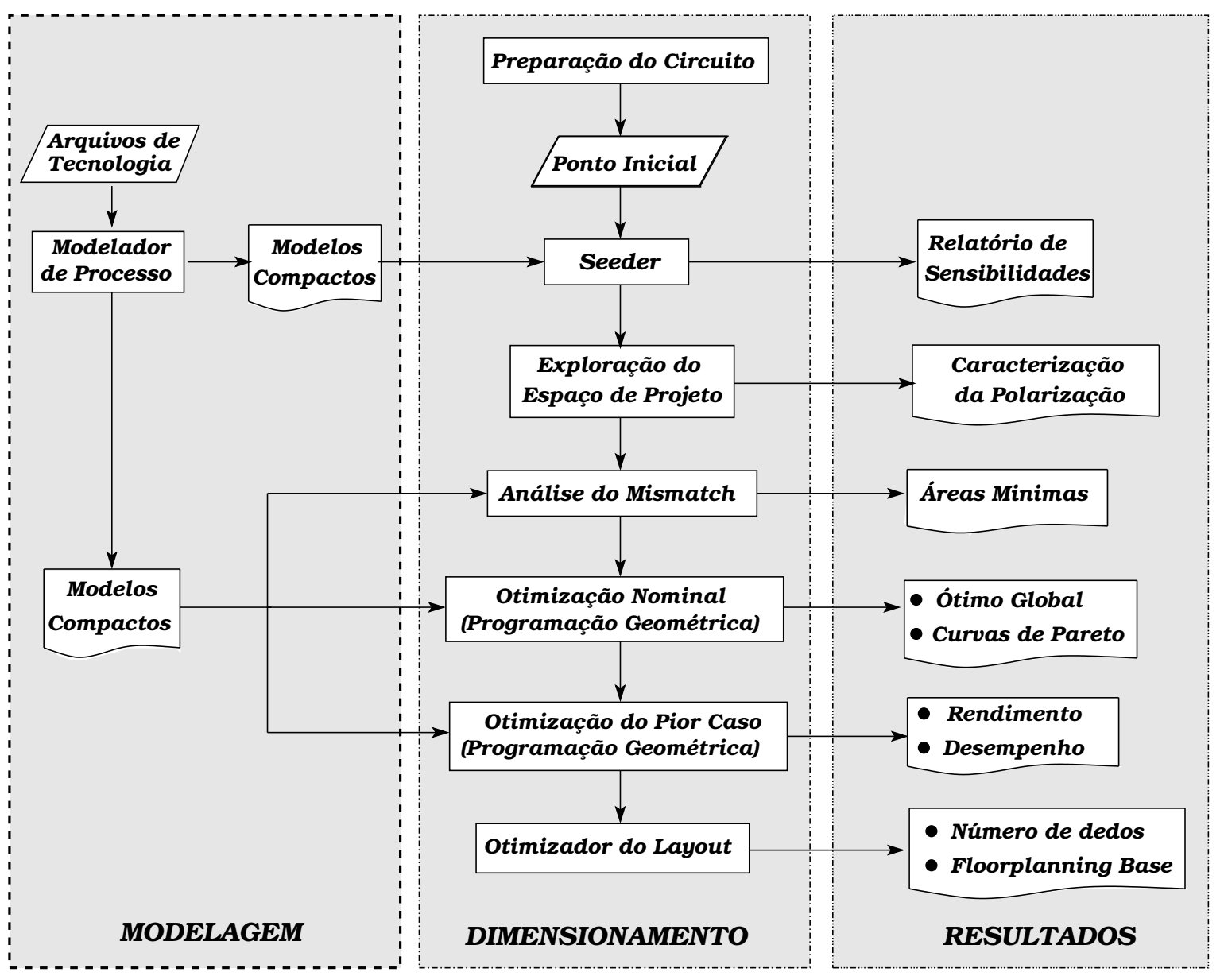

Figura 2.1: Fluxo proposto de projeto analógico para fabricação.

projeto que satisfaça moderadamente os requisitos de desempenho definidos inicialmente pelo projetista. No pior dos casos, esta etapa poderia declarar uma inviabilidade na obtenção das finalidades do projeto, um cenário que implicaria um relaxamento nas especificações ou uma alteração da topologia. Definido o ponto na região de aceitabilidade do espaço de projeto, é possível extrapolar o comportamento funcional, o desempenho e até o efeito das variações de processo e do mismatch do circuito final. Na fase da avaliação de mismatch, tecnologia é caracterizada usando o modelo de variabilidade proposto por Pelgrom em [18] e fazendo uma análise de sensibilidade é realizada para o ponto obtido como semente. Assim, são definidas as restrições de mínima área baseadas nos requerimentos de variabilidade do projetista.

O próximo passo consiste em condensar muitas das informações obtidas nas fases preliminares dentro de um programa geométrico multi objetivo. Inicialmente, será definido um programa geométrico para a otimização nominal, isso significa que sua função objetivo conterá o conjunto de especificações de desempenho que destinam-se a melhorar. Para avaliar os compromissos entre as especificações e traçar as curvas de Pareto, os coeficientes de ponderação são varridos adequadamente. Como resultado final serão gerados valores ótimos 
para cada uma das especificações. Para o caso da análise das variações de processo, os resultados da etapa preliminar são usados para criar um esquema em PG, o qual vai tentar minimizar os desvios gerados pela natureza do processo nas funções de desempenho. Para definir adequadamente os piores casos, uma análise de sensibilidade será realizada sob os parâmetros físicos independentes do processo. Assim, vai-se garantir uma otimização indireta do rendimento do circuito. Os resultados finais incluíram um conjunto de variáveis de projeto e um informe dos resultados de desempenho e rendimento. Finalmente um gerador de layout obtem o melhor conjunto de dedos dos transistores que vão a tentar garantir os requerimentos conjuntos de mismatch e floorplaning definidos pelo projetista.

\subsection{Gerador de sementes e exploração do projeto inicial}

Dado um circuito com um conjunto de elementos definido por $\mathscr{E}$, um conjunto de especificações para otimizar $\mathscr{P}$ e um vetor de variáveis de projeto $\mathbf{x}$, delimitadas por um conjunto $\mathscr{C}$ de restrições $c_{i}(\mathbf{x})$, seu problema de otimização multi objetivo pode ser generalizado como segue:

$$
\begin{array}{llc}
\text { minimizar } & \sum_{i=1}^{p} w_{j} g_{j}(\mathbf{x}) & j=1, \ldots, p \\
\text { sujeito a: } & l_{k} \leq c_{k}(\mathbf{x}) \leq u_{k} & k=1, \ldots, q \\
& \forall V_{G S_{i}}, V_{D S_{i}} \in \mathscr{D} \mathscr{N}, \mathscr{P} & i=1, \ldots, m \\
& \forall j \in \mathscr{P}, \forall i \in \mathscr{E}, \forall k \in \mathscr{C}
\end{array}
$$

onde $w_{j}$ é um coeficiente de ponderação de relevância da $j$-ésima função $g_{j}(\mathbf{x})$ a minimizar e $\mathscr{D}_{\mathscr{N}, \mathscr{P}}$ é o espaço de projeto das polarizações do transistor MOS. Geralmente as restrições $c_{k}(\mathbf{x})$ entre as variáveis de projeto $x_{i}$ são da forma $l_{k} \leq x_{k} \leq u_{k}$, onde $l_{k}$ e $u_{k}$ correspondem a limites inferiores e superiores, respectivamente, definidos pelas dimensões mínimas e máximas e pela polarização do circuito. Por ser o esquema em (2.1) multiobjetivo, ou seja, procura encontrar um conjunto $\mathscr{P}$ de especificações ótimas, vai-se ter um conjunto de especificações para maximizar como o ganho, para minimizar a potência e para estabelecer um valor fixo como a tensão de referência. Além disso, a sequência de otimização deve ser capaz de discernir quando o valor da função de desempenho, ou seja uma especificação, corresponde a um bom ou um péssimo valor. Portanto, tem-se que incrementar o peso da função objetivo para aquelas especificações cujos valores são considerados piores na iteração atual e decrescer o peso para aqueles em que o valor de desempenho corresponde a um bom valor, o qual está perto do ponto para ser atingido $f_{b}$. Além disso, as funções precisam ter iguais ou no pior dos casos semelhantes inclinações, para assim garantir um adequado comportamento do gradiente 
e da matriz Hessiana, condições que ajudam a obter uma boa convergência no ponto ótimo desejado. Desta forma é definida a função $g(\mathbf{x})$, a qual leva em conta todos os casos assumidos anteriormente, sendo esta definida como:

$$
g_{j}(\mathbf{x})= \begin{cases}\arctan \left(z_{j}(\mathbf{x})\right)+\pi / 2 & \text { para funções minimizar e maximizar } \\ \arctan \left(z_{j}(\mathbf{x})\right) & \text { valor objetivo }\end{cases}
$$

onde $z_{j}(\mathbf{x})$ é uma função de ajuste, a qual define o grau de penalização em termos do valor ótimo $f_{b}$, do pior valor $f_{w}$ e valor objetivo $f_{o b j}$ para cada uma das especificações estabelecidas da seguinte maneira:

$$
z_{j}(\mathbf{x})= \begin{cases}\frac{2 k}{\left(f_{w}-f_{b}\right)} f_{j}(\mathbf{x})-k \frac{\left(f_{w}+f_{b}\right)}{\left(f_{w}-f_{b}\right)} & \text { para função maximizar } \\ \frac{2 k}{\left(f_{w}+f_{b}\right)} f_{j}(\mathbf{x})+k \frac{\left(f_{w}+f_{b}\right)}{\left(f_{b}-f_{w}\right)} & \text { para função minimizar } \\ \left|\frac{f_{j}(\mathbf{x})-f_{o b j}}{f_{o b j}}\right| & \text { valor objetivo }\end{cases}
$$

O valor $k$ no conjunto de equações em (2.3) determina a localização dos pontos $f_{w}$ e $f_{b}$ no traçado da função $\arctan \left(z_{j}(\mathbf{x})\right)$. Um traço do comportamento das funções $g_{j}$ para minimizar e maximizar em função das especificações normalizadas pode ser visto na Figura 2.2(a), na qual são ressaltados os pontos do pior e melhor valor para as funções a maximizar, denotados como $f_{w \max }$ e $f_{b \max }$, respectivamente, em conjunto com os pontos do pior e melhor valor para a funções a minimizar, designados de maneira semelhante como $f_{w \min }$ e $f_{b \max }$, respetivamente. É destacado a simetria das curvas das funções de mérito em torno de um ponto em comum, no caso exemplificado corresponde ao valor de 2,5 , característica que permite uma adequada

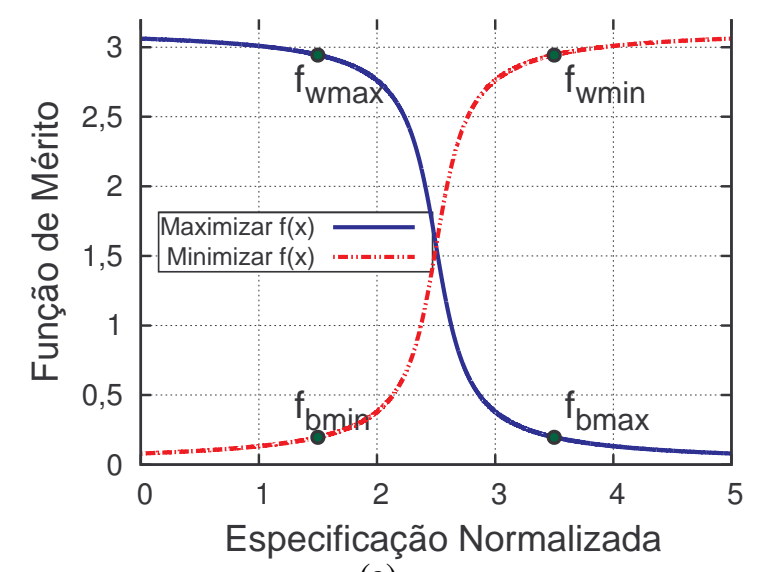

(a)

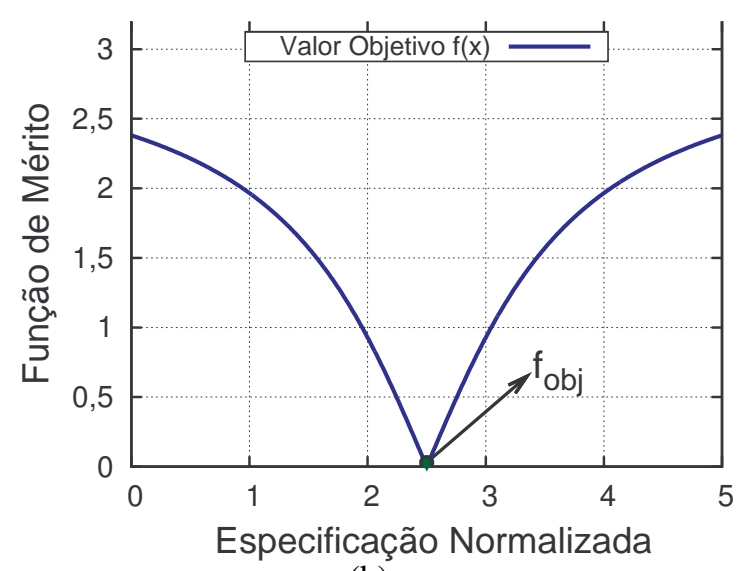

(b)

Figura 2.2: (a) Função de mérito $g_{j}(\mathbf{x})$ para maximizar e minimizar, (b) Função de mérito $g_{j}(\mathbf{x})$ para o valor objetivo. 
normalização das funções de mérito ou objetivo baseado nos requerimentos estabelecidos pelo projetista. No caso da função valor objetivo, o propósito é levar a função de desempenho a um valor específico, definido por $f_{o b j}$, mantendo o comportamento do gradiente e da matriz Hessiana das funções maximizar e minimizar equivalente com aquele da função objetivo, propriedade que pode ser vista na Figura 2.2(b).

Ao resolver o problema de otimização não linear em (2.1) por métodos iterativos, é difícil garantir um adequado controle das variáveis que não são de projeto, mas foram condicionadas pelo projetista para assegurar a funcionalidade do circuito. Um exemplo dessas variáveis são as tensões $V_{G S}$ e $V_{D S}$ de cada transistor. A fim de introduzir uma convergência global para a região de viabilidade do circuito, é preciso redefinir a função objetivo para assim controlar a violação das restrições funcionais usando uma função de penalização. Dado um conjunto de restrições funcionais $c_{f_{i}}(\mathbf{x})$ da forma $l_{f_{i}} \leq c_{f_{i}}(\mathbf{x}) \leq u_{f_{i}}$. O problema de otimização em (2.1) pode ser transformado num problema de otimização equivalente sem restrições funcionais da forma:

$$
\begin{array}{cl}
\operatorname{minimizar} & \sum_{i=1}^{p} w_{j} g_{j}(\mathbf{x})+\sigma \sum_{i=1}^{m}\left\{\phi_{i}\left(c_{f_{i}}(\mathbf{x})-l_{f_{i}}\right)+\phi_{i}\left(u_{f_{i}}-c_{f_{i}}(\mathbf{x})\right)\right\} \\
\text { sujeito a: } \quad & l_{k} \leq c_{k}(\mathbf{x}) \leq u_{k} \\
& \forall j \in \mathscr{P}, \forall i \in \mathscr{E}, \forall k \in \mathscr{C}
\end{array}
$$

onde o parâmetro $\sigma$ determina a quantidade de penalização e $\phi_{i}$ a função de penalização definida como: $\phi_{i}(x)=\min (0, x)^{2}$, a qual é diferente de zero só para aquelas restrições não cumpridas. No caso do método de ponto interior, as funções de penalização ou funções de barreira são definidas como: $\phi_{i}(x)=-\log (x)$. O objetivo é escolher uma sequência fixa $\left\{\sigma^{(k)}\right\} \rightarrow \infty$, tipicamente $\left\{1,10^{2}, 10^{3}, \ldots\right\}$, aumentando a penalização em cada iteração das restrições funcionais garantindo uma convergência do circuito ao ponto desejado. Assim, para cada $\sigma^{(k)}$ é encontrado um ótimo local e logo continua-se resolvendo (2.4) até quando $\phi_{i}(x)$ seja suficientemente pequeno [21]. Para resolver o problema em (2.4) é usada optimtool, uma ferramenta de otimização fornecida junto ao programa $M A T L A B^{1}$. Na Figura 2.3 é mostrado o fluxo de tarefas usado pelo Seeder. Em primeiro lugar, um conjunto de variáveis de projeto factíveis (não precisam ser funcionais) é tomado como ponto de partida da otimização e posteriormente é estabelecido o valor do coeficiente de penalidade $\left(\sigma^{(k)}\right)$, com base na estratégia de convergência proposta acima. Estratégias mais robustas podem variar dinamicamente

\footnotetext{
${ }^{1}$ Esta toolbox oferece a possibilidade de escolha de vários métodos de otimização, entre os quais estão Simulated Annealing, otimização não linear com restrições lineares, min-max, etc. Para nosso propósito foi escolhida a função fmincon, a qual faz uso do algoritmo de ponto interior.
} 


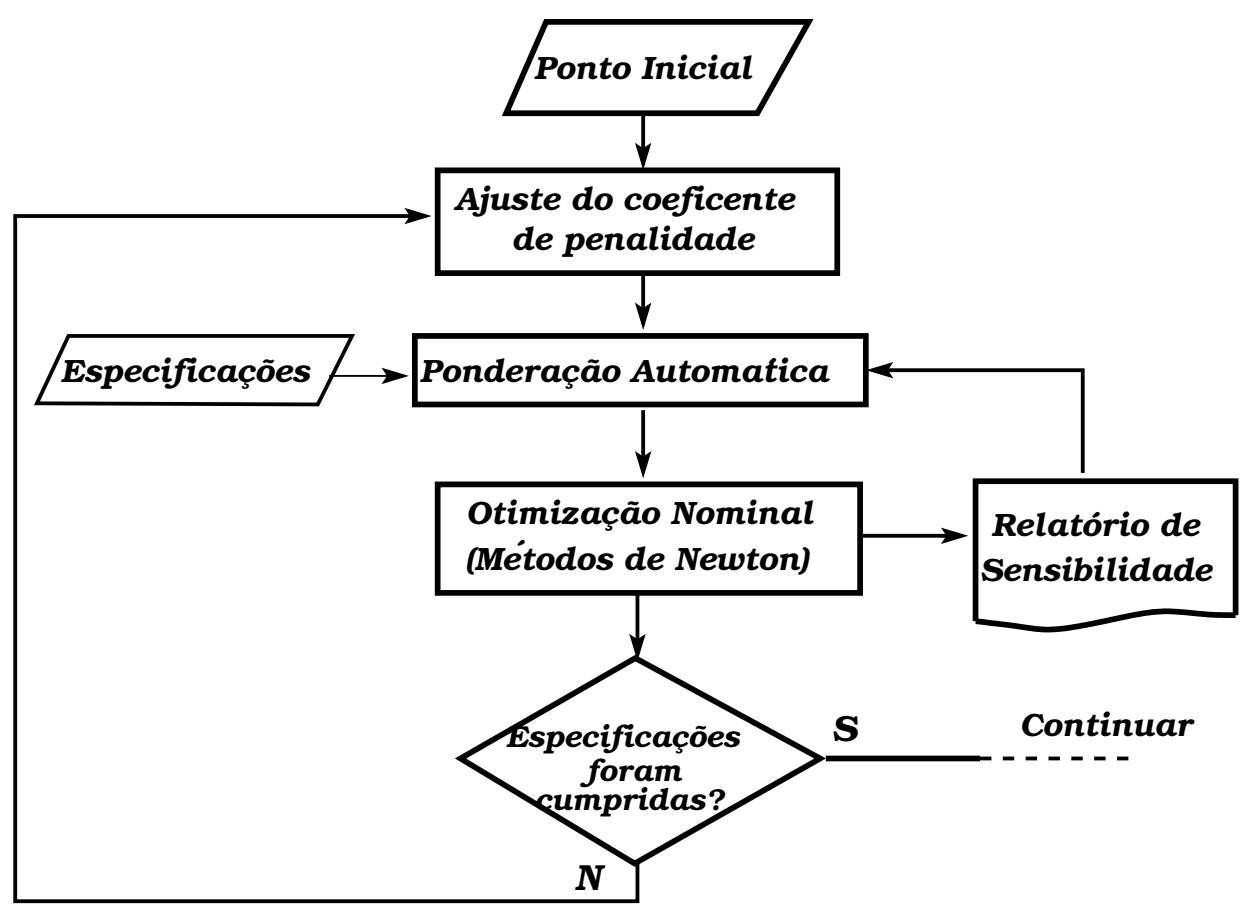

Figura 2.3: Fluxo do gerador de sementes ou Seeder.

este coeficiente com base na otimalidade de primeira ordem ${ }^{2}$ da função objetivo, mas neste trabalho este será só modificado ao longo de um conjunto de valores constantes. Então, uma ponderação automática dos coeficientes $w_{i}$ varia dinamicamente seus valores conforme uma análise estatística do impacto de cada função de desempenho sobre o comportamento global do circuito. Assim, as variáveis de projeto com alta dependência são mais importantes nas iterações iniciais do que aquelas menos globais, mas as menos globais tornam-se importantes uma vez que o comportamento global é atingido. Por exemplo, a área corresponde a uma especificação global pelo fato de que é influenciada por cada uma das variáveis dimensionais de projeto e precisa ser ajustada em primeiro lugar antes que outros parâmetros menos globais, como a margem de fase de um amplificador operacional ou o coeficiente de temperatura de uma fonte de referência, os quais só dependem essencialmente de um conjunto pequeno de variáveis de projeto. Após o estabelecimento dos coeficientes de ponderação, um programa não linear restrito é construído e resolvido iterativamente usando as funções disponíveis em optimtool o número de vezes que seja suficiente, até alcançar um mediano cumprimento das especificações ou uma baixa tolerância da função objetivo e das variáveis de projeto.

\footnotetext{
${ }^{2}$ A otimalidade de primeira ordem é uma medida de quão próximo um ponto $\mathbf{x}$ é ótimo. A maioria dos otimizadores usa esta métrica, embora com definições diferentes. A condição de otimalidade de primeira ordem é necessária, mas não é uma condição suficiente.
} 


\subsection{Explorador da polarização}

Do ponto de vista analógico, o transistor MOS é um dispositivo com um comportamento altamente dependente da região de polarização. Em nível de circuito, esta dependência implica que, para garantir seu correto funcionamento, é necessário restringir o domínio de polarização em cada elemento. A exploração do espaço de projeto de polarizações não é uma tarefa fácil, pois representa um problema de dimensão as vezes até maior ao número de elementos, mas é uma tarefa essencial em termos de otimização para a fabricação de um circuito usando as ferramentas de $C A D$, já que guia sua funcionalidade e afasta o projeto dos pontos extremos. Além disso, pode reduzir o espaço de projeto e, por consequência, diminuir o tempo de modelagem e convergência em esquemas de otimização como a Programação Geométrica.

O problema de limitação da região de polarização funcional de um circuito pode ser colocado como um problema de otimização restritiva. A ideia é levar as tensões de porta fonte $V_{G S}$ e dreno fonte $V_{D S}$ a seus limites superiores e logo a seus limites inferiores: $\ell_{V_{G S}}$ e $\ell_{V_{D S}}$. O problema de otimização geral pode ser expressado como:

$$
\begin{array}{ll}
\operatorname{minimizar} & \sum_{i=1}^{m}\left\{\left|\frac{V_{G S_{i}}-\ell_{V_{G S_{i}}}}{\ell_{V_{G S}}}\right|+\left|\frac{V_{D S_{i}}-\ell_{V_{D S_{i}}}}{\ell_{V_{D S_{i}}}}\right|\right\} \\
\text { sujeito a: } & a_{i} \leq c_{k}(\mathbf{x}) \leq b_{i} \\
& V_{G S i} \in \mathscr{D}_{N, P}, \quad \forall i \in \mathscr{E}, \forall k \in \mathscr{C}
\end{array}
$$

onde $V_{G S_{i}}$ e $V_{D S_{i}}$ são a $i$-ésima tensão porta fonte e dreno fonte de cada um dos $m$ transistores no circuito. Os limites superiores e inferiores, $\ell_{V_{G S}}$ e $\ell_{V_{D S}}$, são escolhidos para que sejam as combinações mais críticas do circuito, existindo só para $V_{G S}$ um número de $2^{m}$ combinações possíveis e, portanto, soluções para o problema de otimização mostrado em (2.5). Por exemplo, para cada transistor em saturação no circuito, seu limite inferior para a tensão de porta-fonte é definido conjuntamente pelas restrições $V_{G S} \geq V_{t}$ e $V_{D S} \geq V_{G S}-V_{t}$, sendo assim dois os valores possíveis para $\ell_{V_{G S}}$. O esforço computacional pode ser reduzido em casos onde há sequências de transistores de um único tipo, NMOS ou PMOS.

Uma vez solucionado o esquema de otimização em (2.5) para cada um dos limites, o espaço de projeto das polarizações $\mathscr{D}_{N, P}$, pode ser definido como:

$$
\mathscr{D}_{\mathscr{N}, \mathscr{P}}=\left\{\left\{V_{G S}, V_{D S}\right\}: l_{V_{G S_{i}}} \leq V_{G S_{i}} \leq u_{V_{G S_{i}}}, \wedge, l_{V_{D S_{i}}} \leq V_{D S_{i}} \leq u_{V_{D S_{i}}}, \forall i \in \mathscr{E}\right\}
$$

onde $l_{V_{G S_{i}}}$ e $l_{V_{D S_{i}}}$ são os mínimos valores do conjunto de soluções obtidas para as tensões portafonte e dreno-fonte, respectivamente, e $u_{V_{G S_{i}}}$ com $u_{V_{D S_{i}}}$ são seus correspondentes máximos 
valores. Desta forma o espaço funcional de polarização é limitado para garantir a funcionalidade do circuito.

\subsection{Otimização multi objetivo e fronteira de Pareto}

Quando houver mais de uma função de desempenho para melhoramento em um circuito, o projeto nominal envolve um problema de otimização multi objetivo ou um problema de otimização de vários critérios. A minimização simultânea de várias características de desempenho como em (2.1), exige um compromisso e, portanto, uma troca entre os objetivos de otimização concorrentes. Exemplos típicos de tais situações de troca são a velocidade vs. potência e o ganho vs. largura de banda. A otimalidade de uma característica de desempenho em um problema de otimização multi objetivo pode ser só avaliada em conexão com outras características de desempenho. Isto leva ao conceito de ótimo de Pareto [22].

Definição 1. Um ponto $\mathbf{x}^{*}$ é considerado um ótimo de Pareto ou uma solução globalmente eficaz. ou um ponto no dominante ou no inferior para um programa de otimização multi objetivo se e somente se não existe um $\mathbf{x}$ tal que $f_{j}(\mathbf{x}) \leq f_{j}\left(\mathbf{x}^{*}\right) \quad \forall j=1, \ldots, p$ com pelo menos uma desigualdade estrita.

Matematicamente, a formulação de um ponto ótimo de Pareto (ponto eficiente de Pareto ou ponto de Pareto) $\mathbf{f}^{*}$ corresponde ao vetor de ponderação de desempenho w com o valor minimo de sua componente máxima entre todos os vetores de desempenho viáveis:

$$
\begin{aligned}
\mathbf{f}^{*}(\mathbf{x}) \leftarrow \operatorname{minimizar} & \underbrace{\max _{j} w_{j} \cdot f_{j}(\mathbf{x})}_{\left\|f_{j}(\mathbf{x})\right\|_{\infty, w}} \quad j=1, \ldots, p \\
\text { sujeito a: } & l_{k} \leq c_{k}(\mathbf{x}) \leq u_{k} \quad k=1, \ldots, q \\
& \forall V_{G S_{i}}, V_{D S_{i}} \in \mathscr{D} \mathscr{N}, \mathscr{P} \quad i=1, \ldots, m \\
& \forall j \in \mathscr{P}, \forall i \in \mathscr{E}, \forall k \in \mathscr{C} \\
& w_{j} \geq 0, \sum_{i} w_{i}=1, f_{j} \geq 0
\end{aligned}
$$

Na equação (2.7) podem ser mostrados dois aspectos: a operação min-máx, ou a norma $\ell_{\infty}$ respectivamente, é uma parte inerente da definição de um ponto ótimo de Pareto. A segunda corresponde ao fato de que o vetor de ponderação do desempenho w é normalizado. Em um problema de otimização com vários objetivos ou Multiple-Objective Optimization (MOP) existe um conjunto de pontos de Pareto, que é chamado ótimo de Pareto ou simplesmente Fronteira 


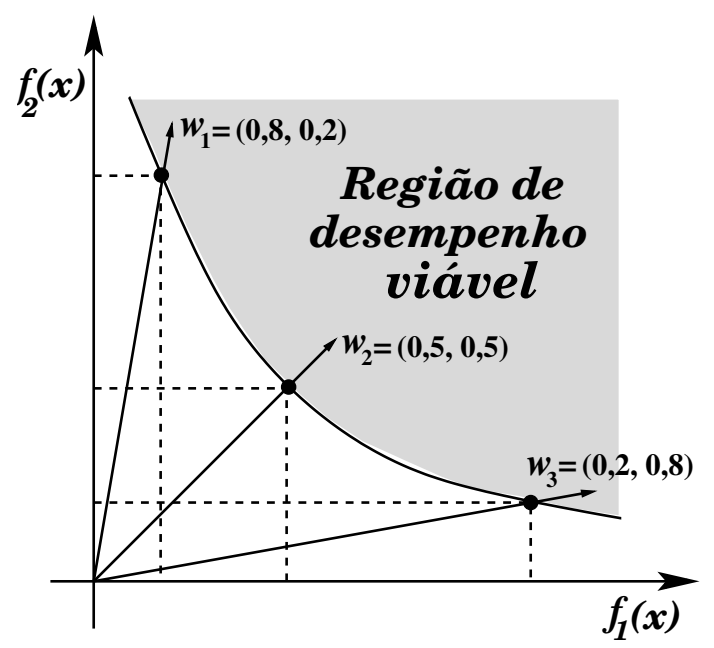

Figura 2.4: Fronteira de Pareto $P F\left(f_{1}, f_{2}\right)$ de duas funções de desempenho.

de Pareto, Pareto Front (PF). A Figura 2.4 ilustra uma fronteira de Pareto de duas funções de desempenho. A região cinza denota o conjunto de todos os vetores de desempenho que são realizáveis tendo em consideração as restrições do problema de otimização. A linha sólida na borda inferior da região de valores viáveis de desempenho representa o conjunto de pontos de Pareto, ou seja, a fronteira de Pareto. Pode-se mostrar que cada ponto representa o mínimo ponderado na norma infinita $\ell_{\infty}$ a qual é possível para um dado vetor de ponderação $\mathbf{w}$. A fronteira de Pareto $P F$ e seu contorno $\mathscr{B}$ pode ser definido como:

$$
\begin{array}{r}
P F(\mathbf{f})=\left\{\mathbf{f}^{*}(\mathbf{x}) \mid w_{j} \geq 0, \sum_{j} w_{i}=1\right\} \quad \forall i \in \mathscr{P} \\
\mathscr{B}\left(P F\left(f_{1}, \ldots, f_{p}\right)\right)=\cup_{i} P F\left(f_{1} \ldots f_{i-1}, f_{i+1} \ldots f_{p}\right)
\end{array}
$$

A partir dos mínimos individuais, a fronteira de Pareto pode ser formulada de forma hierárquica, acrescentando as funções de desempenho de acordo a (2.9) [23]. Além disso, é possível obter os melhores casos por especificação igualando os coeficientes de ponderação $w_{i}$ ao valor de zero, salvo para aquela função de desempenho $f_{j}$ objeto da análise. Em termos matemáticos pode ser representado como:

$$
f_{j_{o p t}}=\left\{\mathbf{f}^{*}(\mathbf{x}) \mid w_{i}=1 \text { para } j=i, \wedge, w_{i}=0 \text { para } j \neq i\right\} \quad \forall i=1, \ldots, p
$$

sendo $f_{j_{o b j}}$ o valor ótimo obtido sob as restrições de projeto definidas e sem manter preocupação no valor das outras especificações. A obtenção deste valor é muito importante no projeto de circuitos, pois estabelece os limites de uma topologia e/ou tecnologia, poupando o tempo do re-projeto e re-definição do circuito. 


\subsection{Análise de mismatch e ruído flicker}

O mismatch e as variações aleatórias podem ser considerados no PG através de restrições de desigualdade que definem inicialmente a área mínima exigida por cada elemento do circuito. Com base nos resultados teóricos obtidos em [24], estabelece-se que para um circuito de $n$ elementos com desvios padrão de uma única função de desempenho $\sigma_{1}, \ldots, \sigma_{n}$, assumidas como independentes, a área ótima global que garante um desvio total padrão $\sigma_{\text {total }}$ de um parâmetro ou função de desempenho é:

$$
A_{\text {total }}=\left(\frac{\rho_{1}+\rho_{2}+\cdots+\rho_{n}}{\sigma_{\text {total }}}\right)^{2}
$$

onde $\rho_{1}, \ldots, \rho_{n}$ em sua forma mais geral, são funções que descrevem a contribuição do $i$-ésimo elemento no desvio padrão $\sigma_{\text {total }}$. Seus valores podem ser determinados analiticamente ou através de simulação. Em particular, a área para o $i$-ésimo elemento que garante uma área total ótima é:

$$
A_{i}=\rho_{i} \frac{A_{\text {total }}}{\rho_{1}+\rho_{2}+\cdots+\rho_{n}}
$$

Neste ponto devemos notar duas coisas: o modelo utilizado para a derivação de (2.11) e (2.12) corresponde ao proposto pelo Pelgrom em [18], onde é iminente uma superestimação da área devido à hipótese de não correlação do mismatch entre os $n$-dispositivos. Além disso, foram assumidos transistores MOS com número unitário de dedos, o qual na realidade não é verdade, pelo fato do dobramento dos transistores para uma melhor disposição final do layout. No entanto, esta informação não pode ser obtida antes do dimensionamento e ajuste final do circuito, embora ela pode ir sendo adequadamente estimada nas subsequentes etapas. Para garantir uma adequada estimativa inicial, o qual vai definir os requerimentos mínimos de área, vai-se adotar o fluxo mostrado na Figura 2.5. Inicialmente é feita uma extração dos parâmetros do projeto semente gerado pela estratégia anterior usando o modelo de Pelgrom para o mismatch e o modelo $1 / f$ para o ruído flicker. Logo é calculada a sensibilidade das funções de desempenho com respeito às correntes em cada elemento avaliando a influência do mismatch e o ruído flicker. O cálculo da área é feito iterativamente até obter diferenças menores que um erro relativo $\% \varepsilon$, além disto, para evitar superestimações da área são aproximados e logo atualizados número de dedos para cada um dos transistores MOS.

Para garantir as condições de aceitabilidade do rendimento para $p$ funções de desempenho definidas como especificações de projeto, (2.11) e (2.12) devem ser estendidas para $p$ dimensões. Usando a relação de propagação da variância, as $p$ especificações de aceitabilidade 


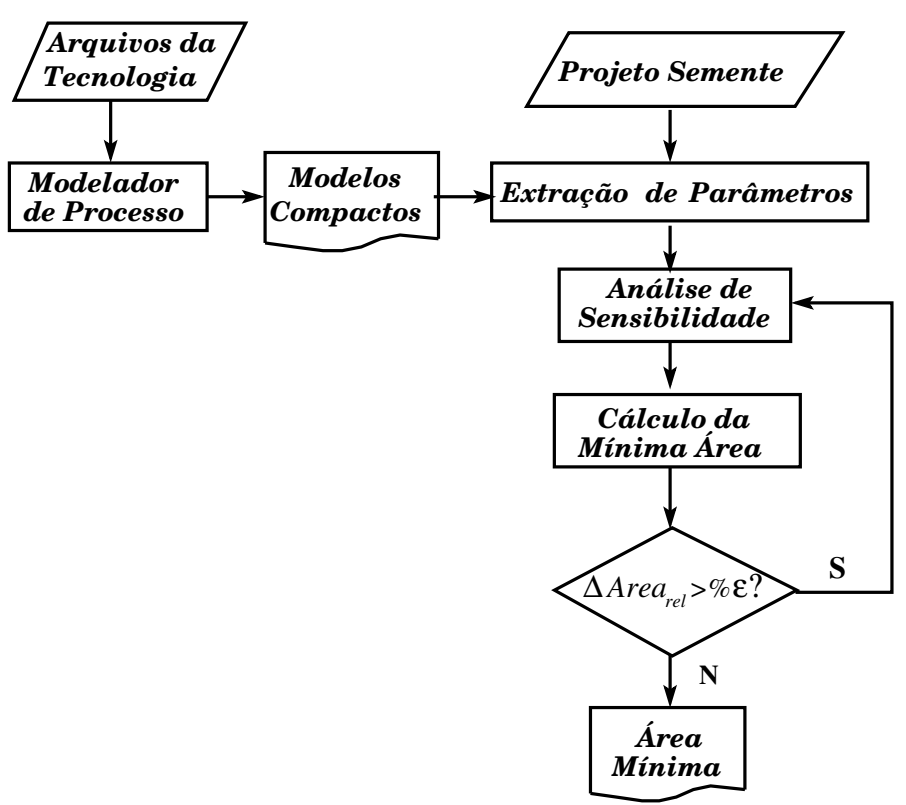

Figura 2.5: Fluxo para o cálculo das áreas mínimas para mismatch e ruído flicker.

seriam dadas por:

$$
\left[\begin{array}{c}
\sigma_{f_{1}}^{2} \\
\sigma_{f_{2}}^{2} \\
\vdots \\
\sigma_{f_{n}}^{2}
\end{array}\right]=\left[\begin{array}{cccc}
\left(\frac{\partial f_{1}}{\partial i_{1}}\right)^{2} & \left(\frac{\partial f_{1}}{\partial i_{2}}\right)^{2} & \ldots & \left(\frac{\partial f_{1}}{\partial i_{n}}\right)^{2} \\
\left(\frac{\partial f_{2}}{\partial i_{1}}\right)^{2} & \left(\frac{\partial f_{2}}{\partial i_{2}}\right)^{2} & \ldots & \left(\frac{\partial f_{2}}{\partial i_{n}}\right)^{2} \\
\vdots & \vdots & \ddots & \vdots \\
\left(\frac{\partial f_{p}}{\partial i_{1}}\right)^{2} & \left(\frac{\partial f_{p}}{\partial i_{2}}\right)^{2} & \ldots & \left(\frac{\partial f_{p}}{\partial i_{n}}\right)^{2}
\end{array}\right]\left[\begin{array}{c}
\sigma_{I_{d 1}}^{2} \\
\\
\sigma_{I_{d 2}}^{2} \\
\vdots \\
\sigma_{I_{d n}}^{2}
\end{array}\right]
$$

onde $f_{1}, \ldots, f_{p}$ representa as funções de desempenho, $\sigma_{f_{j}}$ define um intervalo de aceitação para a $j$-ésima função de desempenho e $i_{i} \operatorname{com} \sigma_{i}^{2}$ representa a corrente e a variância no $i$-ésimo elemento, respectivamente. A variação de corrente no transistor MOS devida a mismatch, de acordo com o modelo Pelgrom, é dada por:

$$
\sigma_{I_{d_{i}}}^{2}=\left(g_{m}\right)^{2} \frac{A_{V_{t}}^{2}}{n_{i} A_{i}}
$$

onde $A_{V_{t}}$ é um valor fixo pelo processo de fabricação, $n_{i}$ é o número de dedos do transistor e $g_{m_{i}} \operatorname{com} A_{i}$ são a transcondutância e a área do elemento $i$, respectivamente. Igualmente para elementos diferentes no circuito, como resistores integrados, a variância pode ser determinada por:

$$
\sigma_{I_{R}}^{2}=\left(\frac{\partial I_{R}}{\partial R}\right)^{2} \frac{A_{R}^{2}}{W L}
$$


onde $A_{R}$ é a constante Pelgrom para o resistor $R, I_{R}$ é a corrente através do resistor e $W L$ a área ocupada por ele. Os valores de $\rho$ definidos em (2.11) e (2.12) são dados por:

$$
\rho_{j i}^{2}= \begin{cases}\left(g_{m_{i}}\right)^{2} \frac{A_{V_{t}}^{2}}{n_{i}}\left(\frac{\partial f_{j}}{\partial i_{i}}\right)^{2} & \text { para o } i \text {-ésimo transistor } \\ A_{R}^{2}\left(\frac{\partial I_{R}}{\partial R}\right)^{2}\left(\frac{\partial f_{j}}{\partial i_{i}}\right)^{2} & \text { para o } i \text {-ésimo resistor }\end{cases}
$$

A mesma derivação pode ser feita para o caso das contribuições do ruído flicker ou de baixas frequências, pois este tem uma dependência semelhante com o área ao mismatch. No entanto, ora as contribuições dos resistores ao ruído são essencialmente mais consideráveis do que seu efeito devido ao mismatch. Para o caso do transistor MOS, a variação da corrente $\sigma_{I d \text {,noise }}$ devida a ruído flicker $^{3}$ usando o modelo $N L E V=2,3$ do Manual de BSIM3v3, é:

$$
\sigma_{I d, \text { noise }}^{2}=\left(g_{m}\right)^{2} \frac{K_{F}}{n_{i} C_{o x} A_{i} f^{A_{F}}} \quad\left[V^{2} / H z\right]
$$

onde $A_{F}$ e $K_{F}$ correspondem ao exponente e o coeficiente do ruído flicker, respectivamente, $f$ a frequência de medida e $n_{i}$ ao número de dedos do transistor MOS. Para os resistores, a variância da corrente devido ao ruído térmico é:

$$
\sigma_{I_{R}, \text { noise }}^{2}=\left(\frac{4 k_{b} T}{R}\right)=\left(\frac{4 k_{b} T W}{R_{S H} L}\right) \quad\left[V^{2} / H z\right]
$$

onde $k_{b}$ é a constante de Boltzmann em $[\mathrm{J} / \mathrm{K}], T$ a temperatura absoluta do resistor e $R$ o valor da resistência em $[\Omega]$, e para resistores integrados, $R_{S H}$ representa a resistência por folha do material e $W \operatorname{com} L$ sua largura e seu comprimento, respectivamente.

$$
\rho_{j i}^{2}= \begin{cases}\left(g_{m_{i}}\right)^{2} \frac{K_{F}}{n_{i} C_{o x} f^{A_{F}}}\left(\frac{\partial f_{j}}{\partial i_{i}}\right)^{2} & \text { para o } i \text {-ésimo transistor } \\ \frac{4 k_{b} T}{R}\left(\frac{\partial y_{j}}{\partial i_{i}}\right)^{2} & \text { para o } i \text {-ésimo resistor }\end{cases}
$$

Assim, as $p$ funções de desempenho produzem $p$ valores possíveis de área para cada elemento, cada um é independente dos outros. Para cumprir o conjunto de restrições de aceitabilidade, a área do pior caso deve ser considerada:

$$
A_{\text {total }}=\max \left\{\left(A_{\text {total } 1}, \ldots, A_{\text {totalp }}\right)\right\}
$$

\footnotetext{
${ }^{3}$ Nesta derivação do ruído térmico no canal do transistor MOS não foi considerado pelo fato de não ser relevante a baixas frequências.
} 
Os valores das áreas possíveis para $n$ elementos do circuito podem ser organizados numa matriz como:

$$
A=\left[\begin{array}{cccc}
A_{11} & A_{12} & \cdots & A_{1 n} \\
A_{12} & A_{22} & \cdots & A_{2 n} \\
\vdots & \vdots & \ddots & \vdots \\
A_{p 1} & A_{p 2} & \cdots & A_{p n}
\end{array}\right]
$$

onde $A_{j i}$ é a área do $i$-ésimo elemento para a $j$-ésima função de desempenho. Como a soma das áreas individuais é sempre maior ou igual a (2.20), a área do $i$-ésimo elemento deve ser ponderada em relação ao pior caso, como:

$$
A_{i}=\max \left\{\left(A_{1 i}, \cdots, A_{p i}\right)\right\} \frac{A_{\text {total }}}{\sum_{k=1}^{n} \max \left\{\left(A_{1 k}, \cdots, A_{p k}\right)\right\}}
$$

Desta forma, a soma das áreas individuais determinada em (2.22) será igual a $A_{\text {total }}$ calculada a partir de (2.20). Uma vez que as restrições de área são impostas, uma estrutura de otimização baseada em conjuntos delimitados como a programação geométrica pode ser utilizada.

\subsection{Otimização nominal (Programação Geométrica)}

Programação geométrica é um tipo de problema matemático de otimização, cuja função objetivo e suas funções de restrição cumprem determinadas regras de composição [25]. A forma padrão de um Programa Geométrico é:

$$
\begin{array}{ll}
\operatorname{minimizar} & f_{o}(\mathbf{x}) \\
\text { sujeito a } & h_{i}(\mathbf{x})=1, \quad i=1, \ldots, r \\
& f_{j}(\mathbf{x}) \leq 1, \quad j=1, \ldots, s \\
& x_{k}>0, \quad k=1, \ldots, n
\end{array}
$$

onde $f_{i}$ e $f_{o}$ são funções do tipo posinomial e $h_{i}$ são funções tipo monômio. Qualquer programa geométrico pode ser facilmente transformado em um problema de otimização convexa, obtendo um ótimo global em pouco tempo. Não obstante o crescimento da complexidade na modelagem de sistemas analógicos requer que as deficiências da PG precisem ser abordadas e resolvidas. Existem dois tipos de desafios na implementação da PG: precisão na modelagem demandada pelos novos processos nanométricos e as formas funcionais não suportadas (por exemplo restrições posinomiais não convexas). A primeira geralmente requer modelos convexos lineares por partes $(P W L)$ e/ou partições do espaço de projeto. No entanto, o tempo gasto na modelagem 
o fragmentação pode ser maior do que o utilizado para obter a solução do programa geométrico. Isso é facilmente aceitável para circuitos que podem ser facilmente modelados com PG. Infelizmente, a maioria dos circuitos analógicos utilizam formas funcionais e restrições as quais não correspondem a um PG. Por exemplo, as leis de Kirchhoff são sempre um somatório de tensões e correntes numa igualdade (forma posinomial). Em geral, a igualdade posinomial é uma restrição não convexa, portanto, não é compatível com PG. Muitas das soluções propostas resolvem parcialmente o problema, mas exigem um esforço computacional adicional para solucionar um grande número de programas geométricos usando espaços de projeto restritos.

\subsubsection{Leis de Kirchhoff em PG}

Num circuito elétrico, a tensão em cada elemento está relacionada com a corrente que flui através dele e com outras correntes e tensões por as leis de Kirchhoff. No entanto, a dificuldade em modelar as leis de Kirchhoff num formato do tipo monômio ou posinômio e uma das lacunas mais importantes da PG. Os erros na estimação da polarização usando as abordagens atuais podem ser críticos na aproximação do desempenho. A fim de incluir as Leis de Kirchhoff no programa geométrico, uma transformação matemática deve ser aplicada. O método pode ser ilustrado através de um caso simples: dois resistores $R_{1}$ e $R_{2}$ ligados em série com uma fonte de tensão $V_{D D}$. A equação que representa as leis de tensão de Kirchhoff nessa rede pode ser dada por:

$$
V_{D D}=V_{A}+V_{B}
$$

Seja $k$ uma constante de dependência entre as duas tensões nos resistores, de modo que $V_{B}=k V_{A}$. A tensão de alimentação pode ser redefinida como:

$$
V_{D D}=(1+k) V_{A}
$$

No entanto, (2.25) não corresponde a uma forma monômio. Mas $(1+k)$ pode ser ajustado a uma função monômio do tipo $a k^{b}$, produzindo:

$$
\begin{array}{r}
V_{D D}=a k^{b} V_{A} \\
V_{B}=k V_{A}
\end{array}
$$

O ajuste de $(1+k)$ a uma forma monômio é adequado para valores de $k$ maiores que um, de modo que $V_{B} \geq V_{A}$. O intervalo permissível de $V_{A}$ e $V_{B}$ pode ser controlado através da definição de um limite inferior $l_{k}$ e superior $u_{k}$ para $k$. Esse método requer apenas uma definição do programa geométrico sem partições do espaço de projeto, o qual é uma vantagem importante 
no custo computacional em comparação com outras soluções. As equações (2.26) e (2.27) pode ser expandida para $n$ ramos ou nós. Os limites superiores e inferiores para $k$ são definidos em função dos intervalos permissíveis das tensões como segue:

$$
\begin{aligned}
l_{k} & =\frac{\min \left(V_{D D}\right)}{\max \left(V_{A}\right)}-1 \\
u_{k} & =\frac{\max \left(V_{D D}\right)}{\min \left(V_{A}\right)}-1
\end{aligned}
$$

A informação dos intervalos de tensões obtida na definição do espaço de polarização em (2.6), vai ser útil para estabelecer os valores máximos e mínimos em (2.28) e (2.29).

\subsubsection{Programação Geométrica aplicada para minimizar mismatch}

Com o propósito de otimizar conjuntamente o desempenho e seu desvio devido a mismatch, dois vetores são definidos: $\mathbf{u}$ e v. O vetor $p$-dimensional $\mathbf{v}$ corresponde à função custo de obter um projeto robusto contra o mismatch para cada uma das funções de desempenho. De forma semelhante, um vetor $n$-dimensional $\mathbf{u}$ representa o custo em área para cada um dos $n$ elementos no circuito. A função objetivo a minimizar é definida em termos de $\mathbf{u}$ e $\mathbf{v}$ e para obter a função custo global é usada a norma euclidiana, a qual é um operador matemático que mede a magnitude dos elementos em um vetor. Outros tipos de vetores ou normas podem ser perfeitamente usados.

A função objetivo é definida como a soma da norma dos vetores u e v. Um valor igual a um para cada elemento em $\mathbf{u}$ e $\mathbf{v}$ indica que não há penalização em área e desempenho, respectivamente, na implementação. A mínima área e o espaço de projeto funcional pode ser incluído no programa geométrico através da definição de restrições tipo desigualdade. A estrutura do programa geométrico proposto é dada por:

$$
\begin{array}{lll}
\text { minimizar } & \underbrace{\|\mathbf{u}\|}_{\text {Área }}+\underbrace{\|\mathbf{v}\|}_{\text {Desempenho }} \\
\text { sujeito a } & a_{k_{\text {min }}}=a_{k} u_{k} & k=1, \ldots, m \\
& f_{j_{o p t}}=f_{j}(\mathbf{x}) v_{j}, \quad \vee, \quad f_{j}(\mathbf{x}) \leq f_{j_{o p t}} v_{j} & f_{j} \text { para minimizar } \\
& f_{j}(\mathbf{x})=f_{j_{\text {opt }}} v_{j}, \quad \vee, \quad f_{j}(\mathbf{x}) v_{j} \leq f_{j_{o p t}} & f_{j} \text { para maximizar } \\
& u_{i} \geq 1, \quad \forall i \quad 1, \ldots, n \\
& v_{j} \geq 1, \quad \forall j \quad 1, \ldots, p
\end{array}
$$

onde $a_{k}$ é o $k$-ésimo elemento do vetor das áreas $\mathbf{a}, \mathbf{a}_{k_{\min }}$ é o $k$-ésimo elemento do vetor das áreas minimas calculadas a partir de $(2.22), f_{j}(\mathbf{x})$ corresponde à $j$-ésima função de desempenho e $f_{j_{o p t}}$ 
é o valor ótimo que é possível obter no circuito. Os vetores $\mathbf{u}$ e $\mathbf{v}$ representam o custo de obter as melhores áreas e o desempenho, respectivamente. A restrição de igualdade que relaciona $f_{j}$ e $f_{j_{o p t}}$ será utilizada para as formas monômio da função $f_{j}(\mathbf{x})$ e as restrições desigualdade para as suas formas posinômio. Este procedimento permite a otimização conjunta da função área e desempenho numa estratégia denominada best-effort. Os valores em $f_{j_{o p t}}$ podem ser extraídos com base em aqueles obtidos em uma definição clássica de PG. Para resolver o problema (2.30), CVX, um pacote para especificar e resolver programas convexos foi usado [26].

\subsection{Análise do pior caso}

Flutuações inevitáveis no processo de fabricação e nas condições ambientais de funcionamento dos circuitos integrados, causam variações aleatórias nas funções de desempenho do circuito em torno dos seus valores típicos. Além de depender das variáveis de projeto, o comportamento de um circuito depende de parâmetros de processo flutuantes como a espessura do óxido de porta $t_{o x}$, a tensão limiar $V_{t}$, e a redução da largura $\Delta W$ e o comprimento do canal $\Delta L$ no transistor MOS. Dada a natureza aleatória destes parâmetros, as especificações do circuito (tais como o ganho ou a velocidade) também variam em torno de seus valores nominais [12]. Estimar e, portanto, otimizar o rendimento paramétrico de um circuito com intervalos de confiança adequados é uma tarefa com um custo computacional bastante elevado, pois sua complexidade computacional é incrementada aproximadamente em $n r$, sendo $n$ o número de dispositivos e $r$ o número de parâmetros de processo objeto da análise. É por isso que os circuitos comumente são verificados usando os modelos do pior caso, que correspondem ao conjunto de parâmetros $\mathbf{p}_{w c}$ que geram o pior desempenho e as condições de desempenho. No entanto, esta técnica resulta muito pessimista em relação ao comportamento real das variações do processo, porque não leva em conta possíveis correlações entre os diferentes parâmetros do processo, os quais fazem que os eventos de pior caso aconteçam conjuntamente com uma probabilidade muito baixa. Além disso, não levam em consideração o acontecimento conjunto de eventos de melhor caso e pior caso, os quais sucedem frequentemente e sua análise leva a estimativas de rendimento mais realistas.

Com o objetivo de fornecer uma melhor explicação sobre as variações de processo e seus impactos sobre o desempenho dos circuitos, alguns conceitos precisam ser esclarecidos no âmbito do projeto de circuitos integrados. Suponha-se que temos um circuito caracterizado por um vetor $n$-dimensional $\overline{\mathbf{x}}$ de variáveis de projeto nominais, um vetor $\mathbf{p}$ de dimensão $r$ o qual representa os parâmetros de processo e um conjunto de $p$ funções de desempenho $\left\{f_{1}, \ldots, f_{p}\right\}$. 
É possível classificar no âmbito da simetria o efeito da $j$-ésima função de desempenho $f_{j}$ para qualquer variação $\delta_{p_{i}}$ em torno do parâmetro do processo $p_{i}$, em dois tipos:

Par: Diz-se que a variação de processo $\delta p_{i}$ produz uma variação par em torno ao valor nominal da função de desempenho $f_{j}$, se:

$$
\operatorname{sgn}\left(\delta f_{j}\left(p_{1}, \ldots, p_{i}+\delta_{p_{i}}, \ldots, p_{r}, \mathbf{x}\right)\right)=\operatorname{sgn}\left(\delta f_{j}\left(p_{1}, \ldots, p_{i}-\delta_{p_{i}}, \ldots, p_{r}, \mathbf{x}\right)\right)
$$

sendo sgn a função sinal. Isto implica que a degradação da função de desempenho $f_{j}$ é mantida independentemente da direção do desvio do parâmetro $p_{i}$.

Impar: Por outro lado, diz-se que a variação de processo $\delta_{p_{i}}$ produz uma variação ímpar em torno ao valor nominal da função de desempenho $f_{j}$, se:

$$
-\operatorname{sgn}\left(\delta f_{j}\left(p_{1}, \ldots, p_{i}+\delta_{p_{i}}, \ldots, p_{r}, \mathbf{x}\right)\right)=\operatorname{sgn}\left(\delta f_{j}\left(p_{1}, \ldots, p_{i}-\delta_{p_{i}}, \ldots, p_{r}, \mathbf{x}\right)\right)
$$

sendo sgn a função sinal. Neste caso, somente a direção de uma das variações de processo $\delta p_{i}$ produz um efeito adverso sobre a função de desempenho $f_{j}$.

A classificação de simetria dada em (2.30) e (2.31) difere das definições matemáticas da simetria de uma função matemática, isto por causa de dois fatores: uma simetria no comportamento dos parâmetros de processo nem das funções de desempenho do circuito podem ser garantidas ${ }^{4}$ e a análise do pior caso precisa conhecer a natureza da tendência das variações de processo, sendo a paridade das variações uma característica importante na hora de uma posterior otimização do pior caso, pois como será visto mais na frente, permite uma redução no tempo de cálculo das piores condições.

Por outro lado, as variações de processo podem ser classificadas com base aos critérios de monotonocidade do desempenho em função do desvio no parâmetro de processo $\delta_{p_{i}}$, desta maneira as mudanças na inclinação das funções desempenho são analisadas para dar uma melhor percepção da natureza não-linear do desvio no desempenho, e para assim tentar mover as variáveis de projeto a um ponto que produz o menor desvio no desempenho. Adicionalmente, a análise da monotonocidade pode estimar a neutralização dos melhores casos sobre os piores casos do circuito, os quais podem acontecer sob as mesmas condições. Assim, em termos de monotonocidade existem três tipos de funções de desempenho:

\footnotetext{
${ }^{4}$ Várias das funções de desempenho e parâmetros de processo apresentam distribuições de probabilidade não simétricas em torno do valor médio, como a distribuição log-normal.
} 
Desvio de desempenho monotonicamente crescente: Correspondem às funções de desempenho, que para todos os $\mathbf{p}_{a}$ e $\mathbf{p}_{b}$, tal que $p_{a_{i}} \geq p_{b_{i}}$ com $i=1, \ldots, r$, tem-se $f\left(\mathbf{x}, \mathbf{p}_{a}\right) \geq$ $f\left(\mathbf{x}, \mathbf{p}_{b}\right)$ para o domínio dos parâmetros de processo.

Desvio de desempenho monotonicamente decrescente: Correspondem às funções de desempenho, que para todos os $\mathbf{p}_{a}$ e $\mathbf{p}_{b}$, tal que $p_{a_{i}} \leq p_{b_{i}}$ com $i=1, \ldots, r$, tem-se $f\left(\mathbf{x}, \mathbf{p}_{a}\right) \leq$ $f\left(\mathbf{x}, \mathbf{p}_{b}\right)$ para o domínio dos parâmetros de processo.

Desvio de desempenho não monotônico: Corresponde às funções de desempenho nas quais existe pelo menos um $\mathbf{p}_{a} \geq \mathbf{p}_{b}$, tal que $f\left(\mathbf{x}, \mathbf{p}_{a}\right) \leq f\left(\mathbf{x}, \mathbf{p}_{b}\right)$, ou tem-se pelo menos um $\mathbf{p}_{a} \leq \mathbf{p}_{b}$ tal que $f\left(\mathbf{x}, \mathbf{p}_{a}\right) \geq f\left(\mathbf{x}, \mathbf{p}_{b}\right)$ para o domínio dos parâmetros de processo. Ou seja, a função de desempenho é não convexa e tem pelo menos uma mudança na sua concavidade.

Devido a que muitos dos parâmetros de processo não são independentes, a escolha do conjunto $\mathbf{p}_{w c}$ deve incluir a maioria dos parâmetros físicos essenciais. Além disso, para realizar um análise $P V T^{5}$ sobre o circuito, devem ser incluídas as variações na temperatura $(T)$ e na tensão de alimentação $\left(V_{D D}\right)$. Como parâmeros físicos são escolhidos a tensão de faixa plana $\left(V_{f b}\right)$, a espessura do óxido $\left(t_{o x}\right)$ e a concentração de dopantes no substrato $\left(N_{c h}\right)$. Assim, o conjunto de parâmetros para a análise do pior caso é definido como:

$$
p_{w c}=\underbrace{\left\{V_{f b}, t_{o x}, N_{c h}\right\}}_{\text {Processo }} \cup \underbrace{\left\{V_{D D}\right\}}_{\text {Tensão }} \cup \underbrace{\{T\}}_{\text {Temperatura }}
$$

Da mesma forma são definidas as matrizes $\mathbf{P}_{w c_{y j}}$ e $\mathbf{W}_{y_{j}}$ de dimensão $5 x m$ (sendo 5 os parâmetros de processo levados em conta para um conjunto de $m$ transistores), contendo os valores dos parâmetros e as direções do pior caso para a função de desempenho $y_{j}$, respectivamente. Os parâmetros $\mathbf{P}_{w c_{y j}}$ são geralmente da forma $\mu \pm n_{s} \sigma$, ou seja, o valor típico $\mu$ mais ou menos $n_{s}$ vezes o desvio padrão. A escolha do sinal é definida pela matriz $W_{j}$, a qual pode ser estabelecida matematicamente como:

$$
\mathbf{W}_{j}=d_{w_{j}} \cdot \operatorname{sgn}\left(\left[\begin{array}{ccccc}
\frac{\partial f_{j}}{\partial V_{f b 1}} & \frac{\partial f_{j}}{\partial t_{o x 1}} & \frac{\partial f_{j}}{\partial N_{c h 1}} & \frac{\partial f_{j}}{\partial V_{D D}} & \frac{\partial f_{j}}{\partial T} \\
\frac{\partial f_{j}}{\partial V_{f b 2}} & \frac{\partial f_{j}}{\partial t_{o x 2}} & \frac{\partial f_{j}}{\partial N_{c h 2}} & \frac{\partial f_{j}}{\partial V_{D D}} & \frac{\partial f_{j}}{\partial T} \\
\vdots & \vdots & \vdots & \vdots & \vdots \\
\frac{\partial f_{j}}{\partial V_{f b m}} & \frac{\partial f_{j}}{\partial t_{o x m}} & \frac{\partial f_{j}}{\partial N_{c h m}} & \frac{\partial f_{j}}{\partial V_{D D}} & \frac{\partial f_{j}}{\partial T}
\end{array}\right]\right)
$$

\footnotetext{
${ }^{5}$ Análise PVT(Process, Supply Voltage, Temperature) leva em conta as variações no pior caso dos parâmetros de processo, da tensão de alimentação e a temperatura de operação no circuito.
} 
onde $m$ é o número de transistores no circuito, sgn é a função sinal, e $d_{w_{j}}$ é uma função definida como:

$$
d_{w_{j}}= \begin{cases}+1 & \text { para a função } f_{j} \text { a minimizar } \\ -1 & \text { para a função } f_{j} \text { a maximizar } \\ \pm 1 & \text { para a função } f_{j} \text { de valor objetivo }\end{cases}
$$

Quando $f_{j}$ é uma função de valor objetivo, a escolha do sinal positiva ou negativa esta sujeita à direção da pior degradação desta função. A matriz em (2.33) deve ser calculada sobre o ponto nominal do circuito $\overline{\mathbf{x}}$. A derivada da função de desempenho $f_{j}$ com respeito à tensão de alimentação e à temperatura é feita só uma vez e logo é replicada na matriz (2.33). Por outro lado, suas derivadas com respeito aos parâmetros de processo são calculadas uma para cada dispositivo, utilizando para este propósito o método das diferenças finitas, o qual define a a derivada como:

$$
\frac{\partial f_{j}}{\partial p_{i}}=\frac{f_{j}\left(\overline{\mathbf{x}}, p_{1}, \ldots, p_{i}+\delta_{p_{i}}, \ldots, p_{r}\right)-f_{j}\left(\overline{\mathbf{x}}, p_{1}, \ldots, p_{i}, \ldots, p_{r}\right)}{\bar{p}_{i}+\delta_{p_{i}}}
$$

sendo $r$ o número de parâmetros de processo objeto da análise. No entanto, o comportamento da derivada $\partial f_{j} / \partial p_{i}$ nem sempre é simétrico em torno do ponto nominal $\left(\overline{\mathbf{p}}, \overline{\mathbf{f}}_{\mathbf{j}}\right)$, pois as vezes os desvios para a frente $p_{i}+\delta_{p_{i}}$ produzem piores resultados nas funções de desempenho do que os desvios para trás $p_{i}-\delta_{p_{i}}$ e vice-versa. Assim, é preciso levar em conta só aquele desvio que produz a pior degradação da função de desempenho $f_{j}$. Portanto, $\partial f_{j} / \partial p_{i}$ é redefinido como:

$\frac{\partial f_{j}}{\partial p_{i}}= \begin{cases}\max \left\{\frac{f_{j}\left(\overline{\mathbf{x}}, p_{1}, \ldots, p_{i}+\delta_{p_{i}}, \ldots, p_{r}\right)}{\bar{p}_{i}+\delta_{p_{i}}}, \frac{f_{j}\left(\overline{\mathbf{x}}, p_{1}, \ldots, p_{i}-\delta_{p_{i}}, \ldots, p_{r}\right)}{\bar{p}_{i}-\delta_{p_{i}}}\right\} & \text { para maximizar } f_{j} \\ \min \left\{\frac{f_{j}\left(\overline{\mathbf{x}}, p_{1}, \ldots, p_{i}+\delta_{p_{i}}, \ldots, p_{r}\right)}{\bar{p}_{i}+\delta_{p_{i}}}, \frac{f_{j}\left(\overline{\mathbf{x}}, p_{1}, \ldots, p_{i}-\delta_{p_{i}}, \ldots, p_{r}\right)}{\bar{p}_{i}-\delta_{p_{i}}}\right\} & \text { para minimizar } f_{j} \\ \max \left\{\left|\frac{f_{j}\left(\overline{\mathbf{x}}, p_{1}, \ldots, p_{i}+\delta_{p_{i}}, \ldots, p_{r}\right)}{\bar{p}_{i}+\delta_{p_{i}}}\right|,\left|\frac{f_{j}\left(\overline{\mathbf{x}}, p_{1}, \ldots, p_{i}-\delta_{p_{i}}, \ldots, p_{r}\right)}{\bar{p}_{i}-\delta_{p_{i}}}\right|\right\} & \text { para valor objetivo } f_{j}\end{cases}$

Daqui podemos concluir que para $p$ funções de desempenho, $r$ parâmetros de processo objeto da análise e $m$ transistores no circuito a complexidade computacional da estratégia do pior caso proposta inicialmente seria $O(2(r m p+2 p))$. No entanto, a análise de paridade do comportamento dos desvios $\delta_{p_{i}}$ pode levar a um decremento do tempo computacional no cálculo dos piores casos, pois para as funções com comportamento ímpar só uma direção no desvio do parâmetro produz o pior caso no circuito. Assim, com a nova estratégia proposta, a complexidade é aproximadamente reduzida para $O\left(2 r_{\text {even }} m p+r_{\text {odd }} m p+2 p\right)$ sendo $r_{\text {even }} \mathrm{o}$ número de parâmetros pares e $r_{o d d}$ o de ímpares ${ }^{6}$. Da mesma forma a matriz $\sigma_{p_{w c}}$ de dimensão $(5 \times n)$ que contém os valores de desvio padrão para cada um dos parâmetros de pior caso $p_{w c}$

\footnotetext{
${ }^{6}$ Foi assumido que as variações na tensão de alimentação $V_{D D}$ e na temperatura tem um comportamento ímpar, fato que acontece frequentemente.
} 
em cada dispositivo é definida como:

$$
\mathbf{S}_{p_{w c}}=\left[\begin{array}{ccccc}
\sigma_{V_{f b 1}} & \sigma_{t_{o x 1}} & \sigma_{N_{c h 1}} & \sigma_{V_{D D}} & \sigma_{T} \\
\sigma_{V_{f b 2}} & \sigma_{t_{o x 2}} & \sigma_{N_{c h 2}} & \sigma_{V_{D D}} & \sigma_{T} \\
\vdots & \vdots & \vdots & \vdots & \vdots \\
\sigma_{V_{f b m}} & \sigma_{t_{o x m}} & \sigma_{N_{c h m}} & \sigma_{V_{D D}} & \sigma_{T}
\end{array}\right]
$$

Assim a matriz de parâmetros do pior caso da $j$-ésima função de desempenho é dada por:

$$
\mathbf{P}_{j_{w c}}=\overline{\mathbf{P}}+n_{s}\left[\begin{array}{ccccc}
\sigma_{V_{f b 1}} \mathbf{W}_{j(1,1)} & \sigma_{t_{o x 1}} \mathbf{W}_{j(1,2)} & \sigma_{N_{c h 1}} \mathbf{W}_{j(1,3)} & \sigma_{V_{D D}} \mathbf{W}_{j(1,4)} & \sigma_{T} \mathbf{W}_{j(1,5)} \\
\sigma_{V_{f b 2}} \mathbf{W}_{j(2,1)} & \sigma_{t_{o x 1}} \mathbf{W}_{j(2,2)} & \sigma_{N_{c h 1}} \mathbf{W}_{j(2,3)} & \sigma_{V_{D D}} \mathbf{W}_{j(2,4)} & \sigma_{T} \mathbf{W}_{j(2,5)} \\
\vdots & \vdots & \vdots & \vdots & \vdots \\
\sigma_{V_{f b m}} \mathbf{W}_{j(m, 1)} & \sigma_{t_{o x m}} \mathbf{W}_{j(m, 2)} & \sigma_{N_{c h m}} \mathbf{W}_{j(m, 3)} & \sigma_{V_{D D}} \mathbf{W}_{j(m, 4)} & \sigma_{T} \mathbf{W}_{j(m, 5)}
\end{array}\right]
$$

sendo $\overline{\mathbf{P}}$ a matriz de valores nominais dos parâmetros do processo de fabricação. Para o caso de elementos diferentes aos transistores MOS, como são os resistores integrados e os capacitores MOS, são usados como parâmetros de pior caso a resistência por folha $\left(R_{S H}\right)$ e a espessura do óxido $\left(t_{o x}\right)$, respectivamente.

\subsection{Otimização da distância do pior caso (WCD)}

Uma vez determinado o conjunto de parâmetros e suas respectivas direções que produzem o pior caso no circuito, agora é necessário estabelecer os valores de pior caso de cada uma das funções de desempenho. Geralmente, o valor de pior caso para $j$-ésima função de desempenho $f_{j}$ é fornecido com o nome de distância do pior caso ou em inglês Worst-Case Distance (WCD) [27], a qual corresponde ao valor normalizado do valor do pior caso $f_{j_{w c}}=f_{j}\left(\overline{\mathbf{x}}, \mathbf{P}_{j_{w c}}\right)$ em relação ao valor nominal $f_{j_{o}}$. Assim, o vetor de dimensão $r$, que correspondente ao vetor das distâncias do pior caso $\mathbf{w c d}_{j}$ da função $f_{j}$, pode ser definido como:

$$
\operatorname{wcd}_{j}\left(\mathbf{x}, \mathbf{P}_{j_{w c}}\right)= \begin{cases}\frac{f_{j}\left(\overline{\mathbf{x}}, \mathbf{P}_{j_{w c}}\right)}{f_{j}(\overline{\mathbf{x}}, \overline{\mathbf{P}})} & \text { para } f_{j} \text { a minimizar } \\ \frac{f_{j}(\overline{\mathbf{x}}, \overline{\mathbf{P}})-f_{j}\left(\overline{\mathbf{x}}, \mathbf{P}_{j_{w c}}\right)}{f_{j}(\overline{\mathbf{x}}, \overline{\mathbf{P}})}+1 & \text { para } f_{j} \text { a maximizar } \\ \left|\frac{f_{j}\left(\overline{\mathbf{x}}, \mathbf{P}_{j_{w c}}\right)-f_{j}(\overline{\mathbf{x}}, \overline{\mathbf{P}})}{f_{j}(\overline{\mathbf{x}}, \overline{\mathbf{P}})}\right|+1 & \text { para } f_{j} \text { de valor objetivo }\end{cases}
$$

Em ausência de variações dos parâmetros de processo e das condições ambientais, a distância do pior caso é igual a um. Para os parâmetros e condições que produzem uma significativa 
degradação sobre as funções de desempenho, a distância do pior caso torna-se muito maior que um. Assim, como objetivo de melhorar o comportamento dos circuitos sob as variações de processo e de ambiente, a $W C D$ se torna numa boa métrica para medir a influência do pior caso e, portanto, uma adequada função objetivo para otimizar [28]. No entanto, levando em conta somente a minimização da função $\mathbf{w c d}_{j}\left(\mathbf{x}, \mathbf{P}_{j_{w c}}\right)$ não é garantido de que as funções de desempenho não sejam pioradas e precisam ser otimizadas conjuntamente com a distancia do pior caso $(W C D)$. Desta maneira, o esquema geral de otimização do pior caso é definido como:

$$
\begin{array}{llc}
\operatorname{minimizar} & \sum_{j=1}^{p}\left\{w_{j} g_{j}(\mathbf{x}, \overline{\mathbf{P}})+\max \left\{\mathbf{w c d}_{j}\left(\mathbf{x}, \mathbf{P}_{j_{w c}}\right)\right\}\right\} & j=1, \cdots, p \\
\text { sujeito a: } & x_{a_{i}} \leq x_{i} \leq x_{b_{i}}, & i=1, \cdots, s \\
& V_{G S}, V_{D S} \in \mathscr{D}_{\mathscr{N}, \mathscr{P}} &
\end{array}
$$

sendo (2.39) resolvido por qualquer método de otimização não linear restrita. O termo $\max \left\{\mathbf{w c d}_{j}\left(\mathbf{x}, \mathbf{P}_{j_{w c}}\right)\right\}$ garante a otimização somente do pior caso e não o efeito total das variações de processo sobre os desvios de desempenho. No caso onde as distâncias de pior caso apresentassem valores semelhantes, é mais recomendado mudar o termo anterior para uma expressão a qual incluía as influências de processo mais relevantes e não somente aquela do pior caso. A fim de aproveitar as vantagens da Programação Geométrica na obtenção do ótimo global e na diminuição do tempo de cálculo, o esquema em (2.39) precisa ser definido em formato de um PG. Tendo resolvido o problema de otimização global (2.23) ou obtido os melhores casos por especificação usando a estratégia de Pareto definida na equação (2.10), onde foram encontrados um conjunto de especificações nominais ótimas $\mathbf{f}_{j_{o p t}}$, o problema de otimização do pior caso em formato de PG pode ser representado de maneira geral como:

$$
\begin{array}{llll}
\operatorname{minimizar} & \underbrace{\|\mathbf{u}\|}_{\text {Área }}+\underbrace{\|\mathbf{v}\|}_{\text {Desempenho }}+\underbrace{\left\|\mathbf{w}_{c d}\right\|}_{\text {Pior caso }} & \\
\text { sujeito a: } & f_{j_{o p t}}=f_{j}(\mathbf{x}, \mathbf{P}) v_{j} & , \wedge, \quad f_{j}(\mathbf{x}, \mathbf{P}) \leq f_{j_{o p t}} v_{j} & \text { Para } f_{j} \text { a minimizar } \\
& f_{j}(\mathbf{x}, \mathbf{P})=f_{j_{o p t}} v_{j} & , \wedge, \quad f_{j}(\mathbf{x}, \mathbf{P}) v_{j} \leq f_{j_{o p t}} & j=1, \cdots, p \\
& f_{j_{o p t}}=f_{j}\left(\mathbf{x}, \mathbf{P}_{j_{w c}}\right) w_{c d_{j}}, \wedge, \quad f_{j}\left(\mathbf{x}, \mathbf{P}_{j_{w c}}\right) \leq f_{j_{o p t}} w_{c d_{j}} & \text { Para } f_{j} \text { a maximizar } \\
& f_{j}\left(\mathbf{x}, \mathbf{P}_{j_{w c}}\right)=f_{j_{o p t}} w_{c d_{j}}, \wedge, f_{j}\left(\mathbf{x}, \mathbf{P}_{j_{w c}}\right) w_{c d_{j}} \leq f_{j_{o p t}} & \\
& a_{k_{\min }}=a_{k} u_{k} & \\
& u_{i} \geq 1, \quad v_{j} \geq 1 & \\
& x_{a_{i} \leq x_{i} \leq x_{b_{i}}, x_{i}>0} & \\
& V_{G S}, V_{D S} \in \mathscr{D}_{\mathscr{N}, \mathscr{P}} &
\end{array}
$$

onde u é um vetor $m$-dimensional que representa o aumento normalizado da área para cada dispositivo em relação à área mínima calculada em (2.22), v é um vetor $p$-dimensional que representa o desvio (degradação) das funções de desempenho calculadas nos parâmetros 
nominais $\mathbf{P}$ com respeito a seus valores ótimos nominais $\mathbf{f}_{o p t}$ e $\mathbf{w}_{c d}$ representa a distância do pior caso. O primeiro conjunto de restrições para o desempenho é definido para aquelas funções a minimizar, enquanto que o segundo conjunto é para aquelas que sejam maximizadas. Deve-se lembrar que as restrições do tipo igualdade correspondem às funções de desempenho modeladas como monômios e aquelas tipo desigualdade são para os modelos posinomiais. As restrições sobre as variáveis de projeto $x$ e para as polarizações são definidas para manter a funcionalidade do circuito ante as variações de processo. Desta maneira, obtém-se uma estratégia para otimizar os desvios do processo no seu pior caso, em relação com os valores ótimos obtidos usando Programação Geométrica, os quais junto com a análise e otimização do mismatch faz parte do núcleo da metodologia para fabricação de CIs proposta neste trabalho. 


\section{Aplicação da Metodología $D F M$ na Otimização de uma fonte de referência}

Uma vez que a metodologia $D F M$ para a análise e otimização sob variações de processo e mismatch é proposta, um correto processo de validação deve ser realizado. O objetivo principal desta etapa de validação pode ser entendido como a adaptação empírica dos fundamentos matemáticos usados na abordagem da metodologia ao contexto real do projeto, fabricação e marketing dos dispositivos. É bem conhecido na indústria o processo de otimização e validação do desempenho dos dispositivos, o contrário acontece com a verificação do rendimento e, portanto, das metodologias $D F M$, aonde o cenário da variabilidade ainda não é bem definido para ser adequadamente atingido.

\subsection{Topologia, especificações e restrições de partida}

Na Figura 3.1 é visualizada a fonte de referência proposta em [20] e usada para validar a metodologia de projeto para fabricação proposta no Capitulo 2. Este tipo de circuito é dos melhores que exemplificam os desafios em termos de desempenho e rendimento que estão enfrentando os projetistas de hoje, isto essencialmente por duas razões. Por um lado, as fontes de referência estão amplamente condicionadas aos fatores variáveis externos e aqueles vinculados ao processo de fabricação. Em paralelo a isto, a tendência da portabilidade dos dispositivos eletrônicos impulsa à premissa de baixo consumo de potência, o qual requer a exploração de regiões de operação dos transistores MOS tais como sub-limiar. No entanto temse estabelecido que a região sub-limiar exibe a maior queda de rendimento devida a mismatch no domínio da polarização [29]. Estas duas circunstâncias, entre outras, levam a grandes diferenças entre o projeto nominal e os resultados da produção, e tornam assim as metodologias DFM como caminho viável para os projetistas. 


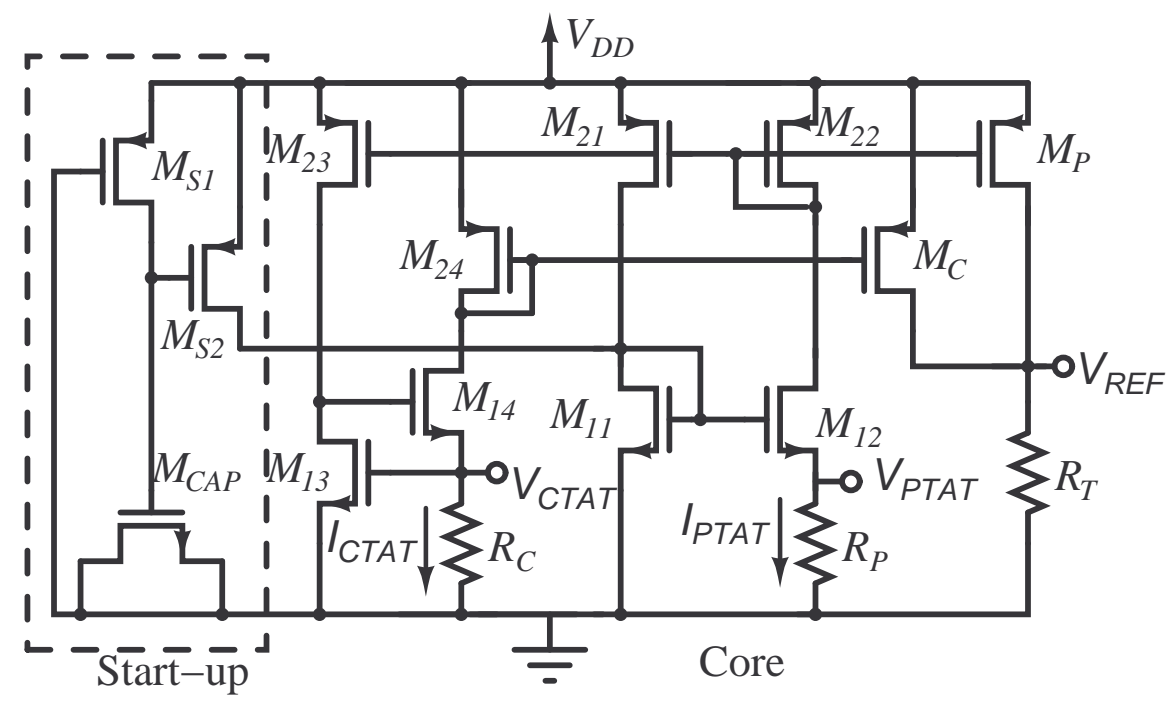

Figura 3.1: Fonte de referência em sub-limiar a otimizar.

Tabela 3.1: Valores das especificações de desempenho em [20] e restrições de partida, num processo $A M S 0,35 \mu m$.

\begin{tabular}{|l|c|c|c|c|c|c|c|c|}
\hline Especificações & $\begin{array}{c}\text { Potência } \\
{[\mu \mathrm{W}]}\end{array}$ & $\begin{array}{c}V_{R E F} \\
{[\mathrm{mV}]}\end{array}$ & $\begin{array}{c}T C \\
{\left[\mu \mathrm{V} /{ }^{\circ} \mathrm{C}\right]}\end{array}$ & $\begin{array}{c}\text { Ruído } \\
{[\mathrm{nV} / \sqrt{\mathrm{Hz}}]}\end{array}$ & $\begin{array}{c}L R \\
{[\mathrm{mV} / \mathrm{V}]}\end{array}$ & $\begin{array}{c}P S R R \\
{[\mathrm{~dB}]}\end{array}$ & $\begin{array}{c}\text { Área } \\
{\left[\mathrm{mm}^{2}\right]}\end{array}$ & $\begin{array}{c}V_{D D_{\text {nom }}} \\
{[V]}\end{array}$ \\
\hline \hline Em [20] & 3,2 & 176 & 7,75 & 1,73 & 4,45 & 42,9 & 0,0223 & \multirow{2}{*}{1,25} \\
\cline { 1 - 8 } Restrições de partida & $\leq 3,5$ & 177 & $\leq 8$ & $\leq 2$ & $\leq 6$ & $\geq 40$ & $\leq 0,04$ & \\
\hline
\end{tabular}

A operação do circuito pode ser descrita da seguinte forma: os transistores $M_{11}$ e $M_{12}$ produzem uma tensão proporcional à temperatura absoluta ou seja uma componente PTAT (Proportional To Absolute Temperature) de tensão através do resistor $R_{P}$. Esta condição é mantida somente se $M_{12}$ é mais largo do que $M_{11}$, gerando assim uma inclinação positiva na diferença de $V_{G S 11}$ e $V_{G S 12}$. A corrente PTAT é espelhada por $M_{23}$, sendo esta usada para gerar através da tensão $V_{G S 13}$ e portanto através do resistor $R_{C}$ uma componente complementar à temperatura absoluta CTAT (Complementary To Absolute Temperature). Tanto as componentes de corrente PTAT e CTAT são espelhadas para a saída através de $M_{P}$ e $M_{C}$, respectivamente, produzindo uma tensão na saída que pode ser definida por meio do ajuste de $R_{T}, W_{P}$ e $W_{C}$. A parte esquerda do circuito corresponde à fase de partida, a qual é usada para garantir que o circuito opere adequadamente quando a fonte de tensão é ativada, fornecendo um caminho de corrente de $V_{D D}$ para terra através de $M_{S 1}$ e $M_{S 2}$.

Inicialmente é preciso definir as especificações a avaliar, seus limites e as restrições funcionais que definiram o espaço de projeto. Como funções de desempenho a levar em conta no método de projeto proposto são escolhidas a tensão de referência $V_{R E F}$, o coeficiente térmico $T C$, potência estática $P_{S}$, regulação da linha ou Line Regulation (LR), Power Supply Rejection 
Ratio (PSRR), área e ruído a baixa frequência. A Tabela 3.1 mostra o conjunto de funções de desempenho analisadas neste trabalho, seus valores de desempenho obtidos inicialmente no artigo [20] e os valores por especificação que querem-se atingir neste trabalho, ambos fabricados em AMS 0,35 $\mu \mathrm{m}$. Todos os valores por especificação foram relaxados com respeito aos apresentados em [20], para assim possibilitar que uma flexibilidade no desempenho possa levar a um incremento do rendimento, característica que é bem comum nos circuitos integrados. Para conseguir um adequado comportamento do circuito e obter os valores requeridos por especificações são definidas as restrições e especificações a seguir:

Condições de simetria e casamento: Com o propósito de garantir a operação dos espelhos de corrente em sub-limiar na fonte de referência, os transistores que compartilham a mesma tensão de $V_{G S}$ devem ter tensões semelhantes de $V_{t}$ e, portanto, o mesmos comprimentos. Estas condições são traduzidas em três restrições de igualdade:

$$
\begin{aligned}
L_{11}=L_{12} & =L_{N 1} \\
L_{21}=L_{22}=L_{23} & =L_{P}=L_{P 1} \\
L_{24} & =L_{C}=L_{P 2}
\end{aligned}
$$

Adicionalmente, para manter um adequado funcionamento do bloco de geração PTAT, devese garantir que as mesmas correntes através de $M_{11}$ e $M_{12}$, isso implica numa igualdade das larguras de $M_{21}$ e $M_{22}$ :

$$
W_{21}=W_{22}
$$

Comportamento térmico: A expressão da corrente de dreno $I_{D}$ em sub-limiar sem levar em conta o efeito de modulação de canal é dada por:

$$
I_{D}=\mu V_{T} \frac{W}{L} \exp \left(\frac{V_{G S}-V_{t}}{n V_{t}}\right)
$$

onde $\mu$ é a mobilidade do elétron ou lacuna, $V_{T}$ é a tensão térmica, $W$ e $L$ a largura e o comprimento do canal transistor MOS respectivamente, $V_{G S}$ é a tensão de porta-fonte, $V_{t}$ é a tensão limiar e $n$ é a inclinação em sub-limiar. Assumindo que o comprimento do canal é suficientemente longo, $V_{B S}=0$ e $V_{D S} \gg 4 V_{T}$ e considerando que as correntes $I_{D 11}$ e $I_{D 12}$ são iguais (desprezando o efeito de modulação de canal), a tensão $V_{P T A T}$ no resistor $R_{P}$ obtida por lei de tensões de Kirchhoff, pode ser descrita por:

$$
V_{P T A T}(T)=V_{G S 11}-V_{G S 12}=n V_{T} \ln \frac{\left(\frac{W}{L}\right)_{12}}{\left(\frac{W}{L}\right)_{11}}=n \frac{k_{b} T}{q} \ln P=K_{P} T
$$

onde $P$ é a relação de aspecto dos transistores $M_{12}$ e $M_{11}, k_{b}$ é a constante de Boltzmann, $q$ é 
a carga do elétron, $T$ é a temperatura em graus Kelvin e $K_{P}$ o coeficiente PTAT de primeira ordem. Para garantir um comportamento proporcional com a temperatura absoluta, o logaritmo $\ln P$ tem que ser positivo, o qual implica que a largura $W_{12}$ seja maior do que a largura $W_{11}$ :

$$
W_{12}>W_{11}
$$

Assim, a corrente que flui através do resistor $R_{P}$, é definida como $I_{P T A T}$ :

$$
I_{P T A T}(T)=\frac{V_{P T A T}(T)}{R_{P}}=\frac{n V_{T}}{R_{P}} \ln P=\frac{K_{P}}{R_{P}} T
$$

Em transistores CMOS polarizados em sub-limiar, a tensão $V_{G S}$ tem um comportamento CTAT. Assim, para obter uma corrente $I_{C T A T}$, uma tensão $V_{G S}$ pode ser usada para polarizar um resistor. Na Figura 3.1, o transistor $M_{13}$ é polarizado com uma corrente $I_{P T A T}$, isso é possível devido ao fato que $I_{P T A T}$ não afeta a característica $C T A T$ de $V_{G S}$. Portanto, $I_{C T A T}$ é a relação entre $V_{G S}$ e $R_{C}$ :

$$
I_{C T A T}(T)=\frac{V_{C T A T}(T)}{R_{C}}=\frac{V_{G S 13}(T)}{R_{C}}=\frac{V_{G S 13}\left(T_{0}\right)}{R_{C}}+K_{C}\left(\frac{T}{T_{0}}-1\right)
$$

onde $K_{C}$ é o coeficiente térmico de $I_{C T A T}$, o qual é dependente de $R_{C}$ e o coeficiente térmico de $V_{t}$ e $T_{0}$ é a temperatura nominal em graus Kelvin. Usando o conceito básico das fontes de referência de adicionar um termo PTAT e um termo CTAT, a fim de cancelar o coeficiente térmico de primeira ordem, este circuito adiciona uma corrente $I_{P T A T}$ e outra $I_{C T A T}$, as duas propriamente escaladas, no resistor $R_{T}$. Assim, a tensão de referência $V_{R E F}$ pode ser definida em termos das componentes $I_{P T A T}$ e $I_{C T A T}$ como :

$$
V_{R E F}(T)=\left(\frac{W_{P}}{W_{22}}\right) \cdot I_{P T A T}(T) \cdot R_{T}+\left(\frac{W_{C}}{W_{24}}\right) \cdot I_{C T A T}(T) \cdot R_{T}
$$

Em termos das variáveis de dimensionamento dos transistores, os resistores e os coeficientes térmicos, a tensão de referência em função da temperatura ficaria:

$$
V_{R E F}(T)=\left(\frac{W_{P}}{W_{22}}\right) \frac{K_{P} T R_{T}}{R_{P}}+\left(\frac{W_{C}}{W_{24}}\right) R_{T}\left[\frac{V_{G S 13}\left(T_{0}\right)}{R_{P}}+K_{C}\left(\frac{T}{T_{0}}-1\right)\right]
$$

Para garantir uma compensação de primeira ordem dos coeficientes térmicos, deve-se tomar a primeira derivada de $V_{R E F}$ em função com a temperatura $T$, é assim, igualar esta a zero:

$$
\frac{\partial V_{R E F}(T)}{\partial T}=\left(\frac{W_{P}}{W_{22}}\right) \frac{K_{P} R_{T}}{R_{P}}+\left(\frac{W_{C}}{W_{24}}\right) \frac{K_{C} R_{T}}{T_{0}}=0
$$


Assim levando em conta a compensação térmica de primeiro ordem, obtém-se como condição de projeto:

$$
\left(\frac{W_{P}}{W_{22}}\right) \frac{K_{P}}{R_{P}}=-\left(\frac{W_{C}}{W_{24}}\right) \frac{K_{C}}{T_{O}}
$$

Deste modo, podem ser escalados os componentes de corrente $I_{P T A T}$ e $I_{C T A T}$ através das dimensões $W_{P}, W_{C}$ para garantir uma adequada compensação dos coeficientes térmicos de primeira ordem.

Consumo de Potência: $O$ consumo de potência estático $P_{S}$ da fonte de referência, pode ser estabelecido como as somas das correntes através dos transistores ligados à fonte de alimentação $V_{D D}$ :

$$
P_{S}=V_{D D} \cdot\left(I_{21}+I_{22}+I_{23}+I_{24}+I_{C}+I_{P}\right)
$$

As componentes de corrente $I_{21}, I_{22}$ e $I_{24}$ são altamente dependentes dos valores dos resistores $R_{P}$ e $R_{C}$, respectivamente. Além disso, as correntes $I_{23}, I_{C}$ e $I_{P}$ são versões espelhadas das correntes $I_{21}, I_{22}$ e $I_{24}$. Assim, para reduzir o consumo de potência, uma das opções é incrementar o valor dos resistores e/ou decrementar a relação das larguras $W_{P} / W_{21}$ e $W_{C} / W_{21}$.

Variações da tensão de alimentação: Um parâmetro comum usado para a avaliação da sensibilidade da tensão de referência às variações de $V_{D D}$ é a regulação de linha. Esta é definida como $L R=\Delta V_{R E F} / \Delta V_{D D}$, sendo $\Delta V_{D D}$ a faixa de tensões de alimentação onde é mantido o circuito proposto em operação e $\Delta V_{R E F}$ a variação absoluta da tensão de referência na faixa de $V_{D D}$ considerada. A otimização da sensibilidade de linha começa a partir da minimização do $\Delta V_{R E F}$. É possível aproximar a regulação de linha por meio de uma análise de pequeno sinal da resposta $\partial V_{R E F} / \partial V_{D D}$ no ponto nominal, influenciada principalmente pelo bloco PTAT, pois é este que estabelece e replica a tensão $V_{G S}$ ao longo da trilha de transistores PMOS $^{1}$. No Apêndice A, foi estimada a resposta em baixas frequências da tensão $v_{\text {ptat }}$ em função das variações na tensão de alimentação em pequeno sinal $v_{s}$ [Equação (A.10)]. A tensão de referência em pequeno sinal $v_{r e f}$ é altamente dependente da resposta $v_{\text {ptat }} / v_{s}$ do bloco PTAT, a qual representa a razão da variação em pequeno sinal da tensão PTAT $v_{p t a t}$ e a variação introduzida pela fonte de alimentação $v_{s}$, e pode ser expressada como:

$$
\frac{v_{r e f}}{v_{s}}=\left(\frac{W_{P}}{W_{22}}\right) \frac{v_{p t a t}}{v_{s}} \frac{R_{T}}{R_{P}}
$$

\footnotetext{
${ }^{1}$ Despreza-se a influência da componente CTAT por dois motivos: sua modelagem dificulta qualquer tipo de cálculo e inclusão na otimização, e seu efeito no resultado final foi considerado desprezível com respeito a aquela exibida pelo bloco PTAT.
} 
Assumindo $g_{d s 12}+g_{d s 22} \ll g_{m 12 t} R_{p} g_{m 22}$, a expressão da resposta $v_{p} / v_{s}$ estabelecida na equação (A.10) é aproximada a:

$$
\frac{v_{p t a t}}{v_{s}} \simeq \frac{g_{d s 12}}{g_{m t 12}}
$$

Substituindo o termo $v_{p} / v_{s}$ em (3.15) por (3.16), obtém-se a uma expressão simplificada da Regulação de Linha $(L R)$ da fonte de referência, dada por:

$$
L R=\frac{\Delta V_{R E F}}{\Delta V_{D D}} \simeq\left(\frac{W_{P}}{W_{22}}\right) \frac{g_{d s 12} R_{T}}{g_{m t 12} R_{P}}
$$

onde $g_{d s 12}$ e $g_{m t 12}$ são a transcondutância de dreno-fonte e a transcondutância total de $M_{12}$, respectivamente, $R_{P}$ o resistor do bloco PTAT e $R_{T}$ o resistor usado para a geração da tensão de referência. No domínio da frequência, a regulação da linha pode ser considerada como o inverso do ganho em banda plana do PSRR, o qual para simplicidade do cálculo no domínio da frequência pode ser considerada como uma função de transferência que contém só um polo dominante [30,31]. Assim pode ser modelado como:

$$
P S R R=\frac{\Delta V_{\text {in }}}{\Delta V_{\text {ref }}}=\frac{\Delta V_{D D}}{\Delta V_{R E F}} \simeq \frac{L R^{-1}}{\left(1+\omega^{2} / p_{1}^{2}\right)^{1 / 2}}
$$

onde $\omega=2 \pi f$ é a frequência de interesse em radianos/s, e $p_{1}$ é o polo dominante definido por:

$$
p_{1} \simeq \frac{g_{m 11}+g_{d s 21}+g_{d s 11}}{2 \pi\left(C_{g d 11}+C_{g s 11}+C_{d b 21}+2 C_{g d 12}+C_{d b 11}\right)}
$$

onde $C_{g d 11}$ e $C_{g d 12}$ são as capacitâncias de porta-dreno e $C_{d b 11}$ e $C_{d b 21}$ são as capacitâncias dreno-corpo de $M_{11}$ e $M_{21}$, respectivamente, e $C_{g s 11}$ a capacitância de porta-fonte de $M_{11}$.

Há uma outra especificação importante que define a mínima tensão de alimentação $\left(V_{D D m i n}\right)$ que garante a funcionalidade da fonte de referência e, indiretamente, faz parte da definição de regulação de linha acima tratada. Nesta referência de tensão tratada, e conforme à Figura 3.1, a especificação de $V_{D D \min }$ é definida pelo caminho direto de $V_{D D}$ para a terra com o maior número de transistores, a qual corresponde a aquela composta por $M_{24}, M_{14}$ e $R_{C}$ :

$$
V_{D D(\text { min })}=V_{D S 14(\text { min })}+V_{G S 13}+\left|V_{G S 24}\right|
$$

Geralmente $V_{G S 13}$ e $V_{G S 24}$ são estabelecidos pelas suas dimensões e pela corrente $I_{C T A T}$, no entanto $V_{D S 14(\text { min })}$ vai ter um valor altamente independente da polarização de $M_{14}$ porém dependente das tensões de porta-fonte dos transistores $V_{G S 13}$ e $V_{G S 24}$, sendo crítico na faixa de baixas temperaturas.

Ruído de baixa frequência na saída: Desconsiderando o ruído introduzido por fontes externas e a contribuição de ruído térmico no canal (atribuído à resistência do canal), no caso 
mais geral, a saída de qualquer tensão de referência pode ser dada por:

$$
\bar{V}_{R E F(\text { rúdo) }}^{2}(f)=\sum_{i=1}^{m}\left(\frac{\partial V_{R E F}}{\partial i_{i}}\right)^{2}\left(g_{m i}\right)^{2} \frac{K_{F i}}{n_{i} C_{O x} A_{i} f^{A_{F i}}}+\sum_{j=1}^{n_{r}} \frac{4 k_{b} T}{R_{j}}\left(\frac{\partial V_{R E F}}{\partial i_{j}}\right)^{2}
$$

onde $m$ corresponde ao número de transistores e $n_{r}$ o número de resistores no circuito, $g_{m i}$ é a transcondutância do $i$-ésimo transistor, $k_{b}$ a constante de Boltzmann, $T$ a temperatura absoluta do $j$-ésimo resistor $R_{j}$ e $\partial V_{R E F} / \partial i_{i}$ é a sensibilidade da tensão de referência $V_{R E F}$ com respeito à corrente que circula através do $i$-ésimo transistor ou resistor, $A_{F}$ e $K_{F}$ correspondem ao exponente e ao coeficiente do ruído flicker. O cálculo da sensibilidade $\partial V_{R E F} / \partial i_{i}$ e da transcondutância $g_{m i}$ deve ser feito no ponto de polarização nominal do circuito, e pode ser estimada como a resistência equivalente na saída no modelo de pequeno sinal. A fim de reduzir o ruído referenciado na saída, os transistores podem ser feitos de dimensões maiores e/ou a resistência de saída do circuito pode ser diminuída. A primeira coisa é mais desejável tanto para o ruído como para o mismatch, ao contrário da segunda que implica num circuito mais sensível ante variações da carga.

\subsection{Projeto semente e migração processo}

No esquema de otimização proposto na seção 2.2, o projetista precisa definir os valores $f_{w}$ e $f_{b}$, os quais representam referências dos piores e melhores resultados por especificação, respetivamente, na topologia escolhida e no processo de fabricação no qual vai ser desenvolvida. Os valores $f_{w}$ e $f_{b}$ vão avaliar quantitativamente o conjunto de especificações obtido ao longo de cada iteração do processo de otimização. Um conjunto de bons valores para cada uma das especificações geralmente já foi obtido por derivação analítica, no mesmo ou em outro processo no qual se requer implementar o circuito. Por outro lado, o conjunto de valores ruins por especificação pode ficar a critério do projetista, e vai ser relaxado ou estreitado conforme à importância das especificações e os compromissos entre elas. Assim, para o caso aqui exposto e com o fim de fazer uma boa comparativa, os valores das especificações de referência $f_{b}$, correspondem aos estabelecidos em [20] e mostrados na primeira linha da Tabela 3.2. Com um ponto inicial aleatório, mas factível, estes valores de especificações guiam o Seeder no dimensionamento de uma nova fonte de referência, com o nome projeto (A). É destacável a obtenção de um melhor conjunto de especificações de referência do que aquele especificado em [20]. O consumo de potência, por exemplo, foi reduzido em $43 \%$ em conjunto com uma diminuição de $31 \%$ na ocupação de área. No entanto teve-se uma diminuição nas especificações relacionadas com a resposta ante variações da fonte nas frequências maiores, 
Tabela 3.2: Valores de desempenho esperados e obtidos da fonte de referência da Figura 3.1.

\begin{tabular}{|c|c|c|c|c|c|c|c|c|c|}
\hline Especificações & $\begin{array}{l}V_{R E F} \\
{[m V]}\end{array}$ & $\begin{array}{c}T C \\
{\left[\mu V /{ }^{\circ} \mathrm{C}\right]}\end{array}$ & $\begin{array}{c}V_{D D \min } \\
{[V]}\end{array}$ & $\begin{array}{l}\text { Potência } \\
{[\mu W]}\end{array}$ & $\begin{array}{c}L R \\
{[m V / V]}\end{array}$ & $\begin{array}{c}P S R R \\
{[d B]}\end{array}$ & $\begin{array}{c}\text { Área } \\
{\left[\mathrm{mm}^{2}\right]^{(1)}}\end{array}$ & $\begin{array}{c}\text { Ruído } \\
{\left[\mu V / \sqrt{ } H_{z}\right]^{(2)}}\end{array}$ & $\begin{array}{l}\text { Tempo } \\
{\left[\mathrm{min}^{(3)}\right.}\end{array}$ \\
\hline Em [20] & 177,3 & 7,4 & 0,90 & 3,24 & 4,45 & 42,9 & 0,0223 & 2,9 & --- \\
\hline (A) & 177,1 & 5,81 & 0,94 & 1,82 & 5,81 & 42,5 & 0,0154 & 3,1 & 31 \\
\hline (B) & 176,5 & 10,1 & 1,01 & 3,86 & 1,18 & 37,1 & 0,0323 & 0,7 & 46 \\
\hline (C) & 176,4 & 9,3 & 0,99 & 3,03 & 0,91 & 36,1 & 0,0245 & 0,6 & 21 \\
\hline \multicolumn{10}{|c|}{ Projeto (A): Obtido com o Seeder baseado nas especificações de [20] (AMS 0,35 $\mu \mathrm{m})$. } \\
\hline \multicolumn{10}{|c|}{ Projeto (B): Obtido com o Seeder baseado nas especificações do projeto (A) $(X F A B 0,18 \mu \mathrm{m})$. } \\
\hline \multirow{2}{*}{\multicolumn{10}{|c|}{$\begin{array}{l}\text { Projeto (C): Obtido com o Seeder baseado nas especificações e no dimensionamento do projeto (A) }(X F A B 0,18 \mu m) \text {. } \\
\text { (1) Aproximado como : } \sum_{i=1}^{m} W_{i} L_{i} \text {. }\end{array}$}} \\
\hline & & & & & & & & & \\
\hline \multicolumn{10}{|c|}{ (2) Medido a $1 \mathrm{~Hz}$} \\
\hline & & & & & & & & & \\
\hline
\end{tabular}

aonde é evidenciada uma pequena diminuição do PSRR de aproximadamente $0,4 d B$, sendo insignificante ante o possível erro do modelo e a característica aleatória própria do processo.

Entretanto, a baixas frequências, a especificação da regulação de linha foi melhorada ligeiramente. Na migração do processo para $X F A B \quad 0,18 \mu m$, é possível avaliar duas coisas: o conjunto de especificações de desempenho no novo processo sob a mesma topologia e a vantagem quantitativa e em tempo de computação da migração do processo usando o Seeder. A primeira foi avaliada com o projeto de nome (B), o qual foi obtido com o Seeder partindo de uma semente aleatória e com a finalidade de dar uma exploração inicial dos valores que podem ser atingidos com o processo $X F A B \quad 0,18 \mu \mathrm{m}$. A Tabela 3.2 mostra como o coeficiente térmico, a potência, o PSRR e a área foram degradados no novo processo. Além disso, o tempo conjunto de simulação e de otimização foi incrementado em 48\%, o qual mostrou um incremento na complexidade de simulação proporcional à redução de canal e ratifica o uso das ferramentas de projeto analógico assistido para as novas tecnologias. No entanto, o projeto (B) mostra um melhoramento de desempenho na regulação da linha, na tensão de $V_{D D}$ miníma e no ruído. Por outro lado, foi obtido o projeto com o nome (C) usando os valores das variáveis obtidas no projeto (A) como semente, para assim avaliar a vantagem no custo computacional e nos valores de desempenho, no caso quando um projeto for previamente desenvolvido em uma tecnologia anterior. A mais destacável foi a obtenção do novo projeto, denominado $(\mathrm{C})$, em um tempo menor ao $60 \%$ do obtido no projeto (B), o qual representa que parte do conhecimento de uma topologia pode ser transferida para processos mais novos. Além disso, a maioria das especificações de desempenho do projeto (C) são melhores às obtidas no projeto (B), o qual reforça a ideia do aproveitamento e experiência adquirida nos processos preliminares. 


\subsection{Otimização Nominal via Programação Geométrica}

Obtido um projeto de partida ou projeto semente na tecnologia $A M S 0,35 \mu \mathrm{m}$, denominado (A) e com um conjunto de especificações mostradas na Tabela 3.2, um esquema de otimização multiobjetivo usando a Programação Geométrica (PG) é usado. A utilização de PG na otimização nominal do circuito permite chegar em pouco tempo a um ótimo global do problema abordado, o qual está sujeito às restrições de projeto e os modelos dos parâmetros elétricos definidos pelo projetista. A obtenção prévia de uma semente permite uma limitação do espaço de projeto, e portanto pode levar a um decremento no tempo de modelagem dos elementos do circuito, tais como transistores, resistores e capacitores. Além disso, reduz a quantidade de iterações necessárias para obter o ótimo global em conjunto com o erro da modelagem. $\mathrm{O}$ programa geométrico multi objetivo é mostrado na Tabela 3.3. A função objetivo é construída a partir de três vetores denominados $\mathbf{s}, \mathbf{v}$ e u, os quais representam fatores de ponderação de custo para obter um coeficiente térmico, um conjunto de especificações ótimas e uma área mínima, respectivamente. No entanto, a função objetivo na Programação Geométrica precisa ser uma função escalar, fato que leva a implementar uma transformação matemática do domínio vetorial para o escalar. Assim, para avaliar e depois minimizar em forma escalar o desvio do valor ótimo das funções de desempenho, é usada a norma euclidiana. Em problemas com funções objetivo tipo min-max relacionados com otimizações do pior caso, a norma infinita é comumente usada [28].

Para a otimização multi-objetivo da potência, a área, a regulação de linha e o PSRR, é usado o princípio de melhor esforço ou best effort definido na seção 2.4. Para isto, são executados separadamente quatro programas geométricos (melhor potência, melhor área, melhor resposta às variações na alimentação, e melhor frequência de corte do $P S R R$ ), cada um dos quais otimiza só uma função desempenho, mantendo restrições de valores do pior caso para as demais especificações. Assim são obtidos quatro valores ótimos por especificações: potência ótima, área ótima, regulação de linha ótima e PSRR ótimo. Com estes valores ótimos globais por especificação, é construída uma função multiobjetivo, a qual leva em conta através do vetor $\mathbf{v}$ as ponderações por especificação do custo de obter um conjunto ótimo de especificações. A tensão de referência é estabelecida através do parâmetro $V_{R E F 0}$, e para o melhoramento do coeficiente térmico são definidas as duas primeiras restrições, nas quais o programa geométrico tenta levar as variáveis $s_{1}$ e $s_{2}$ ao valor de um, para assim igualar as tensões de referência nas temperaturas dos extremos do intervalo em análise $\left(-25^{\circ} \mathrm{C}, 125^{\circ} \mathrm{C}\right)$ ao valor do parâmetro de tensão fornecido $V_{R E F 0}$. De maneira similar, especificações como a potência, a regulação de linha e o PSRR precisam de uma análise nas duas temperaturas das extremidades do intervalo. 
Tabela 3.3: Esquema de otimização multi objetivo da fonte de referência da Figura 3.1

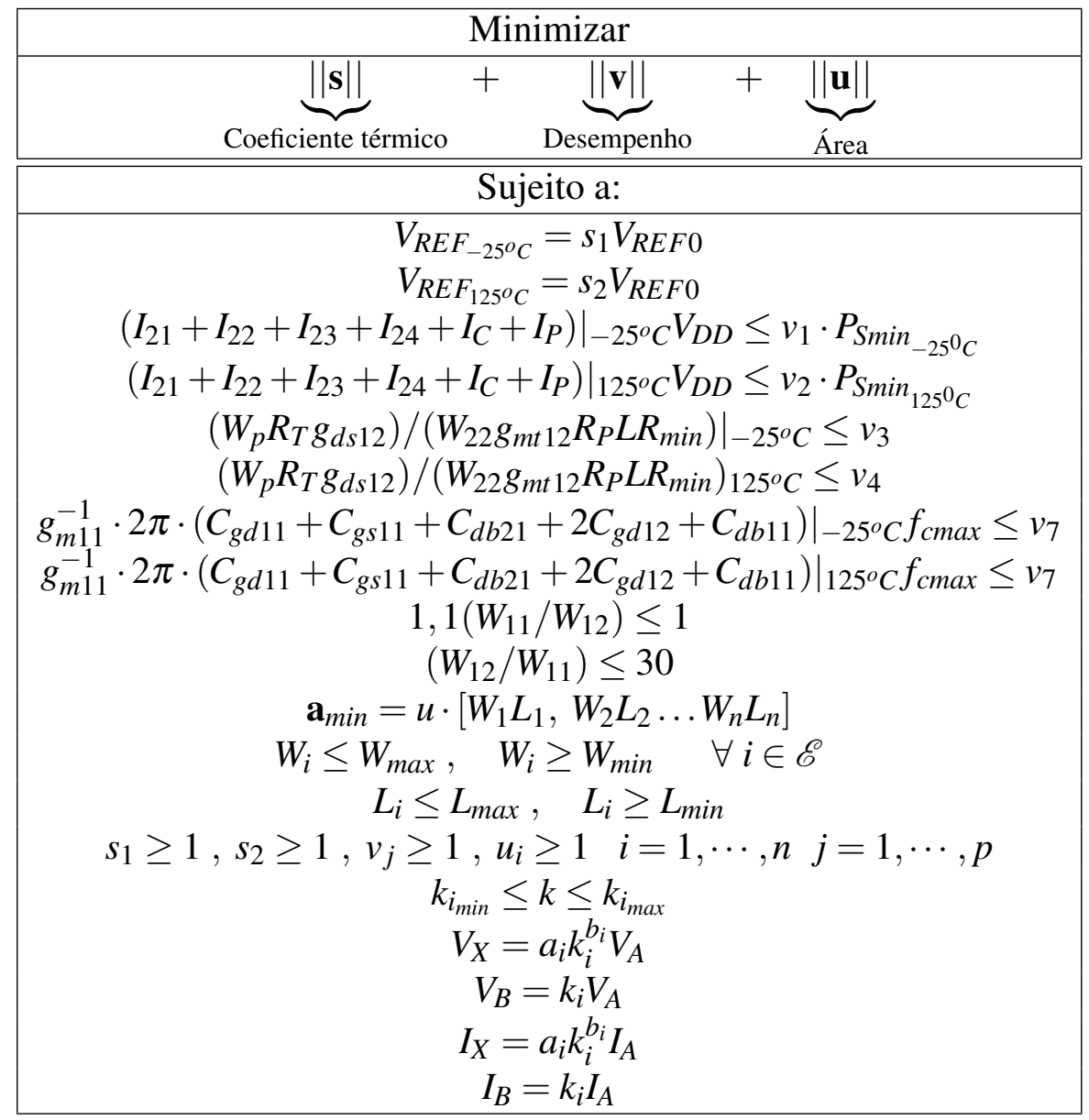

Para o caso da otimização da potência, esta é expressada em função das correntes que saem da fonte de alimentação $V_{D D}$ nas duas temperaturas. Por outro lado, a regulação de linha aproximada pela expressão na equação (3.17), tem uma forma posinomial, a qual pode ser diretamente implementada em PG, resultando nas duas expressões mostradas na tabela. Após, o PSRR é indiretamente otimizado usando a derivação para maximizar com best-effort a expressão do polo de primeira ordem, aproximada na equação (3.18), na sua forma original não corresponde a uma forma posinomial, pois seu numerador é uma composição de somas $g_{m 11}+g_{d s 21}+g_{d s 11}$ do tipo posinomial, as quais não são suportadas pela PG. No entanto, é possível minimizar indiretamente a relação $f_{c_{\max }} / f_{c}(\mathbf{x})$ definindo-a como uma restrição tipo desigualdade da maneira que pode ser vista na Tabela 3.3. Além disso, declarando novas restrições nos comprimentos mínimos dos transistores $M_{11}$ e $M_{21}$ pode-se garantir que as transcondutâncias de dreno fonte $g_{d s 21}$ e $g_{d s 11}$ sejam adequadas para a obtenção de uma boa rejeição das variações na fonte, comportamento previsto da equação (A.10). Na obtenção de uma semente para o projeto da fonte de tensão, foram definidos diferentes limites inferiores para os comprimentos do transistor, obtendo um valor adequado de $P S R R$ em $1 \mathrm{~Hz}$ acima dos 
$42 d B$ para comprimentos maiores a $3 \mu \mathrm{m}$. Assim, a expressão do $P S R R$, a qual na realidade foi indiretamente otimizada via PG em função da magnitude e do polo dominante da resposta $\partial V_{D D} / \partial V_{R E F}$. A análise do comportamento térmico do bloco PTAT estabeleceu que para garantir o seu comportamento proporcional, precisa-se manter a desigualdade da equação (3.7), a qual está inclusa na Tabela 3.3 com um limite inferior para a proporção $W_{12} / W_{11}$ ao valor de 1,1. Adicionalmente, foi demostrado através de simulações em [20] que valores altos da relação $W_{12} / W_{11}$ produzem uma degradação na linearidade do comportamento PTAT, influenciando portanto o comportamento térmico da fonte de tensão. Ao lado disto, a área mínima requerida no circuito é restinguida a valores fatíveis, os quais cumprem os requerimentos de mismatch e ruído de baixa frequência definidos por meio da restrição tipo igualdade mostrada na Tabela 3.3. Finalmente, são definidas as restrições das dimensões mínimas e máximas, de acordo com o processo de fabricação, e restrições para as leis de Kirchhoff usando a estratégia proposta na Seção 2.6.1. Além disso é importante destacar a definição dos modelos para as correntes, as transcondutâncias e capacitâncias no transistor em conjunto com os modelos dos resistores integrados, os quais foram todos definidos como modelos monomiais, pois tiram vantagem do baixo tempo de cálculo, no entanto sacrificam a precisão dos resultados.

Na Tabela 3.4 são comparados os resultados obtidos em [20] e mostrados na primeira fila, com aqueles obtidos na Otimização Nominal via PG. A segunda fila, nomeada PG, contém os resultados estimados usando os modelos de Programação Geométrica para cada uma das especificações. É notória a similaridade entre os valores de PG com aqueles obtidos via simulação Cadence, os quais são mostrados na terceira fila da Tabela 3.4. Isto quer dizer que as suposições feitas na modelagem das funções de desempenho da fonte de referência foram boas, e no marco atual não é necessário usar modelos mais complexos de tipo posinomial nem aqueles definidos por segmentos. Uma indagação aos valores de desempenho obtidos com PG e comparados com aqueles obtidos em [20], leva a determinar a obtenção de um melhor conjunto de especificações, o qual confirma o benefício na obtenção de ótimos globais da Programação Geométrica. A única especificação piorada com respeito aos resultados em [20] corresponde à área dos circuitos fabricados, tendo incrementado em 50\%. Uma parte deste incremento corresponde ao circuito de start-up, o qual foi incluído em nossa estimativa de área e para o caso em [20], foi isolado do core da fonte de referência. Por outro lado, a melhoria na potência tem um preço na área do circuito, pois ela representa valores de resistência maiores. A aproximação do coeficiente térmico em PG não foi incluída, pois resultou ser uma estimativa pouco confiável e um parâmetro de difícil otimização via $\mathrm{PG}^{2}$. Assim, o projeto obtido é logo re-ajustado usando

\footnotetext{
${ }^{2}$ Os erros relativos de modelagem dos parâmetros elétricos via PG atingem em valor médio 0,5\%, o qual representa para a tensão de referência uma precisão de $\pm 5 \mathrm{mV} /{ }^{\circ} \mathrm{C}$ no seu coeficiente térmico.
} 
Tabela 3.4: Resultados da Otimização Nominal da fonte de referência da Figura 3.1 em AMS $0,35 \mu m$ usando PG.

\begin{tabular}{|c|c|c|c|c|c|c|c|}
\hline Especificações & $\begin{array}{c}\text { Potência } \\
{[\mu W]}\end{array}$ & $\begin{array}{c}\text { Área } \\
{\left[\mathrm{mm}^{2}\right]}\end{array}$ & $\begin{array}{c}L R \\
{[\mathrm{mV} / \mathrm{V}]}\end{array}$ & $\begin{array}{c}\text { PSRR } \\
{[\mathrm{dB}]}\end{array}$ & $\begin{array}{c}f_{c} \\
{[\mathrm{kHz}]}\end{array}$ & $\begin{array}{c}T C \\
{\left[\mu V /{ }^{\circ} \mathrm{C}\right]}\end{array}$ & $\begin{array}{c}\text { Ruído } \\
{[\mu V / \sqrt{\mathrm{Hz}}]}\end{array}$ \\
\hline Em [20] & 3,2 & 0,0223 & 4,45 & 42,9 & ---- & 7,75 & 1,73 \\
\hline PG & 2,92 & $0,009^{(a)}$ & 3,49 & 46,16 & 12,33 & ---- & ---- \\
Cadence & 2,94 & $0,033^{(b)}$ & 4,39 & 44,74 & 5,81 & 6,96 & 1,68 \\
\hline (a) Valor da somatória das área das portas dos transistores. \\
(b) Área total do core fabricado. \\
(c) Especificações obtidas para uma tensão de referência de 177,6 $[\mathrm{mV}]$. \\
\hline
\end{tabular}

$M A T L A B$ para garantir um adequado coeficiente térmico, sendo só mudado neste procedimento as variáveis cruciais para o comportamento térmico do circuito: $W_{P}, W_{C}$ e $L_{R T}$.

O comportamento térmico da tensão de referência $V_{R E F}$ ao longo de uma faixa de temperatura de $150^{\circ} \mathrm{C}$ correspondente ao intervalo $\left(-25^{\circ} \mathrm{C}, 125^{\circ} \mathrm{C}\right)$ pode ser visto na Figura 3.2(a). A variação máxima nesta faixa de temperatura é de $1 \mathrm{mV}$, sendo seu coeficiente térmico de $6,96 \mu \mathrm{V} /{ }^{\circ} \mathrm{C}$, ou $39 \mathrm{ppm} /{ }^{\circ} \mathrm{C}$. Adicionalmente, o valor de $V_{R E F}$ para as temperaturas dos extremos $\left(-25^{\circ} \mathrm{C}\right.$ e $\left.125^{\circ} \mathrm{C}\right)$ são iguais e a curva tem sua região de menor inclinação perto da temperatura ambiente, comportamento desejado para as fontes de referência. Por outro lado, a resposta em frequência da rejeição das variações da fonte ou PSRR é mostrada na Figura 3.2(b). Em baixas frequências apresenta um valor de aproximadamente $47 d B$ e sua frequência de corte é de aproximadamente $3 \mathrm{kHz}$. O comportamento do transistor CMOS polarizado em sub-limiar e com valores grandes de canal geralmente apresenta um bom ganho em DC e

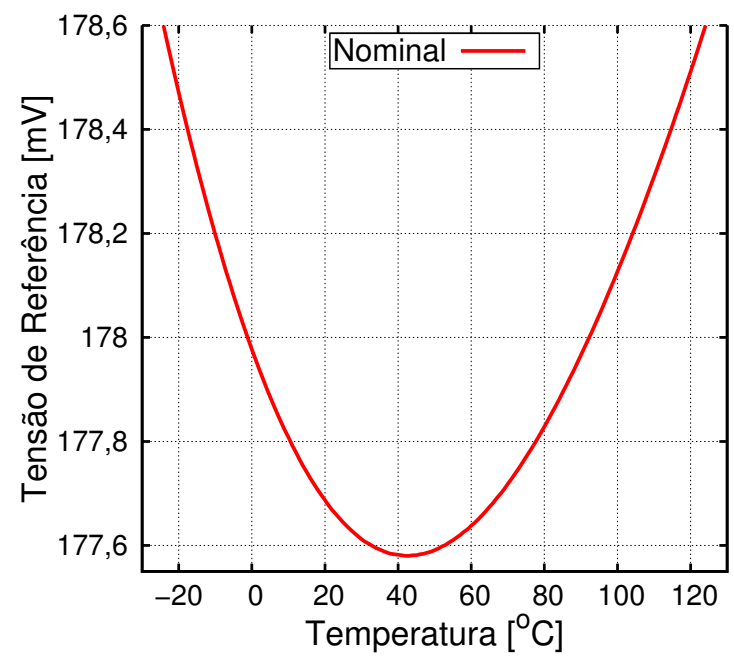

(a)

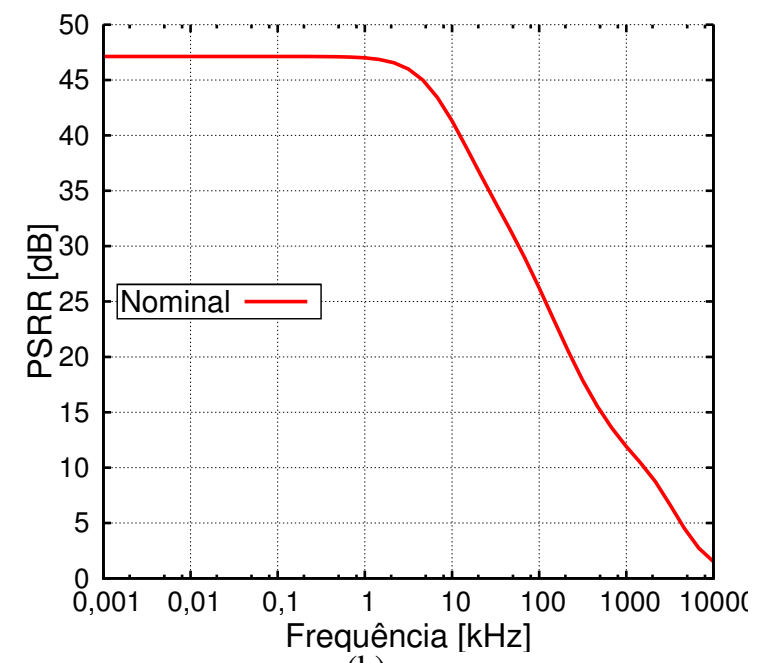

(b)

Figura 3.2: (a) Comportamento térmico da tensão $V_{R E F}$ e, (b) resposta em frequência do PSRR para a fonte de referência otimizada usando PG. 
um bom desempenho de ruído flicker, sendo este mínimo. No entanto, o PSRR é degradado conforme o consumo de potência é diminuído, sendo esta especificação crítica neste tipo de fontes de referência [32].

\subsection{Otimização multi-objetivo e curvas de Pareto}

Em qualquer esquema de otimização, quando se tem várias funções objetivo ou funções de desempenho no contexto dos circuitos analógicos, é desejável estabelecer relações entre as especificações concorrentes, para assim definir por meio de curvas de Pareto os tradeoffs do respectivo circuito. No entanto, em muitos métodos de otimização, a obtenção das curvas de tradeoff ou curvas de Pareto implica um elevado custo computacional, sendo esta uma tarefa de difícil execução, a qual muitas vezes não pode ser efetuada durante o esboço e definição das especificações do circuito. Entretanto não corresponde no caso da Programação Geométrica, através da qual um ótimo global pode ser obtido com um baixo custo computacional. O carácter de ótimo global é bem importante neste âmbito, porque implica que para cada ponto na curva de Pareto teve-se só um programa geométrico para ser resolvido.

O conceito de otimização multiobjetivo nós leva além da obtenção das curvas de Pareto, aos melhores valores por especificação que podem ser atingidos num circuito. No caso da fonte de referência, são levados em conta para a otimização multi-objetivo quatro especificações: potência, área, regulação de linha $(L R)$ e frequência de corte do $\operatorname{PSRR}\left(f_{c}\right)$. Assim, fazendo uso da estrutura de obtenção dos ótimos por especificação proposta na equação (2.10), são estabelecidos os melhores valores nas quatro especificações anteriormente nomeadas, sendo estes valores incluídos na Tabela 3.5. A melhor potência no circuito é obtida à custa de um maior consumo de área e um incremento no ruído. Isto é, para garantir uma baixa potência é necessária a implementação de resistores de valores altos, fato que prejudica o ruído do circuito. Entretanto, o pior desempenho na regulação de linha foi obtido para este caso, sendo principalmente originado pelo aumento no valor da resistência $R_{T}$ como pode ser visto da equação (3.17). A obtenção da melhor área leva a um incremento no consumo de potência do circuito e uma degradação de sua regulação de linha. O primeiro é originado pelo decremento nos valores das resistências, situação que gera um aumento nos valores nominais das correntes para garantir a tensão de referência desejada. O segundo é devido ao decremento nos comprimentos de transistores $M_{11}$ e $M_{12}$, circunstância que origina um incremento nas transcondutâncias de dreno-fonte $g_{d s}$ e produz assim um incremento na regulação de linha estimada em (3.17). De maneira contraria, a melhor regulação de linha produz um incremento na área do circuito. Além disso, leva a um incremento na sua potência, pois tenta-se reduzir 
Tabela 3.5: Valores ótimos por especificação, obtidos via Programação Geométrica (PG)

\begin{tabular}{|c|c|c|c|c|c|c|c|}
\hline \multicolumn{2}{|c|}{$\begin{array}{c}\text { Melhor } \\
\text { Especificação }\end{array}$} & $\begin{array}{c}\text { Potência } \\
{[\mu W]}\end{array}$ & $\begin{array}{c}\text { Área } \\
{\left[\mathrm{mm}^{2}\right]}\end{array}$ & $\begin{array}{c}L R \\
{[\mathrm{mV} / \mathrm{V}]}\end{array}$ & $\begin{array}{c}\text { PSRR } \\
{[\mathrm{dB}]}\end{array}$ & $\begin{array}{c}T C \\
{\left[\mu V /{ }^{\circ} \mathrm{C}\right]}\end{array}$ & $\begin{array}{c}\text { Ruído } \\
{[\mu V / \sqrt{H z}]}\end{array}$ \\
\hline \multirow{2}{*}{ Potência } & PG & 1,59 & 0,027 & 11,18 & 39,17 & ---- & ---- \\
& Hspice & 1,69 & 0,028 & 14,12 & 43,41 & 7,88 & 7,42 \\
\hline \multirow{2}{*}{ Área } & PG & 3,67 & 0,003 & 13,18 & 37,17 & ---- & ---- \\
& Hspice & 3,72 & 0,004 & 8,91 & 44,03 & 6,86 & 2,57 \\
\hline \multirow{2}{*}{$L R$} & PG & 5,27 & 0,026 & 5,60 & 41,17 & ---- & ---- \\
& Hspice & 4,58 & 0,026 & 2,23 & 44,41 & 7,08 & 0,92 \\
\hline \multirow{2}{*}{$f_{c}$} & $f_{c}$ & 2,11 & 0,007 & 7,3 & 40,72 & ---- & ---- \\
& Hspice & 2,06 & 0,007 & 11,1 & 43,41 & 9,02 & 4,03 \\
\hline
\end{tabular}

a resistência $R_{T}$ e incrementar a transcondutância $g_{m 12}$ à custa do incremento na potência. Finalmente, a melhor frequência de corte $f_{c}$ para o PSRR envolveu um decremento na área, comportamento que pode ser inferido da equação (3.19), a qual estima o polo dominante desta resposta. Para sua maximização, o programa geométrico leva as dimensões do bloco PTAT a seus mínimos valores possíveis, decrementando as capacitâncias inerentes a cada transistor.

Por outro lado, a Figura 3.3(a) e 3.3(b) correspondem às curvas de Pareto para a potência em relação à área e ruído em relação à área, respetivamente, da fonte tratada. Para o caso da curva de Pareto que relaciona a potência com a área, é visto como estas duas especificações exibem uma dependência inversamente proporcional. Um aumento da área produz um decremento da tensão porta-fonte $V_{G S}$ e por conseguinte uma diminuição exponencial da corrente $I_{D}$. Além disso, valores de resistência altos, os quais ocupam uma maior área, garantem que a tensão

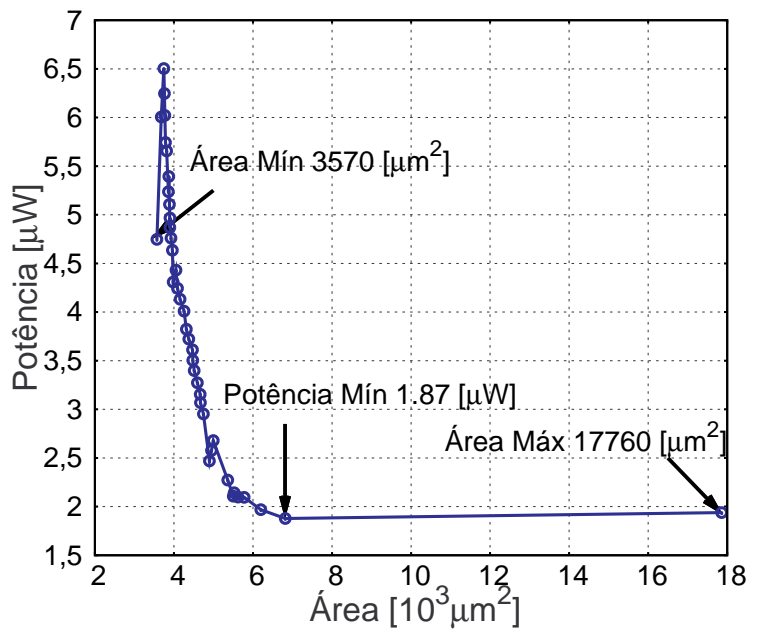

(a)

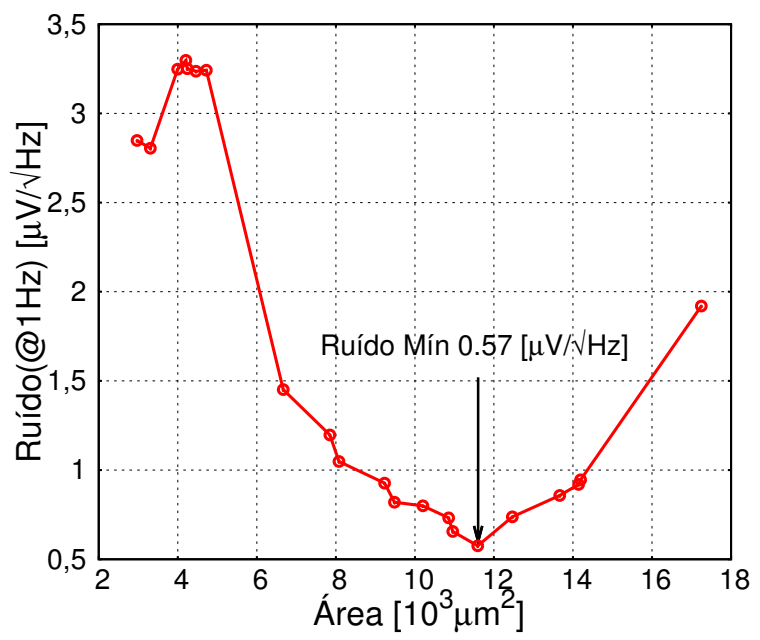

(b)

Figura 3.3: Traço da curva de Pareto para: (a) Potência em função da Área, e (b) Ruído em função da Área. 
de referência seja mantida apesar da redução nas correntes. A Figura 3.3(a) mostra três pontos que estabelecem em resumo os compromissos de área e potência: valor máximo da área, mínimo de potência e mínimo de área, que podem ser atingidos com as restrições de projeto estabelecidas no programa geométrico. A curva de Pareto do ruído em função da área apresenta um comportamento interessante; Para valores de área baixos, o termo correspondente ao ruído flicker da expressão (3.21) torna-se dominante com respeito ao ruído térmico e vai diminuindo conforme a área é reduzida. No entanto, quando a área ocupada alcança um valor de $12000 \mu \mathrm{m}^{2}$ aproximadamente, o termo do ruído térmico da expressão (3.21) começa a ser dominante e impulsa um aumento do ruído, amplamente relacionado com o incremento do valor dos resistores que fazem parte da fonte. Assim, é visto a grande utilidade dos gráficos de Pareto no estabelecimento dos compromissos entre as especificações e seus limites, levando a um melhor entendimento da topologia e o processo tecnológico usados no circuito.

\subsection{Otimização do Mismatch e ruído flicker}

Na seção 2.5 foram analisadas duas especificações de natureza não determinística e relacionadas com o consumo de área do dispositivo: o mismatch e o ruído flicker. Como foi visto, as duas especificações apresentam modelos semelhantes, no entanto em diferentes domínios: o espacial para o mismatch e o temporal para o ruído flicker. Avaliar dois ou mais processos de fabricação sob estas especificações tanto não determinísticas como as determinísticas, representa uma tarefa importante no tempo de introdução do dispositivo no mercado, pois pode ser determinante na escolha de seu processo de fabricação, sua topologia e até ser determinante na arquitetura do sistema. Nesse sentido o Seeder representa uma vital ajuda na rápida geração de um ponto funcional e de especificações adequadas, do qual vai depender a análise de variabilidade e ruído. Por outro lado, quer-se determinar se um incremento na área dos dispositivos originais é a melhor solução, ou simplesmente esta área a mais pode ser usada para a colocação de elementos redundantes e/ou efetuar modificações sutis à topologia inicialmente adotada.

\subsubsection{Análise da influência do processo no mismatch}

Os projetos nominais (A) e (C) obtidos através do Seeder e com as especificações mostradas na Tabela 3.2 são analisados para a obtenção dos valores mínimos de área, os quais vão garantir os requerimentos de aceitabilidade em nível de mismatch e ruído flicker expostos na Tabela 3.6. Primeiro é efetuada uma análise de sensibilidade, o qual muda a corrente do $i$-ésimo elemento em $1 \%$ e mede a variação da $j$-ésima função de desempenho $f_{j}$, para assim aproximar por 
Tabela 3.6: Valores de área obtidos sob requerimentos de mismatch e ruído por especificação.

\begin{tabular}{|c|c|c|c|c|c|c|c|c|}
\hline \multicolumn{2}{|c|}{ Especificações } & Potência & TC & $V_{R E F}$ & LR & PSRR & Ruído & Area total \\
\hline \multicolumn{2}{|c|}{ Aceitabilidade $\left(\sigma_{j}\right)$} & $40[\mathrm{nW}]$ & $0,5\left[\mu \mathrm{NV} /{ }^{\circ} \mathrm{C}\right]$ & $1,2[\mathrm{mV}]$ & $0,001[\mathrm{mV} / \mathrm{V}]$ & $0,5[\mathrm{~dB}]$ & $2,5[\mu \mathrm{N} / \sqrt{ } \mathrm{Hz}]$ & {$\left[\mu \mathrm{m}^{2}\right]$} \\
\hline \hline \multirow{2}{*}{$\begin{array}{c}\text { Consumo de } \\
\text { Area }\left[\mu \mathrm{m}^{2}\right]\end{array}$} & $A M S 0,35 \mu \mathrm{m}$ & 143 & 1012 & 3452 & 488 & 348 & 1810 & 3452 \\
\cline { 2 - 9 } & $X F A B 0,18 \mu \mathrm{m}$ & 1405 & 2494 & 2139 & 259 & 618 & 994 & 2494 \\
\hline \multirow{3}{*}{$\begin{array}{c}\text { Consumo de dea [\%] } \\
\text { Area }\end{array}$} & $A M S 0,35 \mu \mathrm{m}$ & 1,9 & 13,9 & 47,6 & 6,7 & 4,8 & 24,9 & --- \\
\cline { 2 - 9 } & $X F A B 0,18 \mu \mathrm{m}$ & 17,8 & 31,5 & 27 & 3,3 & 7,8 & 12,6 & --- \\
\hline
\end{tabular}

diferenças finitas a resposta $\partial f_{j} / \partial i_{i}$. O cálculo das sensibilidades permite construir a matriz em (2.13), e portanto estimar o consumo de área mínima que garante os requisitos de mismatch e ruído ${ }^{3}$. Na Tabela 3.6 são compilados os resultados de área mínima para cada uma das 6 especificações definidas inicialmente e para cada um dos processos analisados (AMS 0,35 $\mu \mathrm{m} \mathrm{e}$ $X F A B \quad 0,18 \mu \mathrm{m})$. As especificações de aceitabilidade, correspondentes aos desvios padrão das funções de desempenho $\left(\sigma_{f_{j}}\right)$, foram determinadas para ser menores do que aquelas obtidas numa análise Monte Carlo dos projetos sementes (A) e (C), respetivamente. Pode ser visto como o consumo de área total é maior no processo de fabricação $A M S 0,35 \mu \mathrm{m}$ com respeito ao processo $X F A B 0,18 \mu \mathrm{m}$, sendo isto explicado pelo fato de que quantitativamente os parâmetros de mismatch do modelo de Pelgrom proposto em [18] e levados em conta $\left(A_{V_{t}}\right.$ e $\left.A_{R}\right)$, são maiores no caso de $A M S$. Isto mostra que com os mesmos requerimentos de variabilidade e o mesmo consumo de área, projetos analógicos em $X F A B$ possivelmente exibem melhor rendimento comparados com aqueles feitos em $A M S$, quando só uma análise de mismatch seja levada em conta. Por enquanto, só pode ser concluído que $X F A B$ resulta mais adequado para nosso caso, onde se obteve uma área $38 \%$ menor com respeito a $A M S$ mantendo os mesmos requerimentos de aceitabilidade. Embora o comprimento mínimo do canal seja menor no caso do processo $X F A B 0,18 \mu \mathrm{m}$, parte do decremento na área é atribuído à diminuição do parâmetro $A_{V_{t}}$ conforme o comprimento é reduzido nos novos processos de fabricação [33]. Analisando o consumo de área por especificação, é possível determinar as especificações críticas com respeito à variabilidade. Na Figura 3.4(a) é mostrada a porcentagem da contribuição ao total por bloco, tanto para o mismatch como para o ruído. A fonte de tensão é particionada em três blocos: PTAT $\left(M_{11}, M_{12}, M_{21}, M_{22}, R_{P}\right)$, CTAT $\left(M_{13}, M_{14}, M_{23}, M_{24}, R_{C}\right)$ e o estágio final $\left(M_{P}, M_{C}, R_{T}\right)$. Desta Figura, pode ser inferido como os dois processos são semelhantes no comportamento da variabilidade por especificação, pois suas contribuições por blocos são bastante semelhantes. No entanto, uma das coisas mais notáveis é ver a porcentagem de influência ao mismatch e o ruído que tem o bloco PTAT, sendo em todas as especificações um valor maior a $50 \%$ de contribuição e chegando a um valor máximo acima de $90 \%$. Isto

\footnotetext{
${ }^{3}$ Para implementações futuras a variação da corrente precisa ser uma função dependente da resposta $\partial f_{j} / \partial i_{i}$, tornando-se a aproximação por diferenças finitas um processo iterativo.
} 


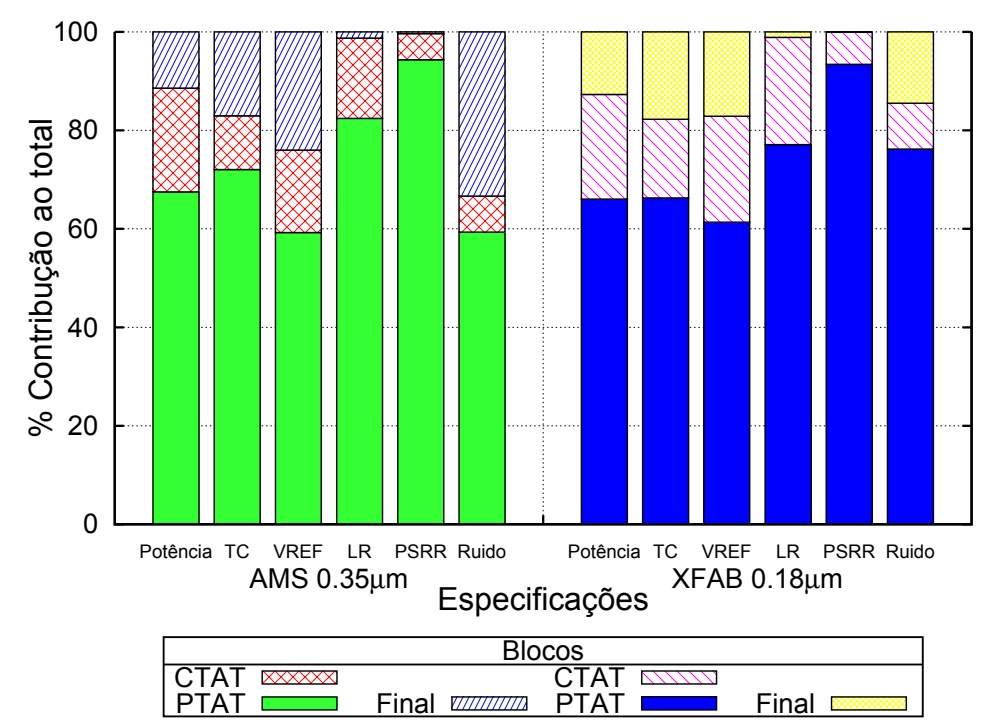

(a)

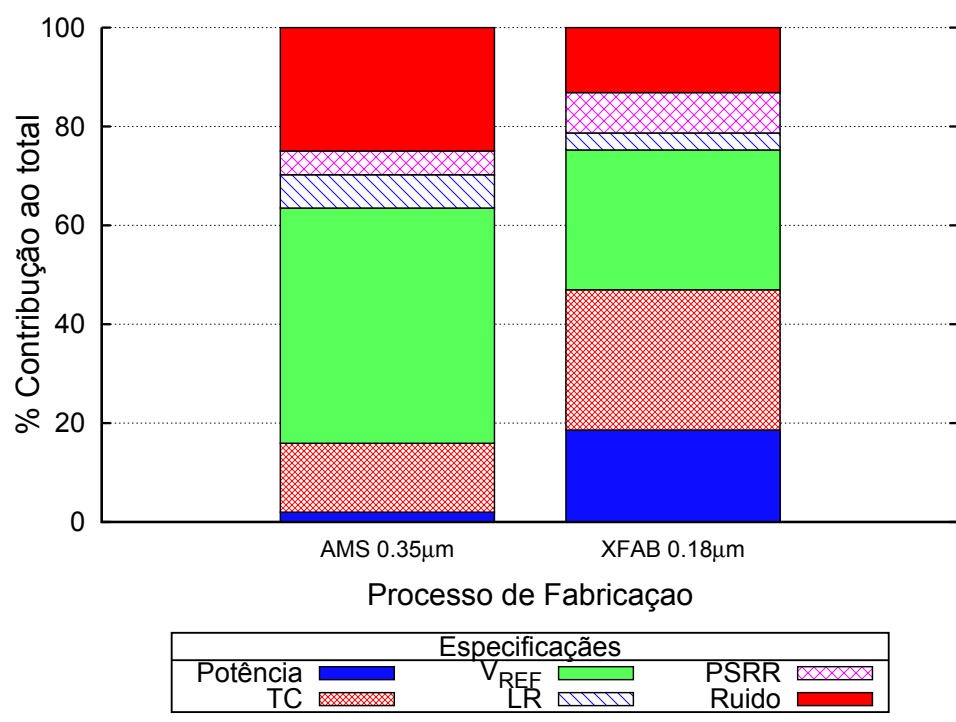

(b)

Figura 3.4: Contribuição ao mismatch e o ruído: (a) Por bloco; (b) Por especificação.

demostra a alta sensibilidade do bloco PTAT ante as variações do processo e a importância do projeto usando metodologias para fabricação neste tipo de circuitos. O comportamento por especificações da Figura 3.4(b) evidenciou um alto impacto das variações de processo na tensão de referência e seu comportamento térmico, o qual significa que no caso de $A M S$ um $60 \%$ da variação global é devida à tensão de referência e ao coeficiente térmico. Em contrapartida é analisado o comportamento da variabilidade no domínio do tempo: o ruído. Na distribuição das variações por especificação amostrada na Figura 3.4(b) uma contribuição próxima ao $25 \%$ é observada para o ruído no processo $A M S$ em contraste com uma de $10 \%$ no caso do XFAB. Este comportamento é explicado pelos valores característicos do ruído $\left(K_{F}\right.$ e $\left.A_{F}\right)$, os quais são maiores para o caso do processo de $A M S 0,35 \mu \mathrm{m}$. Usando os dados de área mínima é possível 
redistribuir a área nos blocos, para assim obter um projeto mais robusto e com o menor consumo de área. Além disso, é possível definir restrições num esquema de otimização convexa do tipo Programação Geométrica, do mesmo jeito como foi definido na seção 2.5.

\subsubsection{Modificando as restrições de área}

A obtenção das áreas mínimas para assegurar o cumprimento das restrições de aceitabilidade são inseridas como o vetor $\mathbf{a}_{\min }$ dentro do esquema de otimização previamente definido na Tabela 3.3. Os resultados da otimização tanto para o desempenho como para o rendimento para o processo AMS 0,35 $\mu \mathrm{m}$ são apresentados na Tabela 3.7. Para estimar o rendimento, o circuito obtido via PG é avaliado estatisticamente por meio de simulações de Monte Carlo usando o método de Latin Hypercube Sampling $(L H S)^{4}$ com 2000 amostras. A escolha da implementação deste número de amostras permite uma resolução para o rendimento de $0,05 \%$ e um erro aproximado do desvio padrão $\sigma$ de $\sigma / \sqrt{2000}$, equivalente ao $2,2 \%$ deste. O benefício no uso de LHS sobre o tradicional Montecarlo é a obtenção com uma maior probabilidade de eventos raros, os quais permitem avaliar rendimentos acima dos $3 \sigma$, sem precisar de um alto número de amostras. Lembre-se do que uma simulação típica de Monte Carlo, extraí pontos diretamente da distribuição da variação de processo. O problema é que muitas amostras são necessárias para o fim de obter eventos raros no projeto. A primeira fila mostra a média estatística para cada uma das funções de desempenho, bastante semelhante ao caso da simulação nominal. O efeito das variações no circuito é discriminado em dos tipos: variações próprias do processo de fabricação e aquelas devidas a mismatch. O objetivo desta diferenciação é indagar a natureza da pior queda no rendimento do circuito, para assim propor uma estratégia de melhoramento do rendimento. A variação global do circuito para uma determinada especificação $\sigma_{\text {total }}$, devida conjuntamente aos desvios nos parâmetros de processo e mismatch e assumindo variações aleatórias Gaussianas pode ser aproximado como:

$$
\sigma_{\text {total }} \simeq \sqrt{\sigma_{p r o c}^{2}+\sigma_{m i s}^{2}}
$$

sendo $\sigma_{\text {proc }}$ o desvio padrão devido às variações de processo, e $\sigma_{m i s}$ o desvio padrão causado pelo mismatch entre os dispositivos, os dois para uma determinada especificação. É possível avaliar a precisão da equação em (3.22), fazendo o cálculo e comparando-o com os desvios padrão da fila nomeada como Mism. + Proc., os quais correspondem às estimativas obtidas via simulação Monte Carlo. Por outro lado, os valores de rendimento estimados na Tabela 3.7 são

\footnotetext{
${ }^{4}$ LHS é um método estatístico para gerar uma distribuição de coleções plausíveis dos valores de uma distribuição multidimensional.
} 
calculados com base nas especificações de aceitabilidade definidas na Tabela 3.6. O rendimento para todos os casos é calculado levando em conta os desvios positivos e negativos, mesmo se fossem funções a minimizar e a maximizar, as quais apresentam perda de rendimento com desvios somente positivos e negativos, respectivamente. $\mathrm{O}$ rendimento total do projeto nominal obtido via PG corresponde a 42,85\%, assim mais da metade dos circuitos fabricados terão seus valores de especificações fora dos limites estabelecidos ao início do projeto. Quantitativamente, as maiores perdas de rendimento para o projeto nominal são causadas pelas variações de processo. A tensão de referência é a especificação de desempenho mais crítica em relação ao rendimento, apresentando um rendimento de 54,20\% no projeto nominal. Para o caso do projeto otimizado usando PG e definindo com restrições de área mínima para mismatch, o rendimento total não foi melhorado consideravelmente. Uma explicação disto é o fato de que as variações de processo sendo muito maiores do que aquelas devidas a mismatch, definem a variança global do circuito. Assim, quando $\sigma_{\text {proc }} \gg \sigma_{\text {mism }}$, o desvio padrão $\sigma_{\text {total }}$ vai tender ao valor do desvio padrão $\sigma_{\text {proc }}$. Embora esta seja a tendência do comportamento do circuito, a Tabela 3.7 mostra como o rendimento levando em conta apenas mismatch foi melhorado de 75,35\% para 92,05\%. Esta melhora de $16,70 \%$ representou um aumento na área de $8800(\mu \mathrm{m})^{2}$ para $13066(\mu \mathrm{m})^{2}$, ou seja $32 \%$. O desvio padrão da especificação considerada a mais crítica, a tensão de referência $V_{R E F}$, foi diminuído de $2,73 \mathrm{mV}$ para $1,32 \mathrm{mV}$, valor que está perto de aquele definido nas restrições de aceitabilidade, e que corresponde a $1,2 \mathrm{mV}$. Isto quer dizer que a estratégia proposta na seção 2.5 permite obter uma boa estimativa do desvio padrão devido ao mismatch para cada uma das funções de desempenho, além de decrementar seu valor a um desejado. Entretanto, o coeficiente térmico TC manteve seu rendimento em relação ao projeto nominal, embora o coeficiente térmico foi reduzido e a especificação de aceitabilidade de $0,5 \mu V /{ }^{\circ} C$ é muito mais crítica para um coeficiente térmico de $7,86 \mu \mathrm{V} /{ }^{\circ} \mathrm{C}$ do que para um de $8,37 \mu \mathrm{V} /{ }^{\circ} \mathrm{C}$. Nestes casos resulta bem melhor definir as especificações de aceitabilidade como uma relação normalizada entre o desvio padrão e o valor médio: $\sigma_{f_{j}} / \overline{f_{j}}$. Uma melhoria no valor nominal da regulação de linha $L R$ foi obtida, a qual está relacionada com o decremento do efeito do mismatch e a leve degradação apresentada pelo PSRR, pois o incremento na área e, portanto, o incremento nas capacitâncias inerentes dos transistores, produz um deslocamento para baixas frequências desta resposta. Finalmente é destacado como o rendimento final do circuito está sujeito ao pior rendimento por especificação, sendo no melhor dos casos o rendimento total igual ao pior por especificação. 
$\sum$

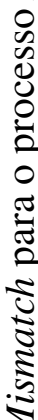

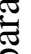

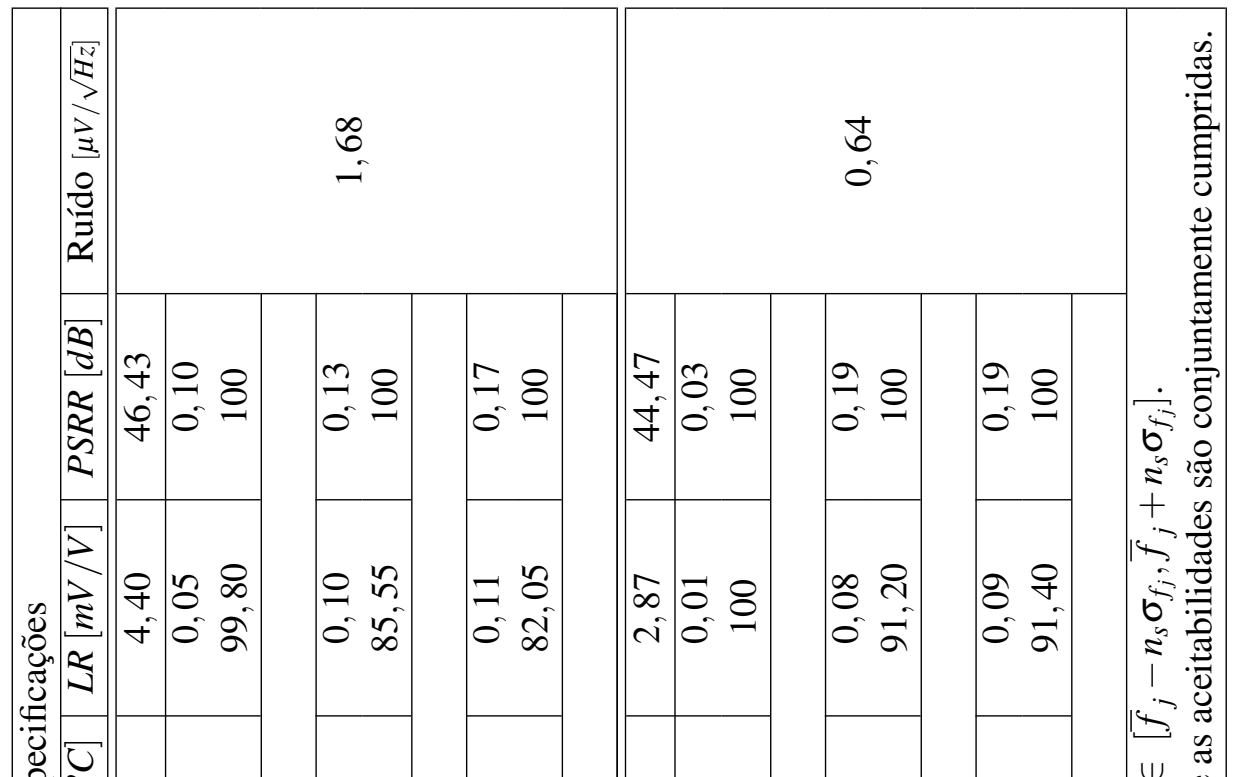

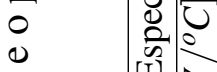

코ำ

$\frac{0}{0} \equiv$

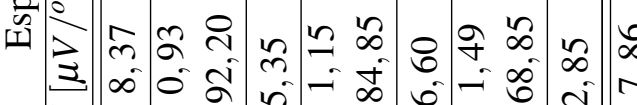

$\therefore \approx 0$ 는

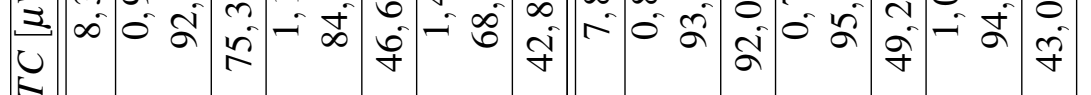

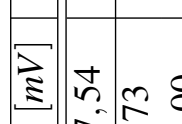

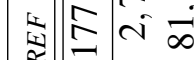

38

$2 \stackrel{4}{2}$

6

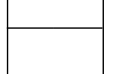

పี

뜔

0
ڤे
0
0
0

\&

$\stackrel{8}{8}$

.\zh14्⿹

$>$

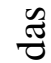

i⿱

:

\%

$\frac{0}{0}$

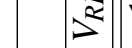

$s$

בิ

I.

in

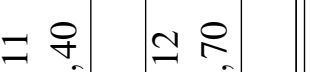

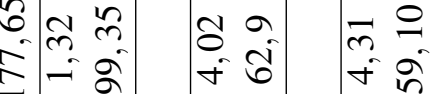

F

芯

$\begin{array}{lll}0 & 0 \\ 0 & \pi \\ 0 & 0\end{array}$

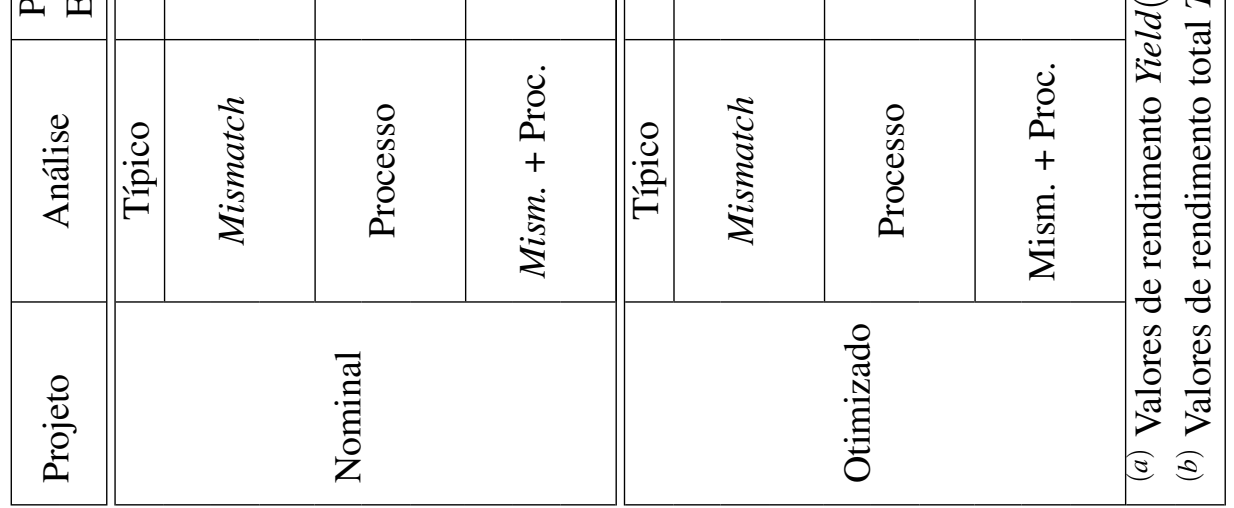




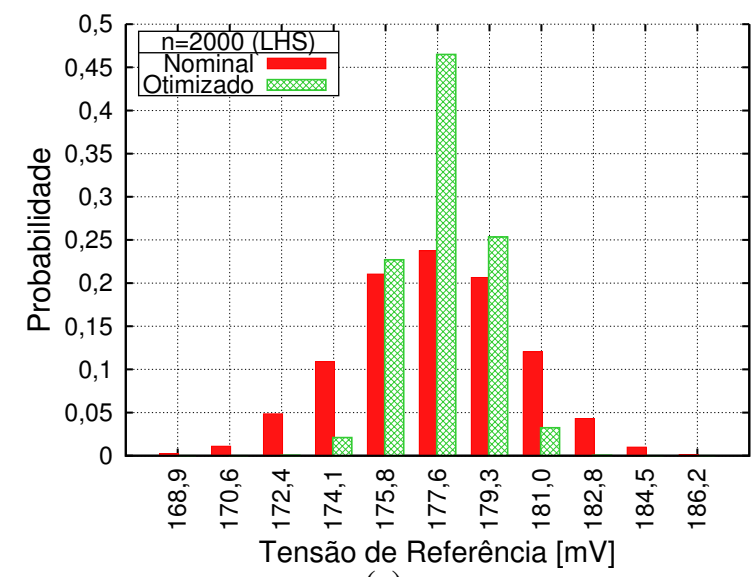

(a)

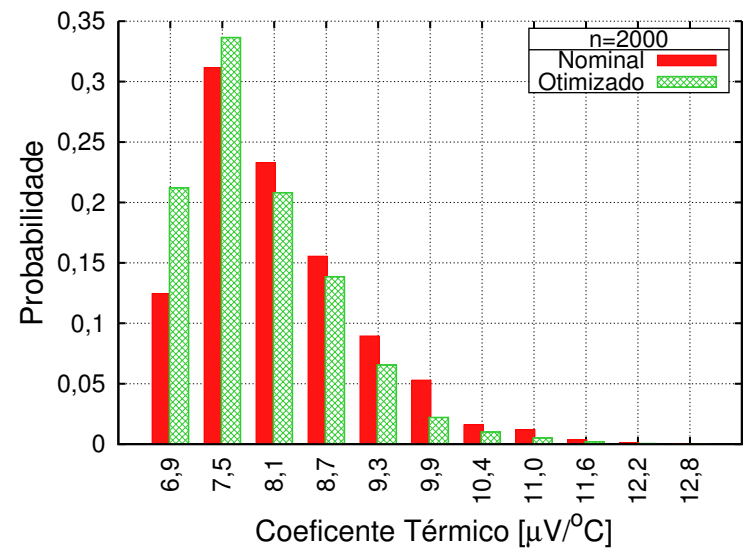

(b)

Figura 3.5: Histograma do projeto nominal e o otimizado para Mismatch: (a) Tensão de referência $V_{R E F}$; (b) Coeficiente Térmico $T C$.

Na Figura 3.5(a) e 3.5(b) são exibidos os histogramas da tensão de referência $V_{R E F}$ e do coeficiente térmico (TC) para o caso nominal e o otimizado. O melhoramento do comportamento de $V_{R E F}$ ante as variações de processo é evidente, sendo sua distribuição de probabilidade estreitada com respeito à média. Pode-se dizer que para o caso otimizado, a probabilidade de obter uma tensão de referência com uma variação de $\pm 0,9 m V$ é de aproximadamente 0,47 , em contraste com 0,24 para o caso nominal, como é notado da distribuição estatística do histograma da tensão de referência. Entretanto, para o caso do coeficiente térmico $(T C)$ teve-se uma leve melhora, sendo garantido um $T C$ menor a $7,5 \mu \mathrm{V} /{ }^{\circ} \mathrm{C}$ para mais da metade das amostras.

\subsubsection{Modificando a topologia}

Uma outra maneira de modificar a área do circuito é mudar a topologia de certos sub-blocos, destinando assim mais área para novos elementos no dispositivo que possam compensar as variações de processo e mismatch. Para o caso da fonte dada, uma das desvantagens da implementação de espelhos de corrente usando transistores polarizados em sub-limiar é sua alta sensibilidade às variações da fabricação e o casamento dos dispositivos, o qual prejudica o desempenho e o rendimento dos dispositivos que dependem da alimentação desta referência de corrente. A topologia da Figura 3.1, proposta em [20], garante tensões de alimentação menores a $1 V$ ao preço de manter todos os transistores em sub-limiar. Embora esta seja uma boa estratégia para a diminuição do consumo de potência, pode não resultar adequada para o projeto voltado a fabricação e comercialização do dispositivo. Foi explicado na seção 3.5.1 como o bloco PTAT precisa de um projeto rigoroso para garantir os margens de variabilidade 


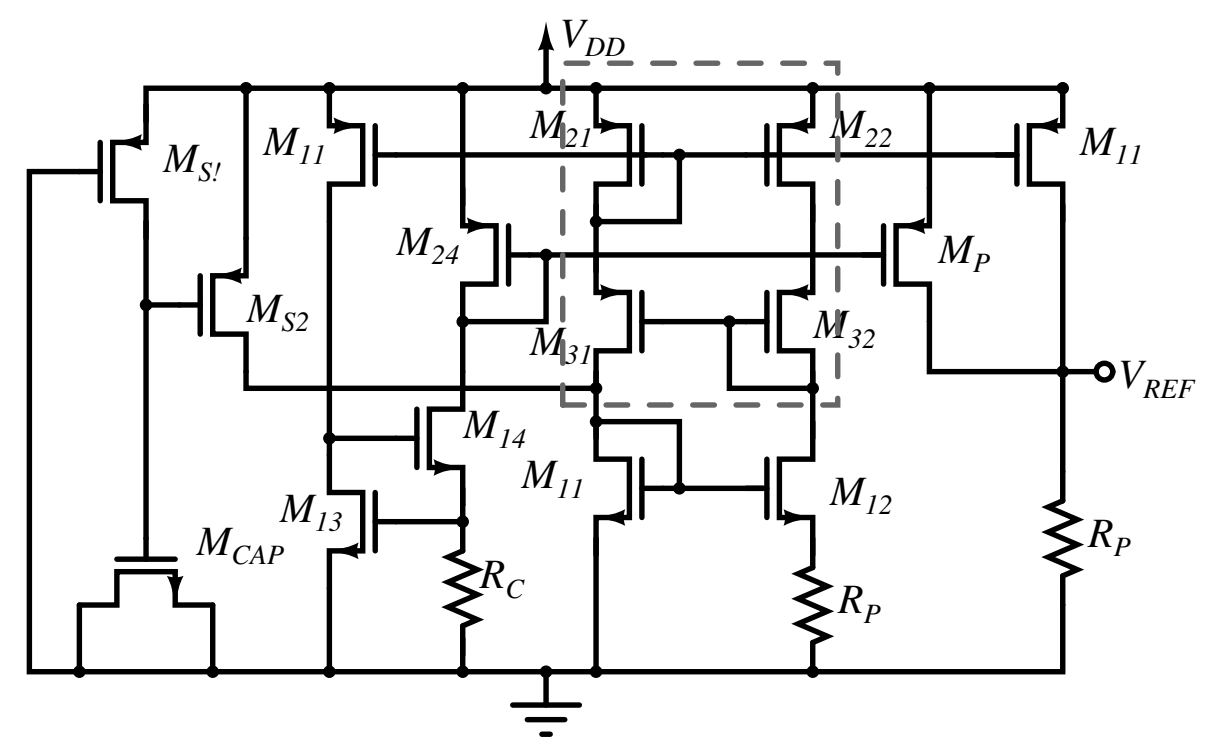

Figura 3.6: Fonte referência, usando um cascode como espelho de corrente no bloco PTAT.

estabelecidos. No entanto, o espelho de corrente conformado pelos transistores $M_{21}$ e $M_{22}$ resulta altamente sensível e pode gerar degradação do comportamento térmico da corrente PTAT, da qual dependem os demais blocos do circuito: CTAT e estágio final. Assim, o espelho de corrente é mudado para um tipo cascode, da maneira que pode ser vista na Figura 3.6. $\mathrm{O}$ arranjo em cascode do espelho que replica a componente PTAT apresenta dois benefícios: primeiro garante um incremento na resistência de saída levando a um melhor casamento e comportamento ante as variações da tensão de alimentação e reduz o efeito Miller o qual produz uma redução na largura de banda [31]. Esta última leva a um melhor comportamento do PSRR em altas frequências. No entanto, uma desvantagem do cascode é que necessita um aumento na tensão nominal de alimentação para assegurar uma adequada polarização dos transistores.

Desta maneira, o circuito da Figura 3.6 é otimizado nominalmente usando o Seeder para atingir o melhor conjunto de especificações. Este processo leva à obtenção de um circuito com os resultados de desempenho e rendimento mostrados na Tabela 3.8, levando 23 minutos computacionais na execução do esquema de otimização numa máquina com as características definidas na Tabela 3.2. Apesar do aumento na tensão de alimentação $V_{D D}$ de $100 \mathrm{mV}$ para garantir uma apropriada polarização dos transistores, o circuito com cascode apresenta uma melhoria no consumo de potência, sendo esta reduzida $10 \%$ aproximadamente. Outro destaque importante é o melhoramento do coeficiente térmico, o qual atinge um valor de $5,85 \mu \mathrm{V} /{ }^{\circ} \mathrm{C}$, o melhor obtido neste trabalho. Tem-se uma correlação entre o comportamento altamente linear da tensão de referência $V_{R E F}$ e a implementação do espelho cascode no bloco PTAT? A resposta a esta pergunta é SIM. No espelho cascode, a resistência de saída vista pelo dreno do transistor $M_{12}$ e aquela vista pelo dreno de $M_{11}$ apresentam valores bastante semelhantes e maiores do 
que um espelho de corrente comum. Para o caso do espelho típico usado na topologia da Figura 3.1, sua resistência de saída vista do dreno de $M_{21}$ corresponde a $1 / g_{d s 21}$, enquanto à vista do dreno de $M_{22}$ é aproximadamente $1 / g_{m 22}$. Esta assimetria degrada o coeficiente térmico, pois os transistores $M_{11}$ e $M_{12}$ vão apresentar diferentes tensões de dreno-fonte $V_{D S}$ e, portanto diferentes componentes não-lineares no comportamento térmico das suas correntes [34]. Este fato pode ser demostrado com a expressão da corrente de dreno $I_{D}$ em função da tensão de porta-fonte $V_{G S}$ e dreno fonte $V_{D S}$ para um transistor MOS polarizado em sub-limiar levando em conta o efeito de modulação de canal, a qual é da forma:

$$
I_{D}=\mu U_{T}^{2} \frac{W}{L} \exp \left(\frac{V_{G S}-V_{t}}{n V_{T}}\right)\left[1-\exp ^{\left(\frac{-V_{D S}}{V_{T}}\right)}\right]
$$

sendo $W$ e $L$ a largura e o comprimento do transistor MOS, $V_{T}$ a tensão térmica e $n$ é o parâmetro da inclinação em sub-limiar. A influência de $I_{D} \operatorname{com} V_{D S}$ é altamente não linear e resulta crítica para tensões $V_{D S}$ muito acima da tensão térmica $V_{T}$. Assim, a resistência de saída do espelho de corrente tipo cascode, além de permitir uma melhor resposta em frequência ante as variações de tensão na alimentação, decrementa o efeito térmico não linear das correntes de dreno $I_{D 12} \mathrm{e}$ $I_{D 11}$, e em consequência permite um menor coeficiente térmico na tensão de referência da fonte da Figura 3.6. No entanto, para que a afirmação anterior permaneça verdadeira, uma relação apropriada $W_{12} / W_{11}$ deve ser escolhida para garantir uma proximidade nas tensões de drenofonte para $M_{12}$ e $M_{11}$ e assim manter a melhora no comportamento térmico com respeito à fonte de referência da Figura 3.1. Geralmente, esta relação não deve ser maior a um limite superior no qual a característica térmica da fonte de referência com espelho cascode não vai apresentar uma melhora considerável em comparação com a fonte típica.

A Tabela 3.8 apresenta uma análise comparativa do rendimento e desempenho da fonte de referência otimizada para mismatch com a fonte de referência que usa um espelho cascode. Assim, deseja-se estabelecer o melhor método de redução de mismatch, o qual pode ser um aumento dos requerimentos de área ou um aumento no número de transistores. Quantitativamente, a fonte com espelho cascode apresenta uma leve melhoria de rendimento total em relação com aquela previamente otimizada para mismatch. Embora o rendimento devido ao mismatch não tenha sido melhorado, um pequeno decremento no efeito das variações de processo favorece o rendimento global. A área ocupada pelas portas dos transistores do projeto otimizado para mismatch foi de $13066(\mu \mathrm{m})^{2}$, em contraste com uma área menor ocupada no caso do projeto da fonte com cascode, sendo esta de $8195(\mu m)^{2}$. Uma redução de $37 \%$ na área foi obtida mantendo quase igual o rendimento do circuito. O projetista de circuitos terá que avaliar os benefícios e desvantagens em cada uma das topologias, e até poderá incrementar a área da fonte com espelho cascode a fim de obter valores de rendimento maiores. 
$\sum$

o

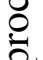

(1)

$\underline{0}$

章

$\Sigma$

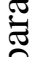

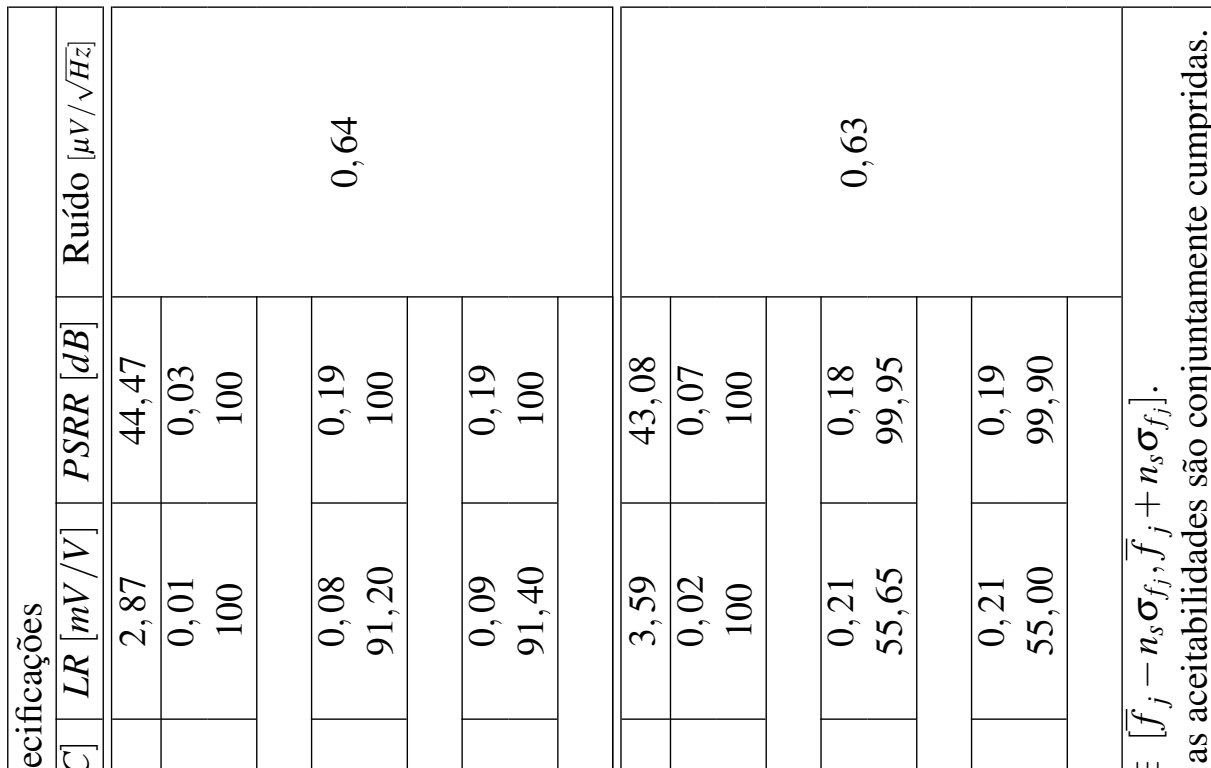

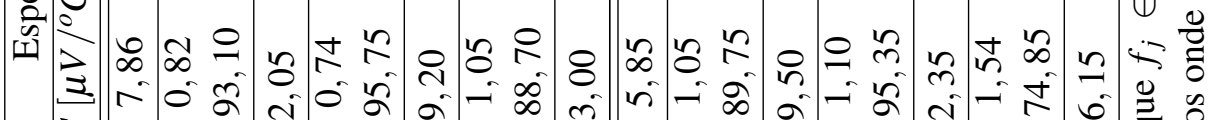

สี

$\stackrel{\circ}{\frac{0}{0}} \leqq$

ำ

00

苞

ב

ठे

రั:

वे

is

.

$\stackrel{3}{>}$

శี

เి.

:

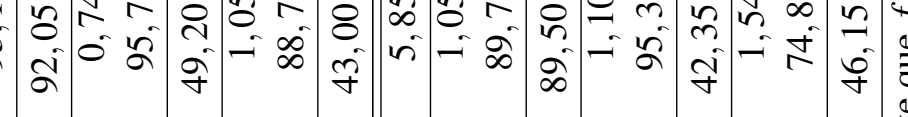

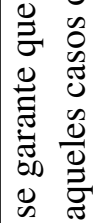

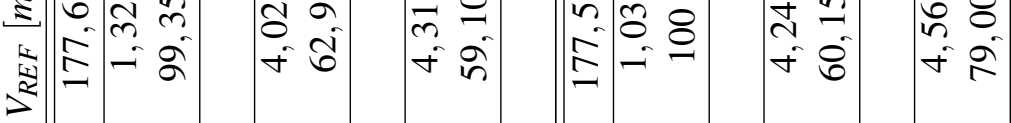

$\frac{2}{3}$

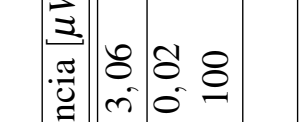

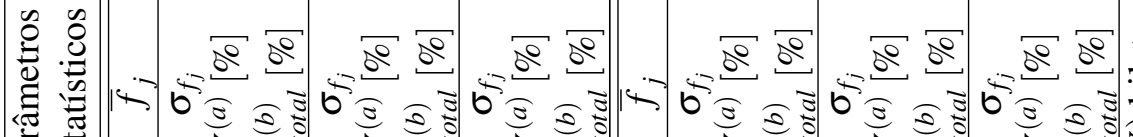

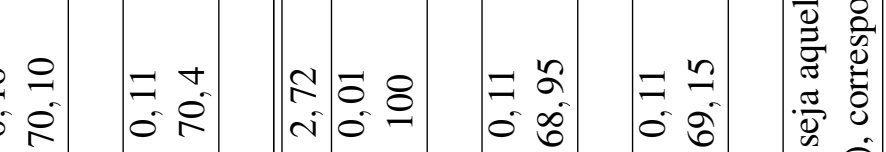

m.

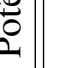

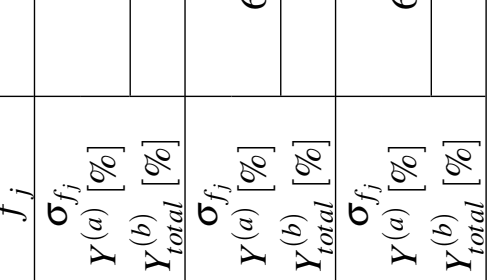

व

\begin{tabular}{|c|c|c|c|c|c|c|c|c|c|}
\hline E. & 14 & $0 \frac{\bar{g}}{\lambda}$ & $\frac{3}{\lambda}$ & $\frac{3}{\lambda}=$ & 14 & $\frac{\pi}{2}$ & , $\frac{\sqrt{3}}{2}$ & & $=\sqrt[0]{2} \vec{\Xi}$ \\
\hline 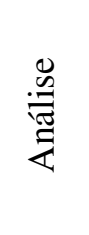 & 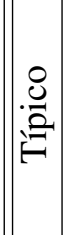 & 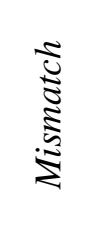 & $\begin{array}{l}0 \\
\tilde{D} \\
\tilde{D} \\
0 \\
0\end{array}$ & 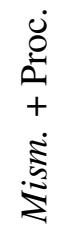 & 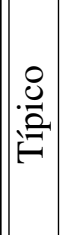 & 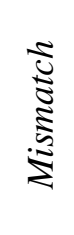 & $\begin{array}{l}0 \\
\text { Dे } \\
0 \\
\delta \\
0 \\
0\end{array}$ & 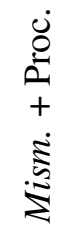 & 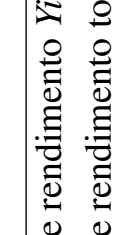 \\
\hline$\frac{\frac{0}{0}}{\frac{0}{2}}$ & & & 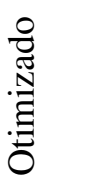 & & & & 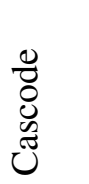 & & 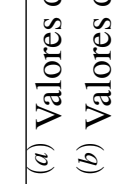 \\
\hline
\end{tabular}




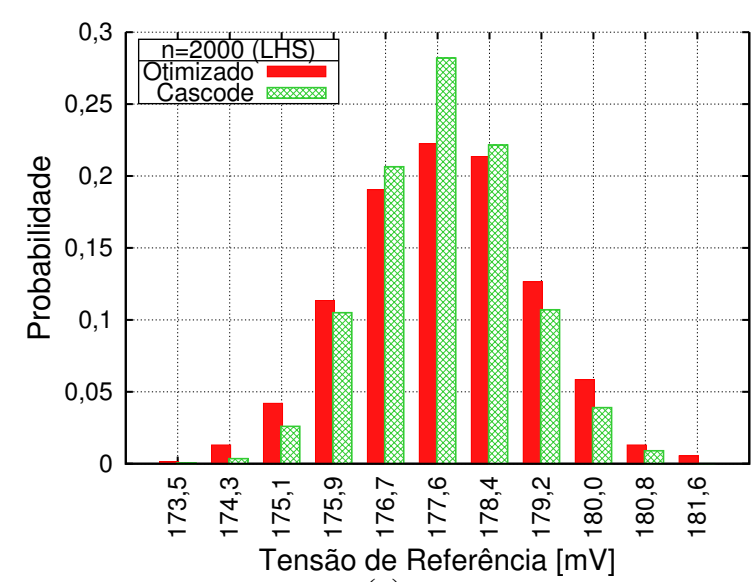

(a)

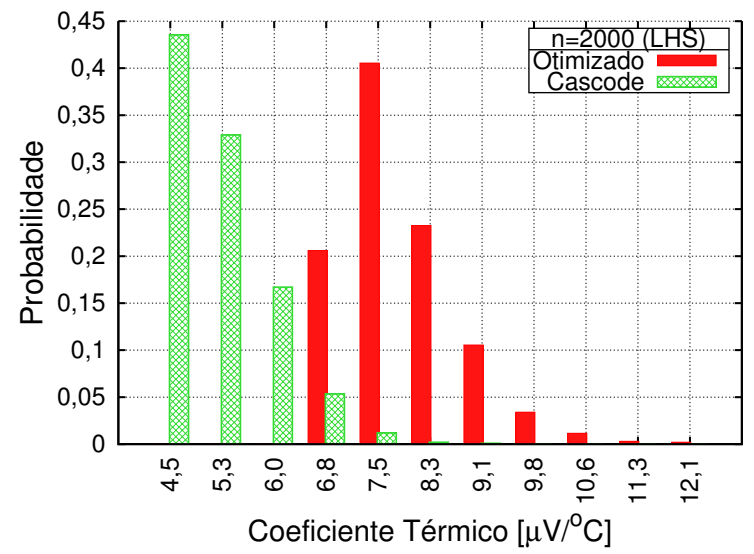

(b)

Figura 3.7: Histograma para o projeto otimizado para Mismatch e para a fonte com espelho cascode: (a) Tensão de referência $V_{R E F}$; (b) Coeficiente Térmico $T C$.

A distribuição estatística para a tensão de referência e o coeficiente térmico comparando a fonte de tensão otimizada para mismatch e aquela com um espelho cascode é mostrada nas Figuras 3.7(a) e 3.7(b). Notavelmente, a otimização do mismatch através da colocação de novos transistores produz melhores resultados tanto do desempenho como do rendimento comparado com a estratégia na qual a área por elemento é restringida e muitos dos casos incrementada. Por exemplo, para a especificação da tensão de referência, a sua ocorrência em torno do valor médio é $10 \%$ mais provável para o caso do cascode do que aquele sem ele. Adicionalmente, o coeficiente térmico foi reduzido e suas variações estreitadas sem incremento no valor da área. Aparentemente a tensão de referência com cascode torna-se a melhor escolha para implementar em silício, mas mostra uma desvantagem quando faz parte de um sistema portável e a tensão de alimentação pode facilmente alcançar valores inferiores ao seu valor nominal.

\subsubsection{Layout e considerações de mismatch}

Os layouts das duas fontes de referência projetadas na tecnologia $X F A B \quad 0,18 \mu m$ e duas projetadas na tecnologia de $A M S 0,35 \mu \mathrm{m}$ podem ser vistos na Figura 3.8 e na Figura 3.9, respectivamente. Para o caso do processo XFAB, correspondente ao layout da Figura 3.8, o core da esquerda foi dimensionado com o Seeder e os valores esperados para cada especificação $f_{b}$ foram definidos para ser os mesmos daqueles apresentados no artigo [20]. No caso do core da direita, foi projetado com Programação Geométrica para obter as melhores especificações de desempenho com restrições de área obtidas com base nos resultados do análise de mismatch proposto na seção 2.5. As dimensões do core da esquerda são $202 \mu \mathrm{mx} 156 \mu \mathrm{m}$ e para o core da direita correspondem a $308 \mu m \times 235 \mu m$. O aumento da área para o caso do projeto 


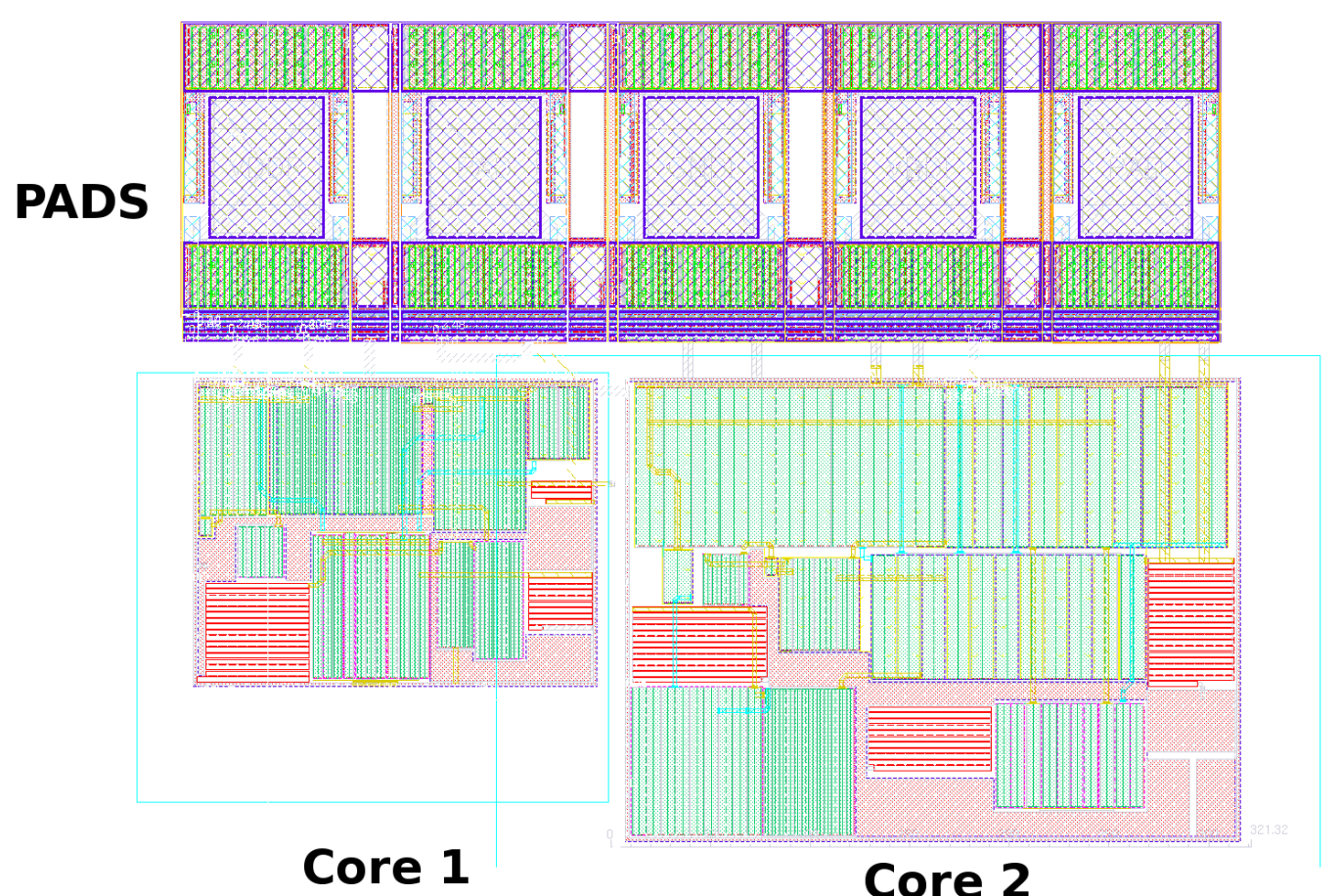

Figura 3.8: Layout da fonte de ref erência gerada pelo Seeder e otimizada para mismatch fabricada no processo $X F A B 0,18 \mu \mathrm{m}$.

otimizado para mínimo mismatch com respeito a aquele gerado pelo Seeder é de 129\%, atribuído essencialmente a três fatos:

- Para o caso do projeto da direita, a otimização do mismatch seguindo a estratégia exposta na seção 2.5 não leva em conta o número de dedos dos transistores, incrementando assim a área mínima requerida para garantir as especificações de aceitabilidade $\sigma_{f_{j}}$.

- A potência foi reduzida para a metade no projeto otimizado para o mismatch, produzindo um aumento na área devido a que os valores dos resistores também foram incrementados. Este comportamento pode ser evidenciado do traço da curva de Pareto da potência em função da área, mostrada na Figura 3.3(a).

- Como foi visto na seção 3.5.1, o bloco crítico para mismatch corresponde ao gerador PTAT, o qual tem a importante função de replicar as correntes para os demais blocos (CTAT e o estágio final). Olhando detalhadamente o esquemático da Figura 3.1, é possível reparar como um aumento na área do bloco PTAT, implica num aumento direto da área da fonte de referência quando são mantidas as relações de aspecto dos transistores, pois aqueles que espelham a componente proporcional da corrente $\left(M_{23} \mathrm{e}\right.$ $\left.M_{P}\right)$ seriam incrementados na mesma razão $W / L$ dos transistores $M_{21-22}$. Por exemplo, um incremento de duas vezes em uma dimensão crítica para a variabilidade, como é o 


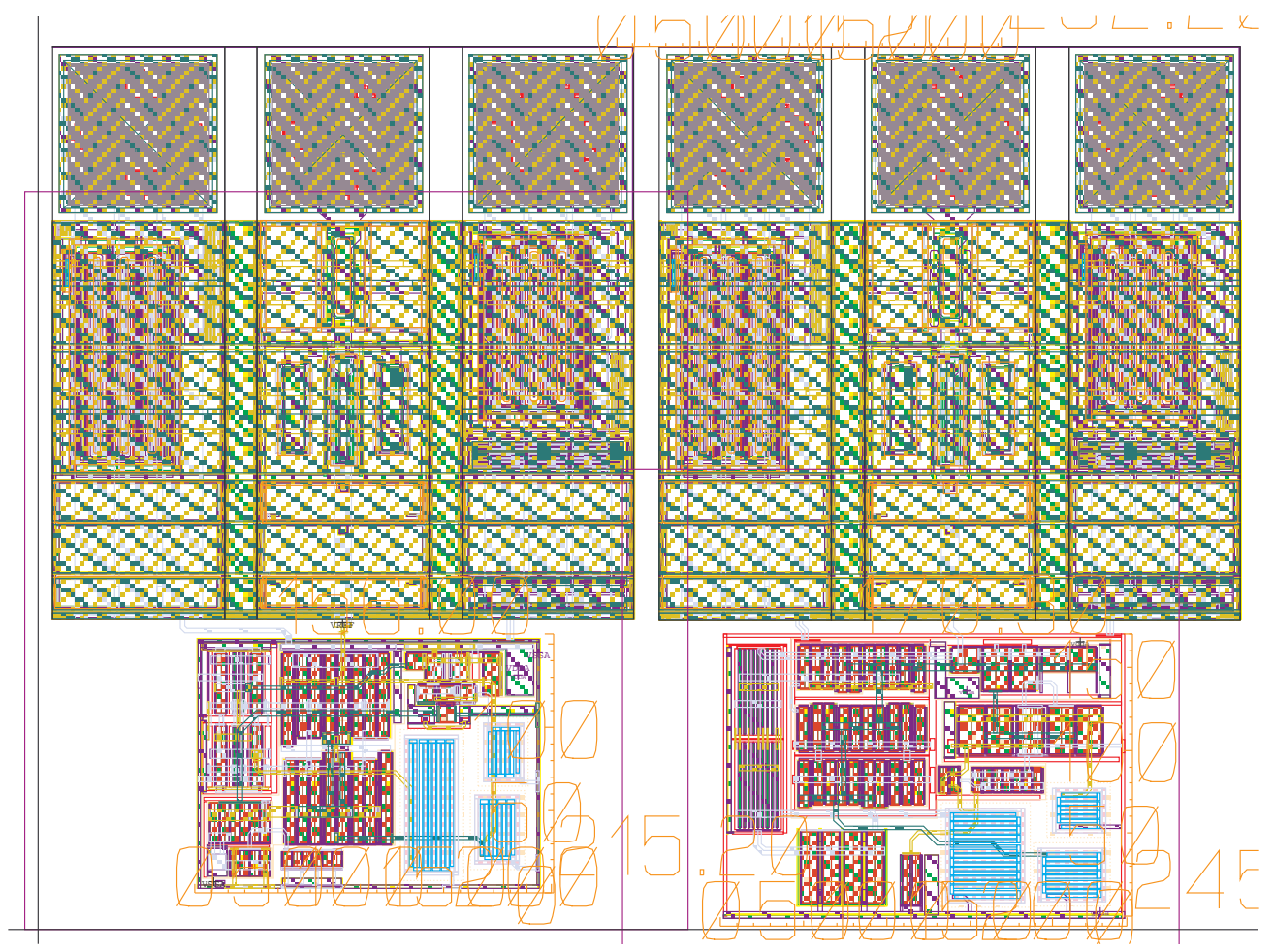

Figura 3.9: Comparação dos layouts para a fonte de referência otimizada com PG para desempenho (esquerda) e aquela otimizada para mismatch (direita) fabricada no processo $A M S$ $0,35 \mu \mathrm{m}$.

comprimento do canal, mantendo a mesma relação de aspecto, implicaria num incremento de 4 vezes o valor da área, que é consideravelmente crítico para muitas implementações. Assim, uma adequada estratégia de otimização de área deve ter por fim o decremento da relação de aspecto em conjunto com a área.

As sugestões anteriores foram levadas em conta e um novo método de obtenção das restrições de área mínima foi desenvolvido. Junto com isto, o programa geométrico foi modificado para obter conjuntamente a menor área e relação de aspecto $W / L$ para os transistores da fonte de referência. Assim foi obtido o projeto da direita da Figura 3.9, cujo dimensionamento corresponde ao projeto analisado na seção anterior e denominado projeto otimizado para mismatch. O layout da esquerda corresponde ao projeto nominal comparado e analisado da mesma maneira. A área total do core do circuito nominal é de $215 \mu \mathrm{m} \times 156 \mu \mathrm{m}$ e do circuito otimizado para menor mismatch é de $245 \mu m \times 170 \mu m$, representando um incremento de $24 \%$. $\mathrm{O}$ incremento na área consumida pelo core do circuito resulta relevante se o layout deste é limitado pelo tamanho do core, e em caso contrário um incremento da área para uma melhora no rendimento não terá um impacto significativo no consumo global de área do chip.

Para levar em conta as variações do processo e mismatch no layout, os espelhos de corrente da fonte de referência foram desenhados usando a técnica de centróide comum. Para 
assegurar um apropriado casamento dos transistores considerados os mais críticos do circuito: $M_{11}$ e $M_{12}$, o número de dedos de $M_{11}$ preferivelmente tem que ser ímpar e par no caso do transistor $M_{12}$, de modo que fique um arranjo mais simétrico. Embora este tipo de restrições inteiras não sejam aceitadas pela PG, precisam ser definidas para aumentar a correlação entre as variações dos parâmetros. Uma estratégia futura pode incluir um tipo de esquema de programação denominado Programação Inteira, o qual leva em conta variáveis com valores inteiros, circunstância que acontece na definição do número de dedos dos dispositivos. Neste estágio foi visto a necessidade de definir restrições para os números de dedos dos dispositivos as quais levem a um arranjo simétrico do layout dos diferentes blocos, em especial o gerador PTAT, o qual foi estabelecido previamente como um bloco altamente crítico no processo de projeto para robustez. Outro aspecto importante que não pode ser diretamente levado a implementação, corresponde ao adequado posicionamento e redundância no número de contatos e nas ligações a substrato, para assim manter a alta probabilidade na obtenção de dispositivos, a qual foi previamente otimizada alterando só o dimensionamento e a polarização do circuito.

\subsection{Análise do pior caso da fonte de referência}

Foi visto na seção 3.5 como as variações de processo eram as maiores causas dos desvios nas funções de desempenho. Apesar de que o mismatch já atingiu níveis de rendimento apropriados, é o momento de concentrar o projeto do circuito considerando apenas às variações do processo, temperatura e condições externas, mais comumente conhecidas como variações $P V T$. Assim, precisa-se analisar para cada uma das funções de desempenho definidas, o grau de influência de cada um dos parâmetros de processo de interesse em cada um dos elementos do circuito. À primeira vista o problema parece ser bem complexo e devem ser analisados todos os fatores variáveis e sua natureza no circuito, para assim, em etapas posteriores tentar reduzir a complexidade da análise e portanto do problema de otimização do circuito. A fim de obter o melhor conhecimento do comportamento do processo ante as variações de diferentes tipos, precisa-se conhecer entre outras as seguintes características do circuito:

- O valor do maior desvio ou desvio de pior caso que produz a variação de um único parâmetro de processo ou ambiente sobre um determinado elemento. Precisa-se para isto obter a resposta $\delta f_{j}(\delta \mathbf{p})$ usando o método das diferenças finitas, tanto para desvios positivos como negativos nos parâmetros.

- Conhecer o sinal ou direção do desvio de parâmetro $\delta \mathbf{p}$ que gera a maior degradação em cada uma das funções de desempenho. 
- A distância do pior caso ou WCD calculada com base na equação (2.38) e usando como referência os valores nominais.

- A simetria da variação $\delta f_{j}(\boldsymbol{\delta} \mathbf{p})$ em relação ao parâmetro $p_{i}$ e denotada como $\operatorname{Sim}_{p_{i}} f_{j}$, pode ser calculada em simulação como:

$$
\operatorname{Sim}_{p_{i}}^{f_{j}}=\operatorname{sgn}\left\{\delta f_{j}\left(p_{1}, \cdots, p_{i}+\delta p_{i}, \cdots, p_{m}\right)\right\} \operatorname{sgn}\left\{\delta f_{j}\left(p_{1}, \cdots, p_{i}-\delta p_{i}, \cdots, p_{m}\right)\right\}
$$

Se a simetria $\operatorname{Sim}_{p_{i}}^{f_{j}}$ é igual a 1 tem-se uma simetria par, no caso onde fosse -1 a simetria vai ser impar.

Um resultado da análise das anteriores características é mostrado na Tabela 3.9, onde parâmetros de processo, temperatura e tensão de alimentação estão ordenados com base na pior influência para cada uma das funções de desempenho. Nesta tabela, o WCD (WorstCase Distance) é a distância de pior caso definida pela equação (2.38). A fim de facilitar a visibilidade e o estudo da informação obtida na análise de pior caso, foram só levados em conta os cinco parâmetros mais relevantes. Esta suposição resulta válida, visto que as distâncias do pior caso da última fila da Tabela 3.9 correspondem a valores próximos à unidade excluindo o caso do coeficiente térmico. Estatisticamente, o parâmetro de processo com mais ocorrências nesta tabela corresponde à tensão de faixa plana $V_{f b}$, tendência que é bastante mais crítica em sub-limiar em relação com outras regiões de polarização. Uma coisa interessante a notar corresponde aos parâmetros que afetam mais a tensão de referência, aonde não se tem influência importante das variações das tensão de alimentação e a temperatura.

Sendo as variações por parâmetros individualmente analisadas, é preciso agora levar em conta as variações em todo o conjunto de parâmetros de processo, temperatura e tensão de alimentação, e assim estimar, provavelmente de uma maneira pessimista, os piores casos para cada função de desempenho. A Tabela 3.10 sumariza a efeito do pior caso estimado fazendo uso do método proposto na seção 2.7. Uma estimativa do rendimento é feita com base nas formulações matemáticas feitas no Apêndice B e utilizando para isto a expressão em (B.5). Conjuntamente, são calculados os valores de pior caso por meio de simulações Monte Carlo com $(L H S)$ e para um conjunto de amostras significativas, neste caso 2000 . O proveito do método de Monte Carlo consiste na sua capacidade para variar conjuntamente os parâmetros de processo, temperatura e tensão mantendo correlação ou independência entre eles, fato que realmente ocorre na realidade. No entanto, apresenta uma desvantagem no tempo de cálculo, o qual faz deste inadequado para implementações de otimização do pior caso. Comparativamente, usando o método de pior caso são gerados resultados de rendimento bem mais pessimistas do que aqueles obtidos via análise Monte Carlo, embora este não foi o caso para a tensão de 
Tabela 3.9: Análise do pior caso: parâmetros com variações mais críticas nas funções de desempenho para o processo $A M S 0,35 \mu \mathrm{m}$.

\begin{tabular}{|l|c|c|c|c|c|c|}
\hline & \multicolumn{7}{|c|}{ Especificações de Desempenho } \\
\cline { 2 - 7 } & Potência & $V_{R E F}$ & $T C$ & Ruído & $L R$ & $P S R R$ \\
{$[\mu W]$} & {$[m V]$} & {$\left[\mu V /{ }^{\circ} C\right]$} & {$[\mu V / \sqrt{H z}]$} & {$[m V / V]$} & {$[d B]$} \\
\hline Parâmetro & $V_{D D}: D C$ & $M_{24}: V_{f b}$ & $T e m p$ & $M_{24}: V_{f b}$ & $V_{D D}: D C$ & $M_{24}: V_{f b}$ \\
sgn $\left(\delta p_{i}\right)$ & $(+1)$ & $(+1)$ & $(+1)$ & $(+1)$ & $(-1)$ & $(+1)$ \\
Valor do Pior Caso & 3,59 & 190,08 & 56,07 & 0,55 & 3,55 & 37,6 \\
$(W C D)$ & 1,08 & 1,07 & 7,92 & 1,05 & 1,04 & 1,02 \\
Simetria & Impar & Impar & Par & Par & Impar & Impar \\
\hline Parâmetro & $M_{11}: V_{f b}$ & $M_{12}: V_{f b}$ & $M_{24}: V_{f b}$ & $M_{21}: V_{f b}$ & $T e m p$ & $R_{T}: \rho_{s h}$ \\
sgn $\left(\delta p_{i}\right)$ & $(+1)$ & $(+1)$ & $(+1)$ & $(+1)$ & $(-1)$ & $(+1)$ \\
Valor do Pior Caso & 3,49 & 168,92 & 32,47 & 0,54 & 3,34 & 38,2 \\
$(W C D)$ & 1,05 & 1,05 & 6,49 & 1,03 & 1,03 & 1,00 \\
Simetria & Impar & Impar & Par & Par & Impar & Impar \\
\hline Parâmetro & $T e m p$ & $M_{11}: V_{f b}$ & $V_{D D}: D C$ & $M_{11}: V_{f b}$ & $M_{11}: V_{f b}$ & $M_{23}: V_{f b}$ \\
sgn $\left(\delta p_{i}\right)$ & $(+1)$ & $(+1)$ & $(+1)$ & $(+1)$ & $(-1)$ & $(+1)$ \\
Valor do Pior Caso & 3,40 & 186,26 & 20,52 & 0,53 & 2,91 & 38,3 \\
$(W C D)$ & 1,03 & 1,05 & 2,88 & 1,02 & 1,00 & 1,00 \\
Simetria & Impar & Impar & Par & Par & Impar & Impar \\
\hline Parâmetro & $M_{21}: V_{f b}$ & $M_{21}: V_{f b}$ & $R_{p}: \rho_{s h}$ & $T e m p$ & $R_{T}: \rho_{s h}$ & $M_{12}: V_{f b}$ \\
sgn $\left(\delta p_{i}\right)$ & $(+1)$ & $(-1)$ & $(+1)$ & $(+1)$ & $(+1)$ & $(+1)$ \\
Valor do Pior Caso & 3,40 & 169,96 & 8,54 & 0,52 & 50,7 & 38,3 \\
$(W C D)$ & 1,02 & 1,05 & 1,20 & 1,01 & 1,00 & 1,00 \\
Simetria & Impar & Impar & Par & Par & Impar & Impar \\
\hline Parâmetro & $M_{24}: V_{f b}$ & $R_{T}: \rho_{s h}$ & $M_{21}: V_{f b}$ & $R_{T}: \rho_{s h}$ & $M_{13}: V_{f b}$ & $M_{24}: t_{o x}$ \\
sgn $\left(\delta p_{i}\right)$ & $(+1)$ & $(+1)$ & $(-1)$ & $(+1)$ & $(+1)$ & $(+1)$ \\
Valor do Pior Caso & 3,36 & 179,12 & 8,54 & 0,52 & 50,8 & 38,3 \\
$(W C D)$ & 1,01 & 1,01 & 1,16 & 1,01 & 1,00 & 1,00 \\
Simetria & Impar & Impar & Par & Par & Impar & Impar \\
\hline Parâmetros ordenados pela pior influência sobre cada uma das funções de desempenho. \\
\hline
\end{tabular}

referência $V_{R E F}$ e para a regulação de linha. Uma das explicações possíveis é que o método de estimação de Monte Carlo proposto neste trabalho usou variações $3 \sigma$ dos parâmetros, ao contrário das variações de $6 \sigma$ assumidas nos modelos estatísticos que fornece $A M S$. No entanto, o destaque é que a tendência do rendimento estimado em relação ao simulado é mantida, fato que permite uma otimização com um baixo custo computacional. Além disso, as derivações feitas no Apêndice B assumem que todos os parâmetros de processo, a variação na temperatura e na tensão de alimentação tem uma característica aleatória Gaussiana, fato que não é bem certo para muitos deles. A utilidade na comparação dos dois rendimentos, estimado em relação ao simulado, é que todos os parâmetros aleatórios no modelo para Monte Carlo do processo $A M S$ 0,35 $\mu m$ possuem uma caracterização seguindo modelos de distribuição do tipo Gaussiano, 
Tabela 3.10: Natureza e piores casos das variações no desempenho (estimado vs. simulação) para o processo $A M S 0,35 \mu \mathrm{m}$.

\begin{tabular}{|c|c|c|c|c|c|c|c|}
\hline & \multicolumn{6}{|c|}{ Especificações de desempenho } \\
\hline & & $\begin{array}{l}\text { Potência } \\
{[\mu W]}\end{array}$ & $\begin{array}{l}V_{R E F} \\
{[m V]}\end{array}$ & $\begin{array}{c}T C \\
{\left[\mu V /{ }^{\circ} C\right]}\end{array}$ & $\begin{array}{c}\text { Ruído } \\
{[\mu \mathrm{V} / \sqrt{\mathrm{Hz}}]}\end{array}$ & $\begin{array}{c}L R \\
{[m V / V]}\end{array}$ & $\begin{array}{c}P S R R \\
{[d B]}\end{array}$ \\
\hline & $\begin{array}{l}\text { Monotonocidade } \\
\text { Tendência }\end{array}$ & $\begin{array}{l}\text { Monotônica } \\
\text { Crescente }\end{array}$ & $\begin{array}{l}\text { Monotônica } \\
\text { Crescente }\end{array}$ & $\begin{array}{l}\text { Monotônica } \\
\text { Crescente }\end{array}$ & $\begin{array}{l}\text { Monotônica } \\
\text { Crescente }\end{array}$ & $\begin{array}{l}\text { Monotônica } \\
\text { Decrescente }\end{array}$ & $\begin{array}{c}\text { Monotônica } \\
\text { Decrescente }\end{array}$ \\
\hline 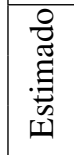 & $\begin{array}{l}\text { Pior Caso } \\
(W C D) \\
Y^{(a)}[\%]\end{array}$ & $\begin{array}{c}3,76 \\
1,13 \\
85,09\end{array}$ & $\begin{array}{c}198,7 \\
1,12 \\
69,46\end{array}$ & $\begin{array}{c}104,39 \\
14,18 \\
51,85\end{array}$ & $\begin{array}{c}0,561 \\
1,08 \\
80,92\end{array}$ & $\begin{array}{c}3,84 \\
1,05 \\
99,67\end{array}$ & $\begin{array}{c}47,7 \\
1,01 \\
100\end{array}$ \\
\hline 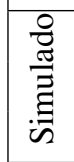 & $\begin{array}{l}\text { Pior Caso } \\
(W C D) \\
Y^{(b)}[\%]\end{array}$ & $\begin{array}{c}3,47 \\
1,04 \\
70,40\end{array}$ & $\begin{array}{c}162,4 \\
1,08 \\
59,10\end{array}$ & $\begin{array}{c}11,78 \\
1,59 \\
88,70 \\
\end{array}$ & $\begin{array}{c}0,655 \\
1,19 \\
----\end{array}$ & $\begin{array}{c}3,21 \\
1,11 \\
91,40\end{array}$ & $\begin{array}{c}47,02 \\
1,035 \\
100,00\end{array}$ \\
\hline
\end{tabular}

sendo o mesmo tipo de caracterização assumida nas derivações analíticas feitas no Apêndice B. Assim, a comparação de valores do rendimento e do pior caso desenvolvida na Tabela 3.10 é feita sob as mesmas condições, razão pela qual possui uma boa validez.

\subsection{Otimização do pior caso}

Tendo desenvolvida uma rigorosa análise da natureza e estimativa da influência que têm as distintas variações sobre o circuito, o interesse posterior do projetista é tornar o dispositivo menos crítico a estes fatores variáveis. Já foi dada uma adequada métrica para conhecer a sensibilidade do circuito aos piores casos nos seus parâmetros, sendo esta métrica denominada distância do pior caso ou Worst-Case Distance (WCD). A implementação do esquema de otimização do pior caso segue o planejado conforme o proposto na equação (2.39). Seu equivalente em Programação Geométrica proposto neste trabalho na expressão (2.40) não foi utilizado, pois para o tamanho e complexidade do circuito da Figura 3.1 resulta ser uma solução pouco útil na hora do projeto. No entanto, uma vez proposto, esta estrutura de otimização pode ser usada na otimização de circuitos de menor complexidade e alta sensibilidade às variações de processo, como são as células de memória estática ou SRAM(Static RandomAccess Memory). Tem-se que lembrar que este trabalho deu a primeira abordagem ao projeto de circuitos analógicos polarizados na região de sub-limiar, fato que representou um desafio entre a precisão requerida e o tempo de cálculo da modelagem dos dispositivos. Por outro lado, quando é implementado um método iterativo de otimização para o pior caso, é preciso 
aprimorar nos tempos de cálculo da análise do pior caso. Tomando como exemplo a fonte de referência abordada neste trabalho e analisando $p$ funções de desempenho e 5 parâmetros de processo, além da temperatura e da tensão de referência, a complexidade da estratégia proposta é de $O(7 \cdot 2 \cdot p)$; No melhor dos casos a complexidade pode ser reduzida levando em conta a paridade das variações a $O(7 \cdot p)$. A baixa correlação entre os resultados para cada um dos piores casos, garante uma diminuição no tempo de cálculo deste tipo de algoritmos quando são executados paralelamente. No entanto, neste trabalho a otimização nos tempos de computo foi voltada à supressão das contribuições consideradas a critério do projetista irrelevantes à influência do pior caso global. Assim, foram levadas em conta para a otimização só os primeiros cinco parâmetros que produzem as mudanças mais críticas no circuito, os mesmos conteúdos na Tabela 3.9. Finalmente, a formulação do programa de otimização do pior caso ficou da seguinte forma:

$$
\begin{array}{llr}
\text { minimizar } & \underbrace{\sum_{j=1}^{p}\left\{w_{j} g_{j}(\mathbf{x}, \overline{\mathbf{P}})\right.}_{\text {Desempenho }}+\underbrace{\left.f_{\mathbf{w c d}_{j}}\left(\mathbf{x}, \mathbf{P}_{j_{w c}}\right)\right\}}_{\text {Pior caso }}+\underbrace{\sum_{k=1}^{m} u_{k}}_{\text {Mismatch }} j=1, \cdots, p \\
\text { sujeito a: } & W_{\min } \leq W_{i} \leq W_{\max }, L_{\min } \leq L_{i} \leq L_{\max } & i=1, \cdots, 2 m \\
& A_{k_{\min }}=u_{k} A_{k} & k=1, \cdots, m \\
& V_{G S}, V_{D S} \in \mathscr{D} \mathscr{N}, \mathscr{P}
\end{array}
$$

sendo $f_{\mathbf{w c d}_{j}}\left(\mathbf{x}, \mathbf{P}_{j_{w c}}\right)$ uma função de ponderação para os piores casos, a qual depende amplamente dos requerimentos do projetista. Neste trabalho foram propostas quatro tipos diferentes de funções de ponderação da distância do pior caso, as quais são:

$$
f_{\text {wcd }_{j}}\left(\mathbf{x}, \mathbf{P}_{j_{w c}}\right)= \begin{cases}\max \left\{\mathbf{w c d}_{j}\left(\mathbf{x}, \mathbf{P}_{j_{w c}}\right)\right\} & \text { pior caso } \\ \operatorname{std}\left\{\mathbf{w c d}_{j}\left(\mathbf{x}, \mathbf{P}_{j_{w c}}\right)\right\} & \text { dispersão } \\ \max \left\{\mathbf{w c d}_{j}\left(\mathbf{x}, \mathbf{P}_{j_{w c}}\right)-1,0\right\} & \text { supressão } \\ \operatorname{sum}\left\{\mathbf{w c d}_{j}\left(\mathbf{x}, \mathbf{P}_{j_{w c}}\right)\right\} & \text { contribuição }\end{cases}
$$

sendo $\max \{\mathbf{x}\}, \operatorname{std}\{\mathbf{x}\}$ e $\operatorname{sum}\{\mathbf{x}\}$ a função que obtém o valor máximo, o desvio padrão e a soma, respectivamente, de um conjunto de valores conteúdos no vetor $\mathbf{x}$. A função denominada do pior caso, é definida inicialmente no esquema de otimização da distância de pior caso (WCD) na equação (2.39). Esta função objetivo permite a diminuição somente do efeito do pior caso global por especificação, garantindo que as demais contribuições sejam menores. No caso da função de dispersão é levada em conta a variação de todas as influências na degradação no valor de desempenho do circuito sem distinção da sinal, assim garante que não só a contribuição do pior caso seja otimizada mas também aquela do melhor caso, ficando as duas mais perto do valor 
nominal. Contrariamente, a função denominada supressão, leva em conta só as degradações, ou seja os piores casos no circuito (aqueles cuja distância do pior caso é maior do que um) sejam minimizados. Finalmente, a função contribuição leva em conta o efeito global das contribuições por parâmetro sem distinção alguma do sinal. Uma análise das quatro funções anteriormente nomeadas, estabeleceu que para o caso no qual vários parâmetros produzem efeitos iguais no rendimento, é bem melhor usar a função soma como ponderação de WCD. Além disso, foram levados em conta para análise os cinco parâmetros de processo mais relevantes, sendo os mesmos amostrados na Tabela 3.9. Quando um conjunto maior de parâmetros foi considerado, a otimização torna-se de difícil convergência aos ótimos locais, levando a resultados ruins em tempos consideravelmente mais longos ao caso assumido neste trabalho. A razão é que a análise de um maior número de parâmetros de processo produz uma diminuição da influência do pior caso na função objetivo do esquema de otimização, em conjunto com descontinuidades geradas na função de mérito as quais degradam o desempenho do método numérico.

\subsection{Validação final}

O problema de otimização dos piores casos definido pelas expressões em (3.25) e para a fonte de referência da Figura 3.1 é resolvido em 47 minutos computacionais usando a ferramenta proposta neste trabalho: Anubis. Apesar de levar em conta 5 parâmetros de processo para 6 funções de desempenho, o método de otimização dos piores casos teve um incremento de aproximadamente $51 \%$ no tempo de execução, sendo menor do que o previsto. A razão para isto é que para a estimativa dos piores casos foi usada uma análise de varredura $D C$, a qual só precisa de uma execução do programa de simulação por iteração do esquema de otimização. Os resultados de rendimento e desempenho após a otimização são mostrados na Tabela 3.11, comparativamente com os valores obtidos via programação geométrica sem levar em conta as variações de processo, sendo cada circuito avaliado para as seis especificações consideradas no início do projeto. O rendimento total para o caso nominal já estimado para casos anteriores e corresponde a um valor de $42,85 \%$, em contrapartida o rendimento para o circuito otimizado usando o método de projeto proposto corresponde a 79,75\%. A melhora absoluta do rendimento do projeto final correspondeu a 36,90\% com incremento de área de $9381(\mu \mathrm{m})^{2}$ no caso nominal para $15241(\mu m)^{2}$ no caso do circuito otimizado, o qual em porcentagem representa $62,5 \%$ da área nominal. A área foi a única especificação que piorou, pois as outras seis levadas em conta tiveram melhorias consideráveis tanto nos seus valores nominais e de rendimento. Por exemplo, teve-se uma redução do ruído em mais da metade, dirigida numa grande proporção pelo melhoramento do circuito ante variações devidas ao mismatch. 


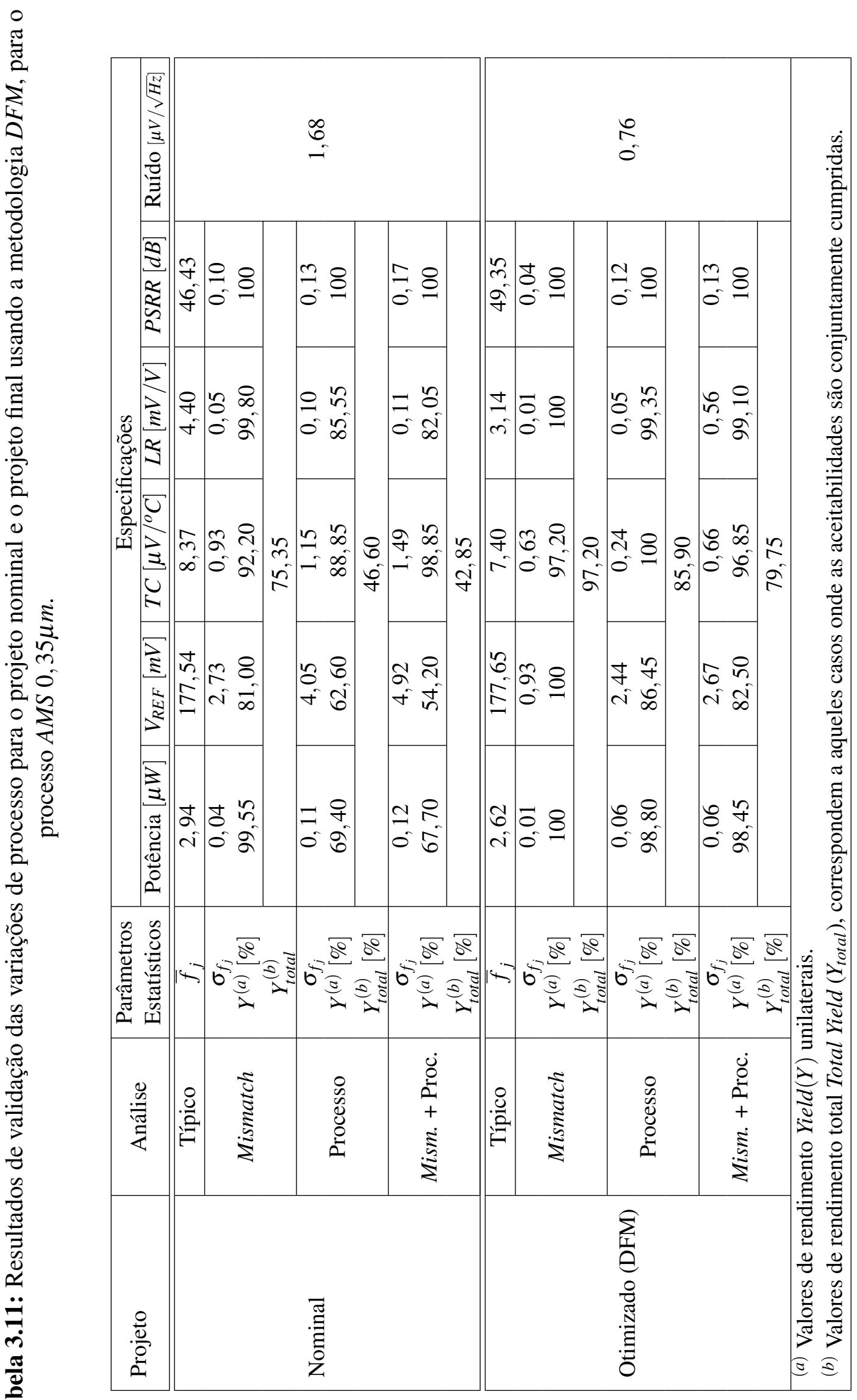


Adicionalmente, o melhoramento na resposta às variações da fonte na tensão de alimentação tem uma alta correlação com a otimização sob variações de processo, pois leva ao dimensionamento de transistores com comprimento alto e garante também uma diminuição da resposta do transistor às variações nos diferentes domínios (tempo, espaço, frequência, etc.), característica geralmente nomeada em estado estável como sensibilidade. A função de desempenho com a maior perda no rendimento corresponde à tensão de referência, a qual teve uma queda de $17,50 \%$ no rendimento. As variações de processo são as mais responsáveis das perdas de rendimento, representando $83,43 \%$ das perdas totais e levando o rendimento do circuito para um valor próximo a $80 \%$. Embora o rendimento devido ao mismatch fosse garantido $100 \%$ para 5 especificações e parcialmente para uma ${ }^{5}$, a característica aleatória dos parâmetros de processo em $A M S$ 0,35 $\mu m$ não ajudou na obtenção do requerimento de variabilidade na tensão de referência. Para tentar resolver esse problema, é necessário fazer uma análise de compromissos entre o valor das especificações de desempenho e das restrições de aceitabilidade. No caso no qual o circuito não cumpre as expectativas de rendimento e desempenho do projetista, mudanças na topologia e no processo de fabricação devem ser feitas.

Desta maneira, qualquer que seja a opção a vantagem do método proposto neste trabalho garante o fornecimento de ferramentas necessárias para que o projetista adote a melhor solução do problema. Se a fonte de referência fizesse parte de um sistema portável, uma implementação com espelhos do tipo cascode em conjunto com uma análise e otimização voltada para reduzir o efeito da variação na tensão de alimentação em conjunto as flutuações de processo e mismatch deve ser efetuada. Adicionalmente, os requerimentos de aceitabilidade e portanto os resultados de rendimento devem ser contrastados com um outro processo, para assim avaliar os possíveis benefícios no rendimento e no conjunto de especificações se este novo processo for adotado.

Assim, a Tabela 3.12 apresenta comparativamente os resultados da otimização usando a metodologia DFM proposta neste trabalho para dois processos: o $A M S 0,35 \mu \mathrm{m}$, e da foundry $X F A B 0,18 \mu \mathrm{m}$. Para o caso de $A M S$, os valores de rendimento são os mesmos mostrados na Tabela 3.11, sendo exibido um rendimento total de 79,75\%. Entretanto, o rendimento obtido no circuito projetado sob a tecnologia de $X F A B$ incrementou-se em $15 \%$ aproximadamente, atingindo assim um valor de 94,80\%. Ou seja, para $X F A B$ a única especificação que sofreu perda de rendimento, e portanto determinou o valor do rendimento global, foi a potência, sendo neste caso o rendimento global do circuito de 94,80\%. Em contraste, para o caso de $A M S$ teve-se conjunto de 4 especificações que apresentaram perdas de rendimento. Em

\footnotetext{
${ }^{5}$ Deve-se lembrar a alta influência do casamento dos transistores $M_{11}$ e $M_{12}$ no comportamento térmico do circuito, assim mantendo as tensões de dreno-fonte muito próximas reduzem as diferenças na suas componentes térmicas da corrente.
} 
Tabela 3.12: Comparação dos resultados de otimização $D F M$ para o processo $A M S 0,35 \mu m$ e $X F A B \quad 0,18 \mu m$.

\begin{tabular}{|c|c|c|c|c|c|c|}
\hline \multirow{2}{*}{$\begin{array}{l}\text { Otimização } \\
\text { (DFM) }\end{array}$} & \multirow{2}{*}{$\begin{array}{l}\text { Parâmetros } \\
\text { Estatísticos }\end{array}$} & \multicolumn{5}{|c|}{ Especificações } \\
\hline & & Potência $[\mu W]$ & $V_{R E F}[m V]$ & $T C\left[\mu V /{ }^{\circ} C\right]$ & $L R[m V / V]$ & $\operatorname{PSRR}[d B]$ \\
\hline \multirow{4}{*}{$A M S 0,35 \mu m$} & \multirow{4}{*}{$\begin{array}{c}\bar{f}_{j} \\
\sigma_{f_{j}} \\
Y^{(a)}[\%] \\
Y_{\text {total }}^{(b)}[\%]\end{array}$} & 2,62 & 177,65 & 7,40 & 3,14 & 49,35 \\
\hline & & 0,06 & 2,67 & 0,66 & 0,56 & 0,13 \\
\hline & & 98,45 & 82,50 & 96,85 & 99,10 & 100 \\
\hline & & \multicolumn{5}{|c|}{79,75} \\
\hline \multirow{4}{*}{$X F A B 0,18 \mu m$} & \multirow{4}{*}{$\begin{array}{c}\bar{f}_{j} \\
\sigma_{f_{j}} \\
Y^{(a)}[\%] \\
Y^{(b)}[\%]\end{array}$} & 2,97 & 177,79 & 6,59 & 2,18 & 41,95 \\
\hline & & 0,07 & 1,31 & 0,33 & 0,05 & 0,183 \\
\hline & & 94,80 & 100 & 100 & 100 & 100 \\
\hline & & \multicolumn{5}{|c|}{94,80} \\
\hline \multicolumn{7}{|c|}{ (a) Valores de rendimento Yield $(Y)$ unilaterais. } \\
\hline
\end{tabular}

relação ao conjunto de valores de desempenho, no processo $X F A B$ apresentou-se uma melhora no coeficiente térmico $T C$ e na regulação de linha $L R$. As diferenças no comportamento elétrico e portanto nas especificações são evidentes: os dois modelos ( $A M S 0,35 \mu \mathrm{m}$ e $X F A B 0,18 \mu \mathrm{m})$ têm diferentes parâmetros elétricos. No entanto, para o caso da caracterização estatística do processo, a modelagem nos dois processos é bem diferente, sendo só possível ser verificada na medição do circuito. Para o caso exposto, a experiência do projeto feito em XFAB 0,18 $\mu \mathrm{m}$ demostrou uma melhoria no comportamento de especificações como a tensão de referência na topologia abordada em relação ao processo $A M S 0,35 \mu \mathrm{m}$, embora uma discussão dos modelos estatísticos e sua confiabilidade é necessária para uma escolha de processo definitiva [35].

A tabela 3.13 mostra os valores das dimensões para o processo $A M S 0,35 \mu \mathrm{m}$ em dois projetos da fonte de referência: o nominal e um outro otimizado para variações de processo. No âmbito da redistribuição da área por blocos, a mudança mais notável foi no conjunto de transistores e no resistor do gerador de PTAT: a percentagem da área ocupada por este bloco foi de $10,9 \%$ no caso nominal e de $34 \%$ para o caso otimizado a variações de processo. Desta maneira é ratificado o dito na seção 3.5.1: o bloco PTAT é o mais crítico a nível de mismatch no circuito. Levando em conta os incremento individual nos elementos do circuito (transistores e resistores), os elementos que mais mudaram foram os transistores $M_{11}$ e $M_{12}$, os quais fazem parte do bloco PTAT. Além disso, o transistor $M_{13}$, gerador da tensão $C T A T$, teve um incremento em torno de $500 \%$. Não entanto, o incremento do tamanho do transistor $M_{13}$ pode ser compensado mudando a topologia do circuito para uma com gerador diferencial de tensão CTAT, a qual vai ser menos crítico às variações de processo e mismatch. 
Tabela 3.13: Dimensionamento da fonte de referência para o projeto nominal e otimizado num processo $A M S 0,35 \mu \mathrm{m}$.

\begin{tabular}{|l|c|c|c|c|c|c|c|c|c|c|c|c|c|c|c|}
\hline Dimensão $[\mu m]$ & $W_{11}$ & $W_{12}$ & $L_{n 1}$ & $W_{22}$ & $L_{p 1}$ & $W_{23}$ & $W_{13}$ & $L_{13}$ & $W_{14}$ & $L_{14}$ & $W_{p}$ & $W_{c}$ & $L_{R_{P}}$ & $L_{R_{C}}$ & $L_{R_{T}}$ \\
\hline Nominal $^{(a)}$ & 9 & 27 & 9,4 & 16 & 9 & 9 & 144 & 5,6 & 437 & 1 & 25 & 308 & 200 & 780 & 289 \\
Otimizado $^{(b)}$ & 45 & 189 & 18 & 33 & 10 & 10 & 600 & 5 & 300 & 5 & 45 & 176 & 220 & 550 & 380 \\
\hline
\end{tabular}

Tabela 3.14: Análise das variações sistemáticas da temperatura e da tensão de alimentação nas funções de desempenho para o processo $A M S 0,35 \mu \mathrm{m}$.

\begin{tabular}{|c|c|c|c|c|c|c|c|c|c|}
\hline \multirow{2}{*}{} & \multicolumn{2}{|c|}{$V_{D D}-\delta V_{D D}$} & \multicolumn{2}{c|}{$V_{D D}+\delta V_{D D}$} & \multicolumn{2}{c|}{ Temp $=-25^{\circ} C$} & \multicolumn{2}{c|}{ Temp $=125^{\circ} C$} \\
\cline { 3 - 9 } & Nom. & $D F M$ & Nom. & $D F M$ & Nom. & $D F M$ & Nom. & $D F M$ \\
\hline \hline \multirow{2}{*}{ Potência } & $\bar{f}_{j}[\mu W]$ & 2,64 & 2,35 & 3,25 & 2,89 & 2,82 & 2,58 & 3,08 & 2,60 \\
& $W C D$ & 0,89 & 0,89 & 1,11 & 1,10 & 0,95 & 0,98 & 1,04 & 0,99 \\
\hline \multirow{2}{*}{$V_{R E F}$} & $\bar{f}_{j}[\mathrm{mV}]$ & 177,11 & 177,24 & 178,25 & 178,06 & 178,72 & 178,66 & 178,70 & 178,64 \\
& $W C D$ & 1,00 & 1,00 & 1,00 & 1,00 & 1,00 & 1,00 & 1,00 & 1,00 \\
\hline \multirow{2}{*}{$T C$} & $\bar{f}_{j}\left[\mu V /{ }^{\circ} \mathrm{C}\right]$ & 36,73 & 40,55 & 8,70 & 7,56 & 8,70 & 7,42 & 8,70 & 7,42 \\
& $W C D$ & 4,40 & 5,40 & 1,04 & 1,00 & 1,04 & 0,98 & 1,04 & 0,98 \\
\hline \multirow{2}{*}{$L R$} & $\bar{f}_{j}[\mathrm{mV} / \mathrm{V}]$ & 5,70 & 4,22 & 3,93 & 2,77 & 5,12 & 3,87 & 3,85 & 2,62 \\
& $W C D$ & 1,29 & 1,32 & 0,89 & 0,89 & 1,16 & 1,23 & 0,87 & 0,83 \\
\hline \multirow{2}{*}{$P S R R$} & $\bar{f}_{j}[d B]$ & 43,24 & 47,95 & 45,38 & 50 & 43,75 & 47,97 & 45,59 & 50,57 \\
& $W C D$ & 1,02 & 1,02 & 0,97 & 0,98 & 1,01 & 1,02 & 0,97 & 0,97 \\
\hline \multirow{2}{*}{ Ruído } & $\bar{f}_{j}[\mu V / \sqrt{H z}]$ & 1,67 & 0,75 & 1,68 & 0,76 & 1,43 & 0,66 & 2,14 & 0,95 \\
& $W C D$ & 0,99 & 0,98 & 1,00 & 1,00 & 0,85 & 0,86 & 1,27 & 1,25 \\
\hline
\end{tabular}

Por outro lado, a Tabela 3.14 contém os valores médios comparativos das especificações para as variações tanto positivas e negativas da temperatura, e a tensão de alimentação no caso do projeto nominal e o gerado pelo método de projeto $D F M$ proposto para o processo $A M S$ $0,35 \mu \mathrm{m}$. Embora as distâncias do pior caso sejam mantidas apesar da melhora apresentada no desempenho usando $D F M$, o decremento na tensão de alimentação é a variação que produz a pior degradação do circuito. Assim, esta fonte de referência continua sendo crítica para aplicações portáveis, no entanto, quando seja necessário, o esquema de otimização dos piores casos pode ser voltado para garantir um melhor comportamento térmico sob variações negativas na tensão de alimentação $V_{D D}$. Este tipo de requerimentos posteriores demostram e põem a prova a flexibilidade do método de projeto proposto, pois deve-se lembrar que o projeto não é ótimo num contexto geral, porém ele é adaptativo à aplicação na qual vai ser usado. 
Finalmente o conjunto de histogramas comparando as distribuições estatísticas para cada uma das especificações é mostrado na Figura 3.10 para o processo $A M S$ 0,35 $\mu m$. Comparativamente, a implementação do fluxo de projeto proposto estreitou em torno do valor médio todas as distribuições estatísticas das especificações levadas em consideração, garantindo assim uma melhora no rendimento evidenciada de maneira gráfica. Alguns das especificações tiveram um deslocamento no seu valor médio por causa da otimização de desempenho conjunta do método de projeto proposto. Este deslocamento é altamente visível em especificações como a regulação de linha, o PSRR e a potência, seguindo todos a tendência para a melhor borda. Por outro lado, as funções de desempenho que não apresentaram melhoramento no seu valor médio correspondem àquelas relacionadas com o comportamento térmico do circuito, mas foram mantidas nos valores do projeto nominal. Para o caso da tensão de referência, a probabilidade de obter um circuito com um desvio de $\pm 0,8 m \mathrm{~m}$ incrementou de 0,26 para 0,42 . Além disso, a probabilidade de obter um circuito com um coeficiente térmico inferior a $8,4 \mu \mathrm{V} /{ }^{\circ} \mathrm{C}$ incrementou de 0,4 para 0,82 aproximadamente. Estes resultados ratificam o benefício em termos de rendimento e desempenho na implementação da metodologia proposta neste trabalho. 


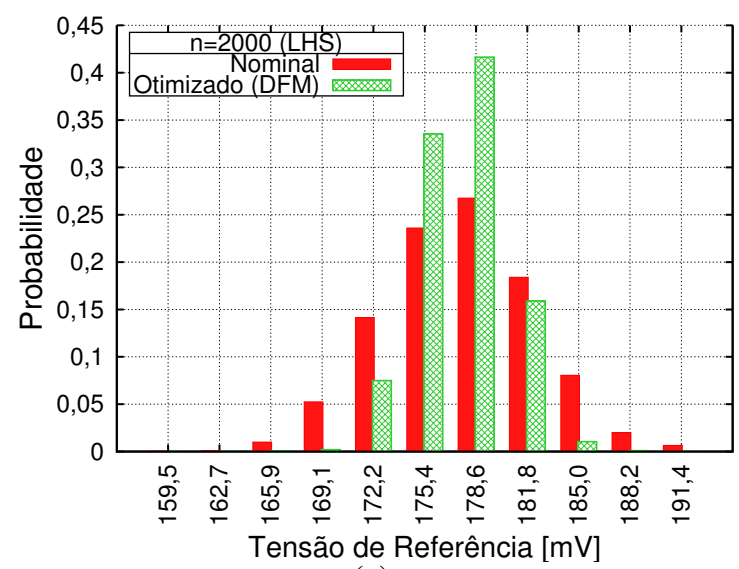

(a)

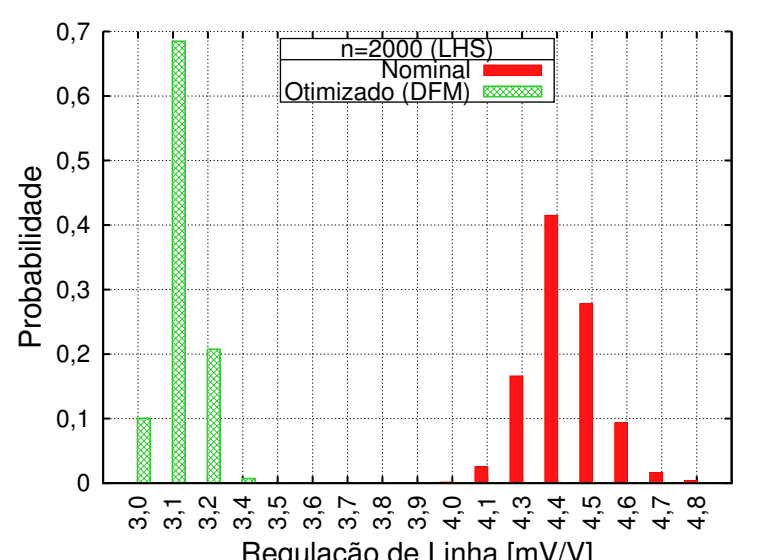

(c)

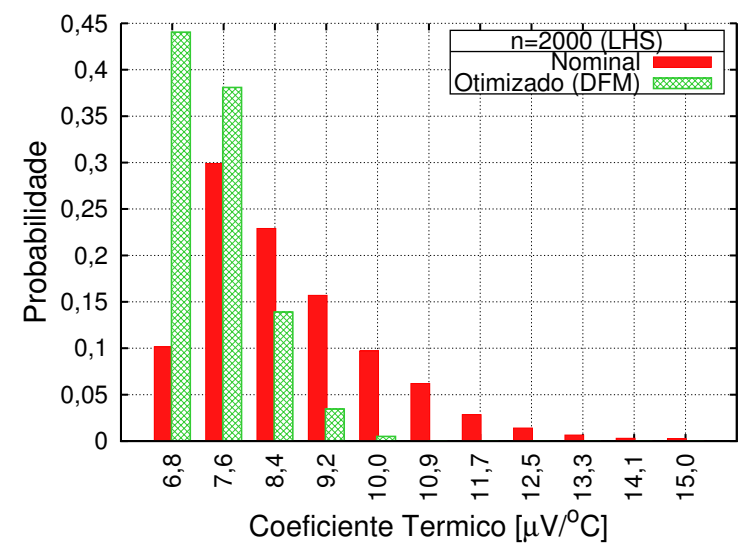

(b)

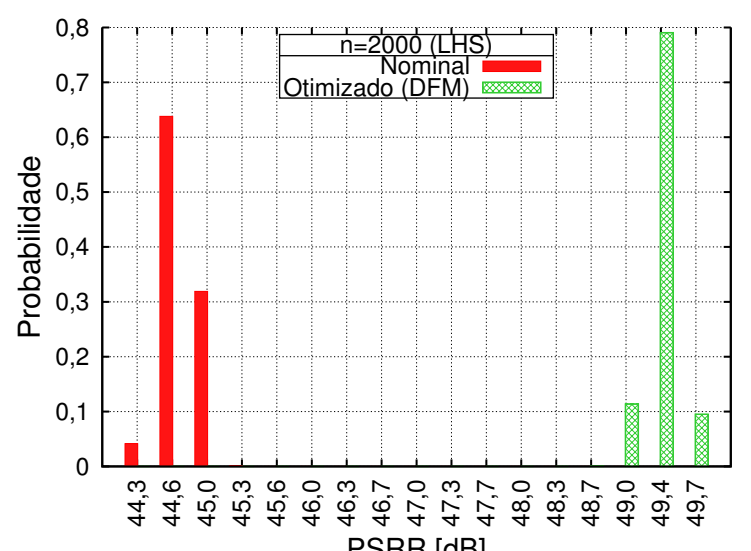

(d)

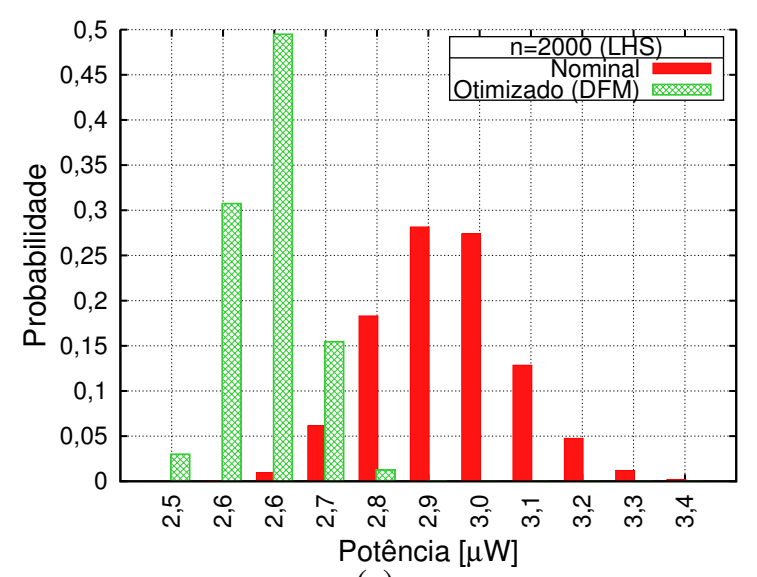

(e)

Figura 3.10: Histograma das variações de processo e mismatch num processo AMS 0,35 $\mu \mathrm{m}$ para: (a) Tensão de referência $V_{R E F}$; (b) Coeficiente térmico $T C$; (c) Regulação de linha ou $L R$; (d) Rejeição das variações da fonte ou PSRR; (e) Potência. 


\section{Conclusões e recomendações}

O conjunto de experiências obtidas ao longo da realização deste trabalho é coletado em duas seções; aqueles aspectos que foram obtidos e/ou deduzidos do desenvolvimento do trabalho estão na seção de conclusões. Por outro lado, os pontos importantes que não foram possíveis de serem realizados neste trabalho por razões inerentes a um trabalho de mestrado, estão discutidos na seção de recomendações.

\subsection{Conclusões}

- Uma metodologia de Projeto para Fabricação (DFM), altamente flexível e aplicável a uma ampla classe de circuitos analógicos foi proposta. Inicialmente, esta faz uso do esquema de otimização da Programação Geométrica para o dimensionamento dos circuitos. No entanto, qualquer método de otimização que admita funções não lineares e restrições tipo igualdade e desigualdade pode ser usado.

- Uma adequada conversão das expressões matemáticas que descrevem o comportamento e as especificações de qualquer circuito analógico, junto com os requerimentos definidos pelo projetista, permitiu a implementação de um esquema de otimização numérico baseado nas respostas obtidas via simulação e usando a ferramenta optimtool disponível em $M A T L A B$. Isto levou a uma redução no tempo de migração tecnológica e ajudou a obter um conjunto de variáveis factíveis para ser usado como semente de subsequentes etapas como a análise de mismatch e a otimização nominal via Programação Geométrica.

- Este trabalho fez a primeira abordagem na literatura sobre a otimização via Programação Geométrica de circuitos analógicos em sub-limiar. Ao contrário das regiões de triodo e saturação, um transistor polarizado em sub-limiar apresenta dependências de tipo exponencial em relação à tensão de porta-fonte $V_{G S}$ e dreno-fonte $V_{D S}$. No entanto, usando a PG modelou-se este tipo de expressões da forma $\alpha V_{G S}^{\gamma_{1}} V_{D S}^{\gamma_{2}}$, o qual em teoria gera erros de estimação bastante altos. Embora esta circunstância, a estratégia de Programação 
Geométrica para a otimização de circuitos na região sub-limiar em conjunto com a estratégia de modelos monomiais para as leis de Kirchhoff, levou à obtenção de erros de modelagem comparáveis aos obtidos em triodo e saturação. Além disso, os tempos de obtenção dos ótimos globais não foram afetados.

- A redução do nó tecnológico do processo não implica necessariamente um aumento na variabilidade devida ao mismatch. Para o caso tratado neste trabalho, a análise do mismatch estabeleceu que os requisitos de área na tensão de referência projetada em $X F A B 0,18 \mu \mathrm{m}$ são menores do que os exigidos em $A M S$ 0,35 $\mu \mathrm{m}$. Adicionalmente, $X F A B$ apresenta um melhor comportamento para a especificação do ruído em baixa frequência, pois seus parâmetros $A_{F}$ e $K_{F}$ são quantitativamente menores em comparação ao processo $A M S$.

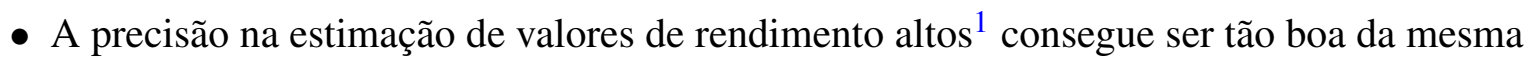
maneira em que os modelos estatísticos fornecidos pela foundry consigam descrever adequadamente as variações de processo. Assim, pode-se dizer que o alto rendimento obtido em simulação pode ser confrontado com os resultados de fabricação do dispositivo, e portanto concluir quão acertada é a ferramenta ou metodologia usada. Quando é usado um modelo pouco confiável, a correlação entre os resultados obtidos e sua dependência da metodologia vai ser mínima. Aliás, uma estimação adequada do rendimento no silício precisa fazer medições em vários lotes e wafers para assim levar em consideração as condições reais de fabricação. A incerteza da medida de rendimento no melhor dos casos corresponde a $\pm 1 /\left(n_{s}+1\right)$, sendo $n_{s}$ o número de circuitos medidos. Com um conjunto de amostras maior que quatro é possível estimar apropriadamente o desvio padrão das especificações.

- Um método de análise e otimização do pior caso para circuitos analógicos, o qual indaga qualitativamente e quantitativamente a influência das variações de processo, a tensão de alimentação e a temperatura nas funções de desempenho foi proposto. Este método leva a um decremento no tempo de cálculo dos piores casos do circuito, e permite sua implementação sob qualquer esquema de otimização não linear restrito.

- A função de ponderação da distância do pior caso que leva em conta mais de um caso obteve melhores resultados de rendimento do que aquela que pondera somente a maior distância de pior caso. Desta maneira, para otimizar o rendimento de um circuito analógico é aconselhável levar em conta as contribuições de todos os parâmetros

\footnotetext{
${ }^{1}$ Um alto rendimento é considerado neste trabalho como aquele que pode avaliar amostras num intervalo igual ou maior a $[\bar{x}-3 \sigma, \bar{x}+3 \sigma]$, tendo como mínimo uma incerteza de $0,26 \%$ no valor do rendimento.
} 
envolvidos em seus piores casos. Adicionalmente, a ocorrência conjunta de desvios de pior e melhor caso, permitiu uma redução no desvio padrão de funções de desempenho críticas para as variações de processo como foram a tensão de referência e o coeficiente térmico.

\subsection{Recomendações}

- Para a análise de mismatch e as derivações do rendimento em função da distância de pior caso desenvolvidas no Apêndice $\mathrm{B}$, foi assumido que as variáveis de processo e as funções de desempenho apresentam um comportamento aleatório do tipo Gaussiano ou Normal, no entanto este tipo de consideração não é muito acertado. Para o caso de especificações como o coeficiente térmico TC ou o PSRR, os histogramas da validação final revelaram um comportamento log-normal ${ }^{2}$ destas funções de desempenho. Por outro lado, o processo de fabricação tem parâmetros que presumivelmente não foram apropriadamente caracterizados por funções de distribuição simétricas em torno ao seu valor médio. Por exemplo, no caso dos parâmetros determinados na fabricação pelo processo da decapagem ou de remoção de material como são $\delta W, \delta L$ e $\rho_{S H}$, a situação mais provável corresponderia a uma diminuição de seus valores e, portanto, sua função de probabilidade apresentaria um comportamento assimétrico em torno da média. Contrariamente, parâmetros associados ao crescimento de camadas, como é o caso de $t_{o x}$, exibiriam uma propensão para ser maiores do que seu valor médio. Este tipo de hipótese precisa ser validada através de uma exaustiva caracterização estatística do processo a fim de garantir uma boa estimativa do rendimento.

- O processo de cálculo de uma determinada situação de pior caso para uma função de desempenho é altamente dependente do conjunto de parâmetros de processo, ambiente e tensão de alimentação nos seus piores casos para esta especificação. A fim de incrementar a velocidade de seu cálculo, e portanto sua otimização, os algoritmos e simuladores deveriam ser usados nas suas versões voltadas para multiprocessamento permitem uma diminuição no tempo de simulação, pois os diversos casos são calculados conjuntamente. Recentemente, novas alternativas tem-se implementado usando processadores gráficos ou GPU [36] para a otimização de circuitos integrados VLSI. A otimização dos circuitos analógicos usando processadores vetoriais gráficos ainda é uma área pouca explorada e provavelmente promissora no futuro.

\footnotetext{
${ }^{2}$ Em probabilidade e estatística, uma variável aleatória $X$ tem a distribuição log-normal quando o seu logaritmo $Y=\log (X)$, tem a distribuição normal.
} 
- Uma análise com um maior grau de aprofundamento das funções de ponderação das distâncias do pior caso deve ser feito, baseado nas necessidades e requerimentos do projeto e no critério do projetista. No caso exposto, a função soma ofereceu os melhores resultados de variação de processo, os quais foram os maiores responsáveis da degradação do desempenho no circuito. Outros contextos ou cenários precisam ser detalhadamente analisados em procura da melhor estratégia $D F M$ que possa ser implementada.

- O presente método de projeto abordou a otimização do nível mais complexo que é o dispositivo em nível do circuito, sem levar em conta níveis de abstração superiores úteis nas otimizações de sistemas. A tendência futura corresponde à caracterização e modelagem de rendimento e desempenho de células analógicas em linguagens comportamentais do tipo Verilog- $A$, para assim otimizar no nível de sistema conjuntamente rendimento e desempenho.

- Quando têm-se duas ou mais funções de desempenho concorrentes no esquema de otimização do rendimento, o cálculo do rendimento total do circuito torna-se um problema de uma complexidade maior e dependentemente do rendimento individual por especificação. Além disso, este não envolve mais probabilidades independentes porém funções de probabilidade conjuntas. Mesmo que seja de difícil estimação, o rendimento total pode ser otimizado com base no comportamento do rendimento por função de desempenho. Sejam duas funções de desempenho $f_{1}(\mathbf{x})$ e $f_{2}(\mathbf{x})$ dependentes do vetor de variáveis de projeto $\mathbf{x}$. É possível classificar o rendimento como independente ou condicional. O primeiro representa a probabilidade de obtenção do valor da função $f_{1}(\mathbf{x})$ dentro da região de aceitabilidade $\mathscr{A}$, sem levar em conta as outras funções de desempenho. Por outro lado, o rendimento condicional ou total é expressado como uma probabilidade conjunta dependente de um evento ligado a duas ou mais especificações. Para este caso, o rendimento total para as funções $f_{1}$ e $f_{2}$ é formulado matematicamente como:

$$
\begin{aligned}
Y_{\text {total }}= & P\left(f_{1}(\mathbf{x}) \in \mathscr{A} \cap f_{2}(\mathbf{x}) \in \mathscr{A}\right) \\
= & P\left(f_{1}(\mathbf{x}) \in \mathscr{A}\right) \cdot P\left(f_{1}(\mathbf{x}) \in \mathscr{A} \mid f_{2}(\mathbf{x}) \in \mathscr{A}\right) \\
= & Y_{1} \cdot Y_{1 \mid 2}
\end{aligned}
$$

onde $Y_{\text {total }}$ é o rendimento total do circuito sob as funções de desempenho $f_{1}$ e $f_{2}, Y_{1}$ é o rendimento sob a função $f_{1}$, e $Y_{1 \mid 2}$ é o rendimento condicional de ocorrência do cumprimento de $Y_{1}$ uma vez tenha acontecido o cumprimento de $Y_{2}$ e $P(z)$ a probabilidade de ocorrência do evento $z$. Já foi abordado o método de otimização para o rendimento 
$Y_{1}$, no entanto o rendimento total não somente tem uma dependência com esta função mas também varia em concordância com o comportamento do rendimento condicional definido pela probabilidade de ocorrência conjunta do evento no qual o valor de $f_{1}$ e $f_{2}$ ficam dentro da região $\mathscr{A}$. Em termos comuns, a otimização do rendimento total tem que procurar a maximização da correlação entre as perdas de rendimento global e sua minimização em valor, para assim garantir que todas as falhas nas especificações não ocorram em chips isolados porém num só. Este assunto representa um desafio que tem-se que levar a cabo em futuros processos. 


\section{APÊNDICE A - Análise da regulação de linha do bloco PTAT}

A regulação da linha ou Line Regulation $(L R)$ conceitualmente mede a alteração na tensão de sáida em resposta a uma mudança na tensão de entrada em baixa frequência analisada no intervalo funcional do circuito [30]. Em termos matemáticos pode-se estabelecer como:

$$
L R=\frac{\Delta V_{o}}{\Delta V_{D D}}=\frac{V_{o_{\max }}-V_{o_{\min }}}{V_{D D_{\max }}-V_{D D_{\min }}}
$$

sendo $V_{D D_{\max }}$ e $V_{D D_{\min }}$ tensões de alimentação máxima e mínima, respectivamente, nas quais é garantida uma adequada funcionalidade do circuito, $V_{o_{\max }}$ e $V_{o_{\min }}$ são as tensões da saída para condições de funcionalidade do mesmo. As faixas de tensão de alimentação e tensão de saída nas quais é garantida a funcionalidade do circuito são denotas como $\Delta V_{D D}$ e $\Delta V_{o}$, respectivamente. No caso do bloco PTAT da Figura A.1(a) e usado na fonte de referência mostrada na Figura 3.1, a regulação de linha $(L R)$ pode ser calculada inserindo uma fonte de sinal $v_{s}$ no nó positivo de $V_{D D}$ e substituindo cada um dos transistores por seu modelo

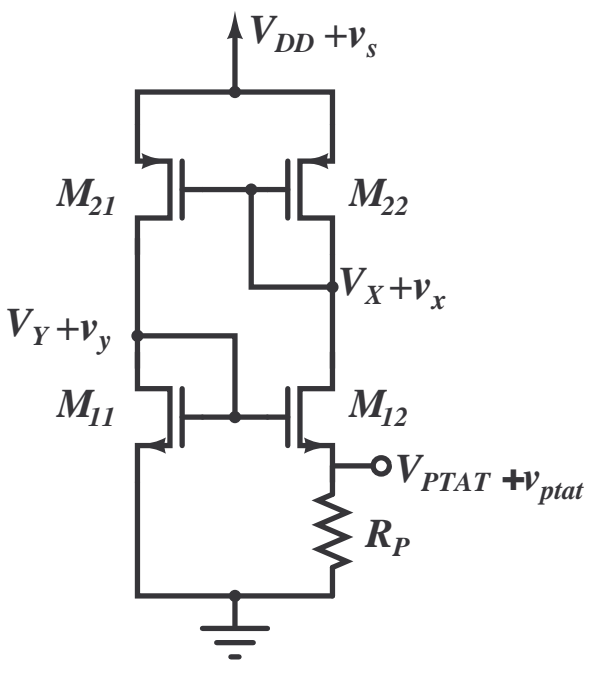

(a)

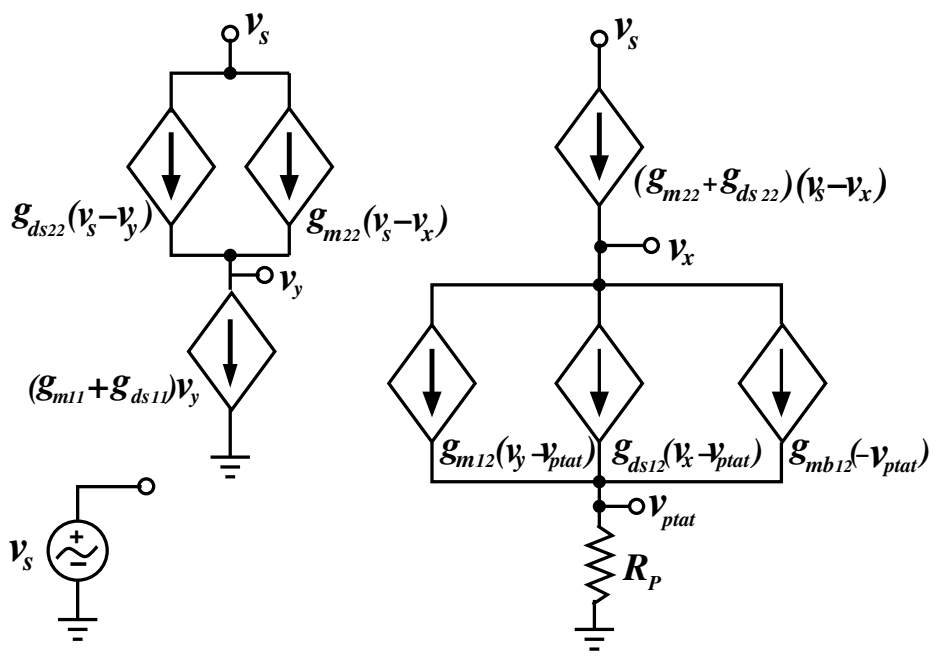

(b)

Figura A.1: (a) Esquemático do bloco PTAT, (b) Seu equivalente no modelo de pequeno sinal. 
equivalente em pequeno sinal, como é mostrado na Figura A.1(b), para assim calcular a resposta de interesse $v_{\text {ptat }} / v_{s}$. Desse modo, fazendo uma análise das leis de correntes de Kirchoff ou KCL para os nós $X, Y$ e $P$ obtêm-se um sistema de três equações e quatro incógnitas ${ }^{1}$ :

$$
\begin{array}{r}
g_{d s 22}\left(v_{s}-v_{y}\right)+g_{m 22}\left(v_{s}-v_{x}\right)=\left(g_{m 11}+g_{d s 11}\right) v_{y} \\
\left(g_{d s 22}+g_{m 22}\right)\left(v_{s}-v_{x}\right)=g_{m 12}\left(v_{y}-v_{\text {ptat }}\right)+g_{d s 12}\left(v_{x}-v_{\text {ptat }}\right)+g_{m b 12}\left(-v_{\text {ptat }}\right) \\
g_{m 12}\left(v_{y}-v_{\text {ptat }}\right)+g_{d s 12}\left(v_{x}-v_{\text {ptat }}\right)+g_{m b 12}\left(-v_{\text {ptat }}\right)=v_{\text {ptat }} / R_{P}
\end{array}
$$

Pondo em evidência a variável $v_{y}$ na equação (A.2), obtém-se:

$$
v_{y}=\frac{g_{m 22}\left(v_{s}-v_{x}\right)}{g_{m 11}+g_{d s 11}+g_{d s 22}}
$$

Na expressão (A.5) podem ser desprezados vários termos. Dessa maneira, assumindo $g_{m 11} \gg g_{d s 11}$, e, $g_{m 22} \gg g_{d s 22}$, a tensão $v_{y}$ é aproximada como:

$$
v_{y}=\frac{g_{m 22}}{g_{m 11}}\left(v_{s}-v_{x}\right)
$$

Inserindo o resultado preliminar na equação (A.3), resulta:

$v_{s}\left(g_{m 22}+g_{d s 22}-g_{m 12} \frac{g_{m 22}}{g_{m 11}}\right)+v_{p t a t}\left(g_{m 12}+g_{d s 12}+g_{m b 12}\right)=v_{x}\left(g_{d s 22}+g_{m 22}+g_{d s 12}-g_{m 12} \frac{g_{m 22}}{g_{m 11}}\right)$

No entanto, na região de sub-limiar as transcondutâncias $g_{m 11}$ e $g_{m 12}$ são aproximadamente iguais. Assim é posto em evidência $v_{x}$ :

$$
v_{x}=\frac{v_{s} g_{d s 22}+v_{p t a t}\left(g_{m 12}+g_{d s 12}+g_{m b 12}\right)}{g_{d s 12}+g_{d s 22}}
$$

Substituindo o valor de $v_{x}$ em A.4 obtém-se:

$$
\frac{v_{\text {ptat }}}{v_{s}}=\frac{R_{P} \cdot g_{m 22} \cdot g_{d s 12}}{\left(g_{d s 12}+g_{d s 22}\right)+\left(g_{m 12}+g_{d s 12}+g_{m b 12}\right) \cdot R_{P} \cdot g_{m 22}}
$$

No entanto, a transcondutância total $g_{m t 12}$ do transistor $M_{12}$ é igual a $g_{m 12}+g_{d s 12}+g_{m b 12}$, então:

$$
\frac{v_{\text {ptat }}}{v_{s}} \simeq \frac{R_{P} \cdot g_{m 22} \cdot g_{d s 12}}{g_{d s 12}+g_{d s 22}+g_{m t 12} \cdot R_{P} \cdot g_{m 22}}
$$

\footnotetext{
${ }^{1}$ Foi assumido nas derivações das equações que: $W_{21}=W_{22}$ e $L_{21}=L_{22}$
} 


\section{APÊNDICE B - Estimativa de rendimento com base na distância do pior caso}

Assumindo que a característica de desempenho $f_{j}$ tem um comportamento linear em relação às variáveis de projeto e sua distribuição corresponde a uma normal, ou seja, $\bar{f}_{j} \sim \mathscr{N}\left(\bar{f}_{j}, \sigma_{f_{j}}^{2}\right)$, sua função de densidade de probabilidade pode ser dada por:

$$
\operatorname{pdf}_{f_{j}}=\frac{1}{\sqrt{2 \pi}} \mathrm{e}^{-\frac{1}{2}\left(\frac{f_{j}-\bar{f}_{j}}{\sigma_{f_{j}}}\right)^{2}}
$$

Seja $Y_{U, j}$ e $Y_{L, j}$ os valores de rendimento levando em conta o pior caso superior $f_{j_{W U}}$ e inferior $f_{j_{W L}}$, respetivamente, o rendimento $Y_{U, j}$ pode ser determinado integrando a pdf de $f_{j}$ no intervalo de interesse:

$$
\begin{aligned}
Y_{U, j}=\int_{-\infty}^{f_{W U, j}} \operatorname{pdf}_{\bar{f}_{j}}\left(\bar{f}_{j}\right) \cdot d \bar{f}_{j} & =\int_{-\infty}^{\frac{f_{W U, j}-f_{O, j}}{\sigma_{f_{j}}}} \frac{1}{\sqrt{2 \pi}} \mathrm{e}^{-\frac{1}{2} t^{2}} \cdot d t \\
& =\int_{\infty}^{\beta_{w}} \frac{1}{\sqrt{2 \pi}} \\
& =Y_{L, j}
\end{aligned}
$$

O rendimento levando em conta os valores inferiores e superiores do pior caso é denominado $Y_{j}$, sendo expressado matematicamente por:

$$
Y_{j}=\int_{f_{W L, j}}^{f_{W U, j}} \operatorname{pdf}_{\bar{f}_{j}} \cdot d \bar{f}_{j}=\int_{-\beta_{W}}^{\beta_{W}} \frac{1}{\sqrt{2 \pi}} \mathrm{e}^{\frac{1}{2} t^{2}} \cdot d t
$$

Sendo o parâmetro $\beta_{W}$ a distância de pior caso entre o valor nominal e o valor de pior caso da função de desempenho característica. Este parâmetro é medido em unidades de variança da função de desempenho. Por exemplo, um valor de $\beta_{W}=3$ refere-se portanto a um projeto com uma margem de segurança de três sigmas. 


\section{Referências Bibliográficas}

[1] SEMICONDUCTORS, I. T. R. F. ITRS Design Report and Roadmap. [S.1.], 2009.

[2] GUARDIANI, C.; SCANDOLARA, P.; BENKOSKI, J.; NICOLLINI, G. Yield optimization of analog ICs using two-step analytic modeling methods. IEEE Journal of Solid-State Circuits., v. 28, n. 7, p. 778 -783, jul. 1993. ISSN 0018-9200.

[3] LOW, K.; DIRECTOR, S. A new methodology for the design centering of IC fabrication processes. IEEE Transactions on Computer-Aided Design of Integrated Circuits and Systems., v. 10, n. 7, p. 895 -903, jul. 1991. ISSN 0278-0070.

[4] SEIFI, A.; PONNAMBALAM, K.; VLACH, J. A unified approach to statistical design centering of integrated circuits with correlated parameters. IEEE Transactions on Circuits and Systems I: Fundamental Theory and Applications., v. 46, n. 1, p. 190 -196, Jan 1999. ISSN 1057-7122.

[5] Sï $\frac{1}{2}$ ENZ, J. J.; ROA, E.; PAB $\dddot{\iota} \underset{i}{2}$ N, A. A.; NOIJE, W. V. A methodology to improve yield in analog circut by using geometric programming. In: SBCCI: Proceedings of the 23st annual Symposium on Integrated Circuits and System Design. New York, NY, USA: ACM, 2010. p. 140-145. ISBN 978-1-4503-0152-7.

[6] STROJWAS, A. Design for manufacturability and yield. In: 26th Conference on Design Automation, 1989. [S.1.: s.n.], 1989. p. 454 - 459. ISSN 0738-100X.

[7] JAKATDAR, N. DFM: What, Why, When \& How. [S.1.]: Cadence Design Systems, February 2007. Solid State Technology and Devices Seminar, EECS 298-12, UC at Berkeley.

[8] WHITE, K. P.; TRYBULA, W. J.; ATHAY, R. N. Design for semiconductor manufacturingperspective. In: IEEE Transactions on Components, Packaging, and Manufactuing Technology. [S.1.: s.n.], 1997. v. 20, n. 1, p. 58-72.

[9] NYE, W.; RILEY, D.; SANGIOVANNI-VINCENTELLI, A.; TITS, A. DELIGHT.SPICE: an optimization-based system for the design of integrated circuits. Computer-Aided Design of Integrated Circuits and Systems, IEEE Transactions on, v. 7, n. 4, p. 501 -519, abr. 1988. ISSN 0278-0070.

[10] GIELEN, G.; WALSCHARTS, H.; SANSEN, W. Analog circuit design optimization based on symbolic simulation and simulated annealing. IEEE Journal of Solid-State Circuits, v. 25, n. 3, p. 707 -713, jun. 1990. ISSN 0018-9200.

[11] MAULIK, P.; CARLEY, L.; ALLSTOT, D. Sizing of cell-level analog circuits using constrained optimization techniques. IEEE Journal of Solid-State Circuits, v. 28, n. 3, p. $233-241$, mar. 1993. ISSN 0018-9200. 
[12] DHARCHOUDHURY, A.; KANG, S. Worst-case analysis and optimization of VLSI circuit performances. IEEE Transactions on Computer-Aided Design of Integrated Circuits and Systems, v. 14, n. 4, p. 481 -492, abr. 1995. ISSN 0278-0070.

[13] DEBYSER, G.; GIELEN, G. Efficient analog circuit synthesis with simultaneous yield and robustness optimization. In: International Conference on Computer-Aided Design. [S.1.: s.n.], 1998. p. $308-311$.

[14] WU, P.; MACK, R.; MASSARA, R.; BENSOUIAH, D.; KEMP, A. AMODA: a flexible framework for automatic migration of analog macro designs using optimization techniques. In: Proceedings of the 43rd IEEE Midwest Symposium on Circuits and Systems. [S.1.: s.n.], 2000. v. 2, p. $988-991$ vol.2.

[15] HERSHENSON, M.; BOYD, S.; LEE, T. Optimal design of a CMOS OP-AMP via geometric programming. Computer-Aided Design of Integrated Circuits and Systems., v. 20, n. 1, p. 1 -21, jan. 2001. ISSN 0278-0070.

[16] XU, Y.; LI, X.; HSIUNG, K.-L.; BOYD, S.; NAUSIEDA, I. OPERA: optimization with ellipsoidal uncertainty for robust analog IC design. In: Design Automation Conference. Proceedings. 42nd. [S.1.: s.n.], 2005. p. 632 - 637.

[17] YU, G.; LI, P. Hierarchical analog/mixed-signal circuit optimization under process variations and tuning. IEEE Transactions on Computer-Aided Design of Integrated Circuits and Systems., v. 30, n. 2, p. 313 -317, 2011. ISSN 0278-0070.

[18] PELGROM, M.; DUINMAIJER, A.; WELBERS, A. Matching properties of MOS transistors. IEEE Journal of Solid-State Circuits, v. 24, n. 5, p. 1433 - 1439, out. 1989. ISSN 0018-9200.

[19] ANTREICH, K. et al. WiCkeD: Analog circuit synthesis incorporating Mismatch. In: Proceedings of the IEEE Custom Integrated Circuits Conference. [S.1.: s.n.], 2000. p. $511-514$.

[20] MATEUS, J.; ROA, E.; HERNANDEZ, H.; NOIJE, W. V. A 2.7uA sub1-V Voltage Reference. In: SBCCI: Proceedings of the 21st annual Symposium on Integrated Circuits and System Design. New York, NY, USA: ACM, 2008. p. 81-84. ISBN 978-160558-231-3.

[21] FLETCHER, R. Practical methods of optimization. [S.1.]: Wiley, 2000. (A WileyInterscience Publication). ISBN 9780471494638.

[22] WEBER, T. O.; NOIJE., W. A. M. V. Analog design synthesis performing fast pareto frontier exploration. In: Proocedings of the 2011 IEEE Second Latin American Symposium on Circuits and Systems. [S.1.: s.n.], 2011. p. 62-66.

[23] GRAEB, H. E. Analog Design Centering and Sizing. 1. ed. [S.1.]: Springer Verlag Publishing, 2007. 195 p. p.

[24] GREGOIRE, B. Optimum area allocation for minimum mismatch [IC device area optimization]. In: Proceedings of the IEEE 2004 Custom Integrated Circuits Conference. [S.l.: s.n.]. p. $643-646$. 
[25] BOYD, S.; VANDENBERGHE, L. Convex Optimization. 1. ed. [S.1.]: Cambridge University Press, 2004.

[26] GRANT, M.; BOYD, S. CVX: Matlab software for disciplined convex programming. February 2009. Internet. Build 711. Disponível em: $<$ http://stanford.edu/ boyd/cvx $>$.

[27] COX, P.; YANG, P.; MAHANT-SHETTI, S.; CHATTERJEE, P. Statistical modeling for efficient parametric yield estimation of MOS VLSI circuits. IEEE Journal of Solid-State Circuits., v. 20, n. 1, p. 391 - 398, Feb 1985. ISSN 0018-9200.

[28] ANTREICH, K.; GRAEB, H. E.; WIESER, C. U. Circuit analysis and optimization driven by worst-case distances. IEEE Trans. on CAD of Integrated Circuits and Systems, v. 13, n. 1, p. 57-71, 1994.

[29] GALUP-MONTORO, C.; SCHNEIDER, M.; KLIMACH, H.; ARNAUD, A. A compact model of MOSFET mismatch for circuit design. IEEE Journal of Solid-State Circuits., v. 40, n. 8, p. 1649 - 1657, Aug. 2005. ISSN 0018-9200.

[30] RINCi $i \frac{1}{2}$ N-MORA, G. A. Voltage References: From Diodes to Precision High-Order Bandgap Circuits. 1th ed.. ed. [S.1.]: John Wiley \& Sons, Inc., 2002. 350 p. p.

[31] Allen, P. E.; HOLBERG, D. R. CMOS Analog Circuit Design. 2. ed. [S.1.]: Oxford University Press, 2002. 250 p. p.

[32] BINKLEY, D. M. Tradeoffs and Optimization in Analog CMOS Design. 1. ed. [S.1.]: John Wiley \& Sons, Ltd., 2008. 632 p. p.

[33] KINGET, P. Device mismatch and tradeoffs in the design of analog circuits. IEEE Journal of Solid-State Circuits, v. 40, n. 6, p. 1212 - 1224, june 2005. ISSN 0018-9200.

[34] TSAI, J.-s.; CHIUEH, H. High linear voltage references for on-chip CMOS smart temperature sensor from $-60^{\circ} \mathrm{C}$ to $140^{\circ} \mathrm{C}$. In: IEEE International Symposium on Circuits and Systems (ISCAS). [S.1.: s.n.], 2008. p. 2689 -2692.

[35] NOVAL, J. J. S.; FUENTES, E. R. Analysis and evaluation of statistical models for

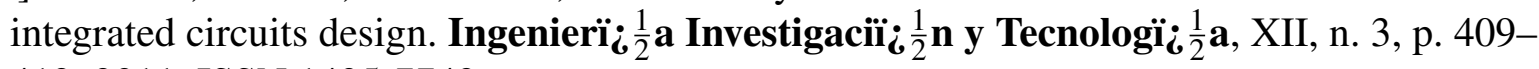
419, 2011. ISSN 1405-7743.

[36] LIU, Y.; HU, J. GPU-based parallelization for fast circuit optimization. In: Design Automation Conference (DAC), 46th ACM/IEEE. [S.1.: s.n.], 2009. p. 943 -946. ISSN 0738-100X. 